ADVANCED STEEL CONSTRUCTION

An International Journal

Volume 9 Number 2

June 2013

CONTENTS

\section{Technical Paper}

Study on Behavior of Concrete Filled Elliptical Steel Tube Members

Part I : Short and Long Columns under Axial Compression

Xiaoxiong Zha, Guobin Gong and Xichao Liu

Study on Behavior of Concrete Filled Elliptical Steel Tube Members

Part II : Under Bending and Eccentric Compression

Xiaoxiong Zha, Guobin Gong and Xichao Liu

Nonlinear Finite Element Analysis on Long Columns of High-Strength Concrete-Filled Square Steel Tube with Inner CFRP Circular Tube under Axial Load

G.C. Li, C.Y. Di, L. Tian and C. Fang

Push-Out Experiments of Headed Shear Studs in Group Arrangements

Milan Spremic, Zlatko Markovic, Milan Velikovic and Dragan Budjevac

Progressive Collapse Analysis of Transmission Tower-Line System under Earthquake W.M. Wang, H.N. Li and L. Tian

Conference Announcement

\section{Copyright $\odot 2013$ by :}

The Hong Kong Institute of Steel Construction

Website: $h$ ttp://www.hkisc.org

ISSN 1816-112X

Science Citation Index Expanded, Materials Science Citation Index and ISI Alerting

Cover: The Tamar Headquarters of Hong Kong SAR Government

Top five floors spanning over the two mega cores are made of composite trusses with concrete infilled

rectangular sections and designed by second-order direct analysis

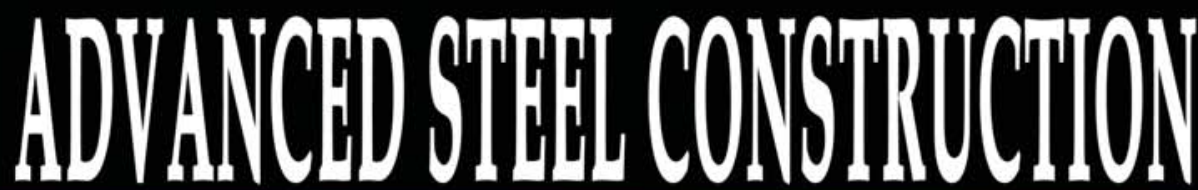

an International Jounal

ISSN 1816-112X

Volume 9 Number 2

June 2013

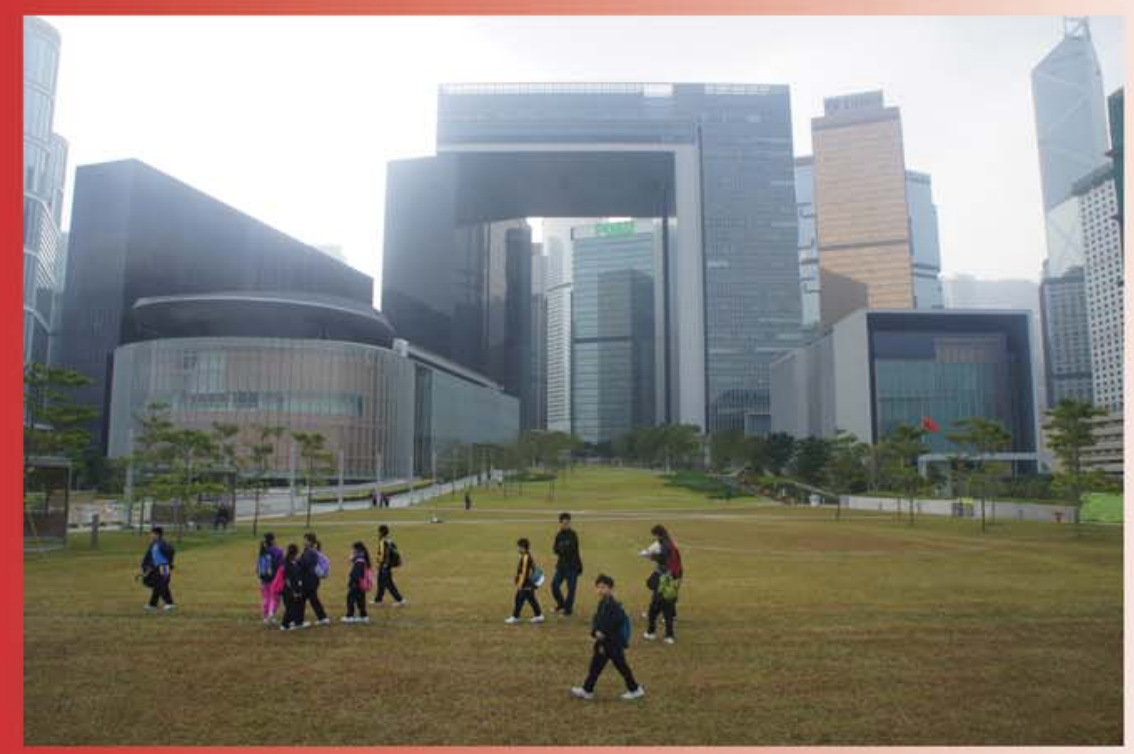

Editors-in-Chief

S.L. Chan, The Hong Kong Polytechnic University, Hong Kong

W.F. Chen, University of Hawaii at Manoa, USA

R. Zandonini, Trento University, Italy 


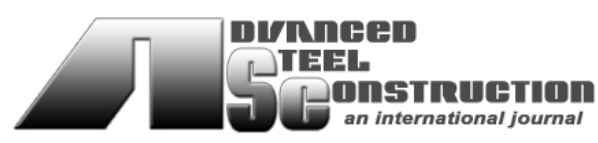

ISSN 1816-112X

Science Citation Index Expanded, Materials Science Citation Index and ISI Alerting

\section{EDITORS-IN-CHIEF}

Asian Pacific, African and organizing Editor

S.L. Chan

The Hong Kong Polyt. Univ., Hong Kong

American Editor
W.F. Chen
Univ. of Hawaii at Manoa, USA

\section{European Editor}

R. Zandonini

Trento Univ., Italy

\section{INTERNATIONAL EDITORIAL BOARD}

F.G. Albermani

The Univ. of Queensland, Australia

I. Burgess

Univ. of Sheffield, UK

F.S.K. Bijlaard

Delft Univ. of Technology, The Netherlands

R. Bjorhovde

The Bjorhovde Group, USA

M.A. Bradford

The Univ. of New South Wales, Australia

D. Camotim

Technical Univ. of Lisbon, Portugal

C.M. Chan

Hong Kong Univ. of Science \& Technology, Hong Kong

T.H.T. Chan

Queensland Univ. of Technology, Australia

S.P. Chiew

Nanyang Technological Univ., Singapore

W.K. Chow

The Hong Kong Polyt. Univ., Hong Kong

K.F. Chung

The Hong Kong Polyt. Univ., Hong Kong

G.G. Deierlein

Stanford Univ., California, USA

L. Dezi

Univ. of Ancona, Italy

D. Dubina

The Politehnica Univ. of Timosoara, Romania

\section{Advanced Steel \\ Construction an international journal}

R. Greine

Technical Univ. of Graz, Austria

L. Gardner

Imperial College of Science, Technology and

Medicine, UK

L.H. Han

Tsinghua Univ. China

S. Herion

University of Karlsruhe, Germany

G.W.M. Ho

Ove Arup \& Partners Hong Kong Ltd., Hong Kong

B.A. Izzuddin

Imperial College of Science, Technology and

Medicine, UK

J.P. Jaspart

Univ. of Liege, Belgium

S. A. Jayachandran

IIT Madras, Chennai, India

S.E. Kim

Sejong Univ., South Korea

S. Kitipornchai

City Univ. of Hong Kong, Hong Kong

D. Lam

Univ. of Bradford, UK

G.Q. Li

Tongji Univ., China

J.Y.R. Liew

National Univ. of Singapore, Singapore

E.M. Lui

Syracuse Univ., USA

Y.L. Mo

Univ. of Houston, USA

J.P. Muzeau

CUST, Clermont Ferrand, France

D.A. Nethercot

Imperial College of Science, Technology and

Medicine, UK

Y.Q. Ni

The Hong Kong Polyt. Univ., Hong Kong

D.J. Oehlers

The Univ. of Adelaide, Australia

K. Rasmussen

The Univ. of Sydney, Australia

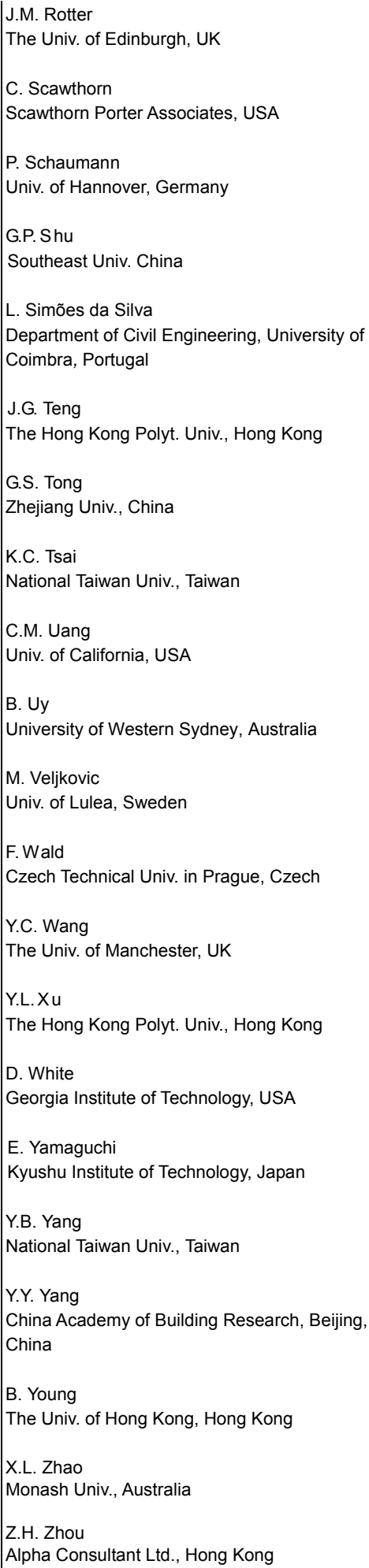




\begin{tabular}{ll}
\hline \hline & General Information \\
& Advanced Steel Construction, an international journal \\
\hline \hline Aims and scope
\end{tabular}

\section{Aims and scope}

The International Journal of Advanced Steel Construction provides a platform for the publication and rapid dissemination of ori ginal and up-to-date research and tec hnological developments in steel c onstruction, design and anal ysis. Scope of research $p$ apers published in this journal includes but is not limite $d$ to theor etical and expe rimental research on elements, assemblages, sy stems, material, design philosophy and codification, standards, fabrication, projects of innov ative nature an d computer tech niques. The journal is specifically $t$ ailored to channel the e xchange of tec hnological know-ho $w$ bet ween $r$ esearchers an $d$ practitioners. Contributions from all aspects related to the recent developments of advanced steel construction are welcome.

\section{Instructions to authors}

Submission of the manuscript. Authors may submit double-spaced manuscripts preferably in MS Word by emailing to one of the chief editors as follows for arrangement of review. Alternatively papers can be submitted on a diskette to one of the chief editors.

Asian Pacific, African and organizing editor: Professor S.L. Chan, Email: ceslchan@polyu.edu.hk

American editor :

European editor :

Professor S.L. Chan, Email: ceslchan@polyu.edu

Professor R. Zandonini, Email: riccardo_zandonini@ing.unitn.it

All manuscripts submitted to the journal are recommended to accompany with a li st of four potential reviewers suggested by the author(s). This list should include the complete name, add ress, telephone and fax num bers, em ail address, and at least five keywords that identify the expertise of each reviewer. This scheme will improve the process of review.

Style of manuscript

General. Author(s) should provide full postal and email addresses and fax number for correspondence. The manuscript including abstract, keywords, references, figures and tables should be in English with pages numbered and typed with double line spacing on single side of A4 or letter-sized paper. The front page of the article should contain:

a) a short title (reflecting the content of the paper);

b) all the name(s) and postal and email addresses of author(s) specifying the author to whom correspondence and proofs should be sent;

c) an abstract of $100-200$ words; and

d) 5 to 8 keywords.

The paper must contain an introduction and a conclusion. The length of paper should not exceed 25 journal pages (approximately 15,000 words equivalents).

Tables and figures. Tables and figures including photographs should be typed, numbered consecutively in Arabic numerals and with short titles. They should be referred in the text as Figure 1, Table 2, etc. Originally drawn figures and photographs should be provided in a form suitable for photographic reproduction and reduction in the journal.

Mathematical expressions and units. The Systeme Internationale (SI) should be followed whenever possible. The numbers identifying the displayed mathematical expression should be referred to in the text as Eq. (1), Eq. (2).

References. References to published literature should be referred in the text, in the order of citation with Arabic numerals, by the last name(s) of the author(s) (e.g. Zandonini and Zanon [3]) or if more than three authors (e.g. Zandonini et al. [4]). References should be in English $w$ ith occasional allow ance of 1-2 e xceptional referenc es in local lang uages and $r$ eflect the curren $t$ state-of-technology. Journal titles should be abbreviated in the style of the Word List of Scientific Periodicals. References should be cited in the following style $[1,2,3]$.

Journal: [1] Chen, W.F. and Kishi, N., "Semi- rigid Steel Beam-to-column Connections, Data Base and Modellin g", Journal of Structural Engineering, ASCE, 1989, Vol. 115, No. 1, pp. 105-119.

Book: [2] Chan, S.L. and Chui, P.P.T., "Non-linear Static and Cyclic Analysis of Semi-rigid Steel Frames", Elsevier Science, 2000 .

Proceedings: [3] Zandonini, R. a nd Zanon, P., "Experimental Analy sis of S teel Beams with Semi -rigid Joint s", Proceedings of International Conference on Advances in Steel Structures, Hong Kong, 1996, Vol. 1, pp. 356-364.

Proofs. Proof will be sent to the c orresponding author to correct an y typesetting errors. Alternations to the original manuscript at this stage will not be accepted. Proofs should be returned within 48 hours of receipt by Express Mail, Fax or Email.

Copyright. Submission of an article to "Advanced Steel Construction" implies that it presents the original and unpublished work, and not under consideration for publication nor published elsewhere. On acceptance of a manuscript submitted, the copyright thereof is transferred to the publisher $b y$ the Transfer of $C$ opyright Agreement and upon the acceptance of publication for the $p$ apers, the corresponding author must sign the form for Transfer of Copyright.

Permission. Quoting from this journal is granted provided that the customary acknowledgement is given to the source.

Page charge and Reprints. There will be no page charges if the length of paper is within the limit of 25 journal pages. A total of 30 free offprints will be supplied free of charge to the corresponding author. Purchasing orders for additional offprints can be made on order forms which will be sent to the authors. These instructions can be obtained at the Hong Kong Institute of Steel Construction, Journal website: http://www.hkisc.org

The International Journal of Advanced Steel Construction is published quarterly by non-profit making learnt society, The Hong Kong Institute of Steel Construction, c/o Department of Civil \& Structural Engineering, The Hong Kong Polytechnic University, Hung Hom, Kowloon, Hong Kong.

Disclaimer. No responsibility is assumed for a ny injury and / or damage to per sons or property as a matter of products liability, negligence or otherwise, or from any use or operation of any methods, products, instructions or ideas contained in the material herein.

Subscription inquiries and change of address. Address all subscription inquiries and correspondence to Member Records, IJASC. Notify an address change as soon as possible. All communications should include both old and new addresses with zip codes and be accompanied by a mailing label from a recent issue. Allow six weeks for all changes to become effective.

The Hong Kong Institute of Steel Construction

HKISC

c/o Department of Civil and Environmental Engineering,

The Hong Kong Polytechnic University,

Hunghom, Kowloon, Hong Kong, China.

Tel: 852- 27666047 Fax: 852- 23346389

Email: ces/chan@polyu.edu.hk Website: http://www.hkisc.org/

ISSN 1816-112X

Science Citation Index Expanded, Materials Science Citation Index and ISI Alerting

Copyright $\odot 2013$ by:

The Hong Kong Institute of Steel Construction. 


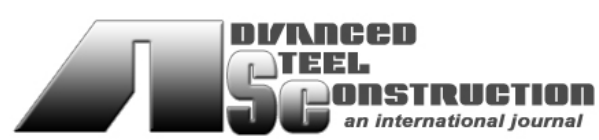

ISSN 1816-112X

Science Citation Index Expanded, Materials Science Citation Index and ISI Alerting

\section{EDITORS-IN-CHIEF}

\section{Asian Pacific, African} and organizing Editor

S.L. Chan

The Hong Kong Polyt. Univ., Hong Kong

Email: ces/chan@polyu.edu.hk

\section{American Editor \\ W.F. Chen}

Univ. of Hawaii at Manoa, USA

Email:waifah@hawaii.edu

\section{European Editor}

R. Zandonini

Trento Univ., Italy

Email: riccardo.zandonini@ing.unitn.it

\section{Advanced Steel Construction an international journal}

VOLUME 9 NUMBER 2

JUNE 2013

Technical Papers

Study on Behavior of Concrete Filled Elliptical Steel Tube Members Part I : Short and Long Columns under Axial

Compression

Xiaoxiong Zha, Guobin Gong and Xichao Liu

Study on Behavior of Concrete Filled Elliptical Steel Tube Members Part II : Under Bending and Eccentric Compression Xiaoxiong Zha, Guobin Gong and Xichao Liu

Nonlinear Finite Element Analysis on Long Columns of High-Strength Concrete-Filled Square Steel Tube with Inner CFRP Circular Tube under Axial Load G.C. Li, C.Y. Di, L. Tian and C. Fang

Push-Out Experiments of Headed Shear Studs in Group Arrangements

Milan Spremic, Zlatko Markovic, Milan Veljkovic and Dragan Budjevac

Progressive Collapse Analysis of Transmission Tower-Line System under Earthquake

W.M. Wang, H.N. Li and L. Tian

Conference Announcement 


\title{
STUDY ON BEHAVIOR OF CONCRETE FILLED ELLIPTICAL STEEL TUBE MEMBERS PART I : SHORT AND LONG COLUMNS UNDER AXIAL COMPRESSION
}

\author{
Xiaoxiong Zha ${ }^{1,}{ }^{*}$, Guobin Gong ${ }^{2}$ and Xichao Liu ${ }^{2}$ \\ ${ }^{1}$ Shenzhen Graduate School, Harbin Institute of Technology, Shenzhen 518055, China \\ ${ }^{2}$ Shenzhen Graduate School, Harbin Institute of Technology, Shenzhen 518055, China \\ *(Corresponding author: E-mail: zhaxx@hit.edu.cn)
}

Received: 21 September 2011; Revised: 18 January 2012; Accepted: 27 January 2012

\begin{abstract}
This paper presents theoretical analysis of concrete filled elliptical steel tube (CFEST) members under axial compression. The theoretical analysis presents the distribution rule of interaction between steel tube and core concrete for CFEST column, which is verified and compared with both experimental tests and finite element (FE) simulations. The assumption of effective confined zone distribution of core concrete is proposed and the influence of cross-section shape on the confinement effect is analyzed. A unified axial compressive strength formula and stability factor are obtained for CFEST columns based on existing formulas for concrete filled circular steel tube (CFCST) columns.
\end{abstract}

Keywords: Theoretical analysis, Interaction, Concrete filled elliptical steel tube, Axially compressive strength, Stability factor

\section{INTRODUCTION}

Concrete filled steel tube (CFST) is a composite structure with concrete filled in the steel tube, and if the steel tube is partially filled the CFST is called hollow concrete filled steel tube (HCFST), and if the steel tube is fully filled the CFST is called solid concrete filled steel tube (SCFST). According to the section shapes, CFST can be divided into concrete filled circular steel tube (CFCST), concrete filled elliptical steel tube (CFEST), concrete filled rectangular/square steel tube(CFRST, CFSST) and so on.

$\mathrm{Yu}$ et al. [1] proposed a unified formulation to predict composite compressive strength of concrete-filled circular steel tube (CFCST) columns for hollow and solid sections under axial compression based on theory of elasticity. Chitawadagi and Narasimhan [2] studied strength deformation behavior of CFCST under flexure and they examined the effects of steel tube thickness, the cross sectional area of concrete, strength of in-filled concrete and the confinement of concrete on moment capacity and curvature of CFCST. Yang et al. [3] presented testing and analysis of concrete-filled elliptical hollow sections (CFEHS), and they found that the compressive response of CFEHS is sensitive to both steel tube thickness and concrete strength, i.e. higher tube thickness resulting in higher load carrying capacity and enhanced ductility, and higher concrete strengths improving load-carrying capacity but reducing ductility. Dai and Lam [4] proposed a new stress-strain model for the confined concrete for CFEHS member under axial compression, which is validated by finite element simulations. Besides circular and elliptical sections, square hollow sections have been studied by Guo et al. [5, 6]. The effect of eccentricity has been studied by some researchers [7, 8, 9] among others. Unified theory for CFST members is proposed by Zhong [10], in which all the CFST members can be constructed within one framework whether the section is solid or hollow, circular shape or other general shapes. 
In the literature, most CFST research is focused on circular sections and axial compressive behavior, and there is little research work for CFEST members [11]. Therefore, the fundamental study of the CFEST can not only fill in the gap in this field, but also provide guidance for practical engineering.

Figure 1 shows a typical CFEST cross section, which has the following characteristics.

- Architectural aesthetics for the elliptical shape cross section and mobile choices of aspect ratios (long side length against short side length).

- Provision of strong and weak axes in an effective manner. For example, for cross sections with equal size in area and with the same material, the major flexural capacity for CFEST member is larger than for CFCST member. In this sense, CFEST will be more economical compared with CFCST under one-way bending and compression.

- Based on the smooth convex characteristic of elliptical cross section compared with round, square and polygonal shaped sections, the elliptical shape can be more effective in reducing the load on the structure caused by fluid. For example, the use of concrete filled elliptic steel tube as bridge pier is more effective in reducing the impact on the pier caused by water flow than the use of concrete filled circular steel tube and rectangular tube [11].

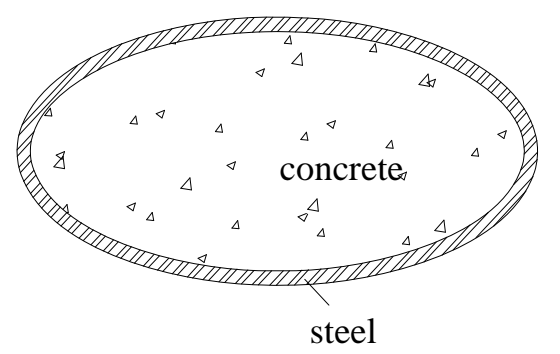

Figure 1. Typical Cross Section of a CFEST Member

In this paper, solid CFEST with steel tube fully filled by concrete will be considered. The paper is followed by section 2 (Stress analysis for the core concrete and external steel tube of CFEST), section 3 (Finite element simulation of short columns under axial compression for CFEST members), and section 4 (Axial compressive strength formula for CFEST short columns), section 5 (Experimental Verification), section 6 (Stability factor under axial compression for CFEST long columns) and section 7 (Concluding remarks). 


\section{STRESS ANALYSIS FOR THE CORE CONCRETE AND EXTERNAL STEEL TUBE OF CFEST}

The analysis of CFEST is divided into two parts: one part is the vertical compressive stress for the steel tube and core concrete respectively, and the second part is the interaction steel tube and core concrete in the horizontal plane. The second part is focused in this paper. The interaction between concrete and steel tube is analyzed according to plane stress consideration, and a unit height is used.

Figures 2(a) and 2(b) show half isolated free body to the symmetrical plane. According to the principle of static equilibrium we have:

$\sum F_{x}=0 \Rightarrow 2 N_{2}-f_{l x}(0) \cdot 2 b=0$

$\sum F_{y}=0 \Rightarrow 2 N_{1}-f_{l y}(0) \cdot 2 a=0$

Solution of (1) and (2) gives:

$$
f_{l x}(0)=\frac{N_{2}}{b}, f_{l y}(0)=\frac{N_{1}}{a}
$$

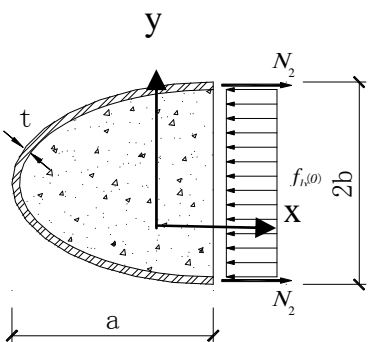

(a)

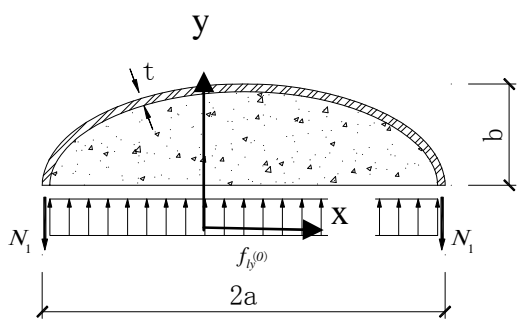

(b)

Figure 2. Half Isolated Free Body to the Symmetrical Plane for CFEST

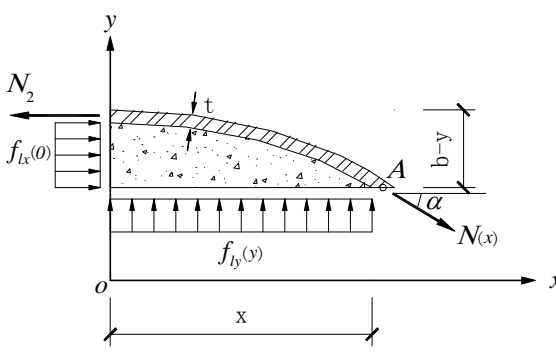

(a)

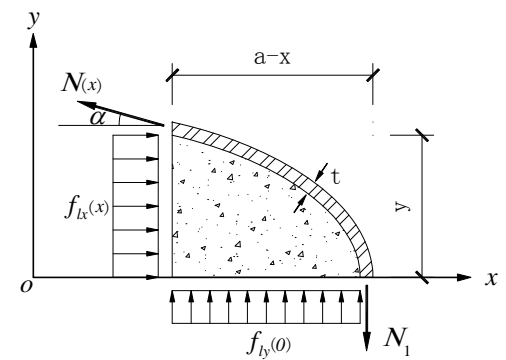

(b)

Figure 3. Part of Isolated Free Body for CFEST

Part of isolated free body for concrete filled elliptical steel tube is shown in Figure 3(a) and 3(b). $f_{l x}(x)$ is the lateral pressure of concrete along $\mathrm{x}$ when abscissa is $\mathrm{x}, f_{\mathrm{y}}(y)$ is the lateral pressure of concrete along $\mathrm{y}$ when ordinate is $\mathrm{y}, f_{\mathrm{yy}}(0)$ is the lateral pressure of concrete along $\mathrm{y}$ when ordinate is $0, f_{x}(0)$ is the lateral pressure of concrete along $\mathrm{x}$ when ordinate is $0, N(x)$ is circumferential tension of steel tube when abscissa is $\mathrm{x}, N_{1}$ is circumferential tension of steel tube when abscissa is a , i.e. $\mathrm{x}=\mathrm{a}, N_{2}$ is circumferential tension of steel tube when $\mathrm{x}=0, \quad \alpha$ is the angle between $\mathrm{x}$ axis and the tangential to the elliptic curve at $\mathrm{x} . \quad N(x)=\sigma(x) \cdot t, N_{1}=\sigma_{1} \cdot t, N_{2}=\sigma_{2} \cdot t$, and $\sigma(x), \sigma_{1}, \sigma_{2}$ are the circumferential tension of steel tube at $\mathrm{x}, \mathrm{x}=\mathrm{a}$ and $\mathrm{x}=0$ respectively. 
According to the principle of static equilibrium we have:

$\sum F_{x}=0 \Rightarrow f_{l x}(0) \cdot(b-y)+N(x) \cdot \cos \alpha-N_{2}=0$

$\sum F_{y}=0 \Rightarrow f_{l y}(y) \cdot x-N(x) \cdot \sin \alpha=0$

Taking moment about A, according to $\sum M_{A}=0$, we have:

$f_{l x}(0) \cdot \frac{1}{2}(b-y)^{2}+f_{l y}(y) \cdot \frac{1}{2} x^{2}-N_{2} \cdot(b-y)=0$

Since $\tan \alpha=\frac{\frac{b x}{a^{2}}}{\sqrt{1-\left(\frac{x}{a}\right)^{2}}}$, we have:

$\sin \alpha=\frac{\frac{b x}{a^{2}}}{\sqrt{1-\left(\frac{x}{a}\right)^{2}+\frac{b^{2} x^{2}}{a^{4}}}}, \quad \cos \alpha=\frac{\sqrt{1-\left(\frac{x}{a}\right)^{2}}}{\sqrt{1-\left(\frac{x}{a}\right)^{2}+\frac{b^{2} x^{2}}{a^{4}}}}$

Combining the Eqs. 3, 4, 5, 6, 7 we have the solutions as follows:

$N_{1}=\frac{b}{a} \cdot N_{2}$

$f_{l x}=\frac{N_{2}}{b}$

$f_{l y}=\frac{b}{a^{2}} \cdot N_{2}$

$N(x)=\sqrt{1-\left(\frac{x}{a}\right)^{2}+\frac{b^{2} x^{2}}{a^{4}}} \cdot N_{2}$

As shown in Figure 4, taking the concrete differential element, and taking each of the stresses with orthogonal decomposition and combine along the normal vector $\vec{n}$, we have

$p(x) \cdot d s=f_{l x} \cdot d y \cdot \sin \alpha+f_{l y} \cdot d x \cdot \cos \alpha$

$d s=\sqrt{(d x)^{2}+(d y)^{2}}$

Combining Eqs. 12, 13, we have:

$p(x)=\frac{\frac{b}{a^{2}}}{1-\left(\frac{x}{a}\right)^{2}+\frac{b^{2} x^{2}}{a^{4}}} \cdot N_{2}$ 


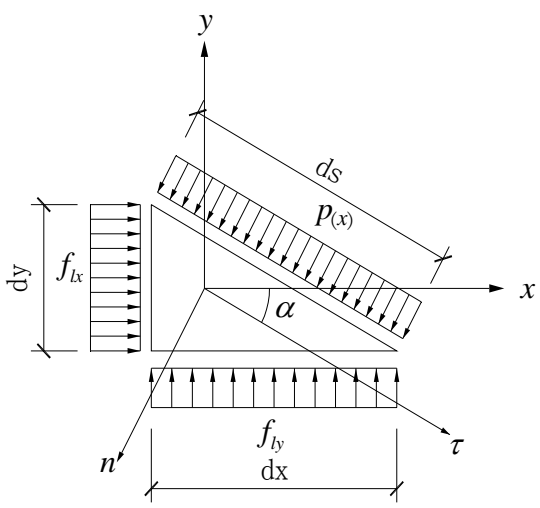

Figure 4. Core Concrete Differential Element

Assuming $a=142, b=71, t=6$ as an illustrational example, we obtain the resulting circumferential tension of steel tube and the core concrete lateral pressure distribution shown in Figure 5 and Figure 6.

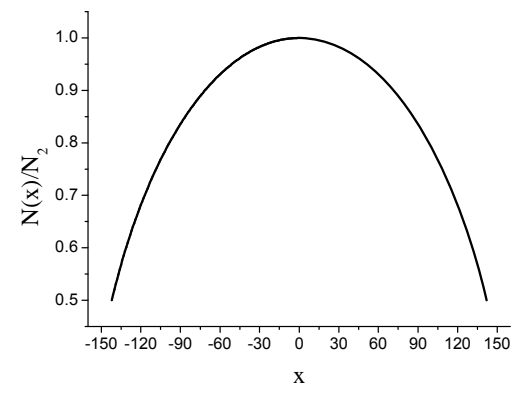

Figure 5. Circumferential Tension of External Steel Tube Along x

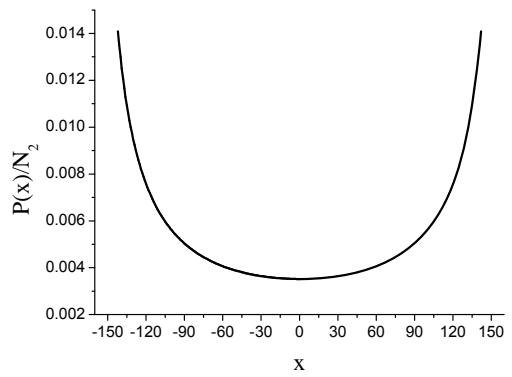

Figure 6. Core Concrete Lateral Pressure Along $\mathrm{x}$

Based on the above theoretical analysis, the distribution of lateral pressure of core concrete in CFEST, is parabolic along the $\mathrm{x}$-axis. The lateral pressure reaches minimum at both ends of short axis of elliptical cross section. The lateral pressure reaches maximum at both ends of long axis of elliptical cross section. The distribution of circumferential tension of external steel tube is parabolic along the x-axis. The circumferential tension reaches maximum at both ends of short axis of elliptical cross section. The circumferential tension reaches minimum at both ends of long axis of elliptical cross section. The distribution of circumferential tensile strain of external steel tube is parabolic along the $\mathrm{x}$-axis. The circumferential tensile strain reaches maximum at both ends of short axis of elliptical cross section. The circumferential tensile strain reaches minimum at both ends of long axis of elliptical cross section. 


\section{FINITE ELEMENT SIMULATION OF SHORT COLUMNS UNDER AXIAL COMPRESSION FOR CFEST MEMBERS}

A general-purpose finite element software ABAQUS is used for simulating CFEST members. Solid elements are used for both steel tube and concrete, and the nodes are tied together, i.e. no sliding. The concrete damaged plasticity model is employed for concrete material, and the details can be found in [12]. The concrete axial compressive stress-strain relation is shown in Figure 7, and the mathematical formulation of expression can be described as follows. More details can be found in [13]

when $\varepsilon \leq \varepsilon_{\mathrm{e}}, \sigma=E_{\mathrm{c}} \varepsilon, E_{\mathrm{c}}=0.3 f_{\mathrm{ck}} / \varepsilon_{\mathrm{e}}$;

when $\varepsilon_{\mathrm{e}} \leq \varepsilon \leq \varepsilon_{\mathrm{c}}, \sigma=f_{\mathrm{ck}}\left[\alpha_{\mathrm{a}}\left(\frac{\varepsilon}{\varepsilon_{\mathrm{c}}}\right)+\left(3-2 \alpha_{\mathrm{a}}\right)\left(\frac{\varepsilon}{\varepsilon_{\mathrm{c}}}\right)^{2}+\left(\alpha_{\mathrm{a}}-2\right)\left(\frac{\varepsilon}{\varepsilon_{\mathrm{c}}}\right)^{3}\right]$;

when $\varepsilon_{\mathrm{c}} \leq \varepsilon \leq \varepsilon_{\mathrm{u}}, \sigma=f_{\mathrm{ck}} \frac{\varepsilon / \varepsilon_{\mathrm{c}}}{\alpha_{\mathrm{d}}\left(\varepsilon / \varepsilon_{\mathrm{c}}-1\right)^{2}+\varepsilon / \varepsilon_{\mathrm{c}}}$;

where:

$\varepsilon_{\mathrm{e}}$ - compressive strain corresponding to stress with the value of $0.3 f_{\mathrm{ck}}$ at hardening stage

$\varepsilon_{\mathrm{c}}$ - compressive strain corresponding to stress with the peak value of $f_{\mathrm{ck}}$

$\varepsilon_{\mathrm{c}}$ - compressive strain corresponding to stress with the value of $0.5 f_{\mathrm{ck}}$ at softening stage

$\alpha_{\mathrm{a}}, \alpha_{\mathrm{d}}$-model constants

The axial tensile stress-strain relationship is based on energy criterion for concrete, i.e. softened stress-fracture energy relation and the stress-strain curve is shown in Fig. 8, with the mathematical formulation of expression described as follows, $G_{\mathrm{f}}$ and $\sigma_{\mathrm{t} 0}$ are concrete fracture energy (the energy required to cause one continuous crack per unit area), and failure stress respectively. When $f_{\mathrm{ck}}=20 \mathrm{MPa}, G_{\mathrm{f}}=40 \mathrm{~N} / \mathrm{m}$; when $f_{\mathrm{ck}}=40 \mathrm{MPa}, G_{\mathrm{f}}=120 \mathrm{~N} / \mathrm{m}$, and the values of $G_{\mathrm{f}}$ can be obtained using linear interpolation corresponding to other values of $f_{\mathrm{ck}}$. The failure stress $\sigma_{\mathrm{t} 0}$ is calculated according to the following formula [14]:

$\sigma_{\mathrm{t} 0}=0.26 \times\left(1.5 f_{\mathrm{ck}}\right)^{2 / 3}$

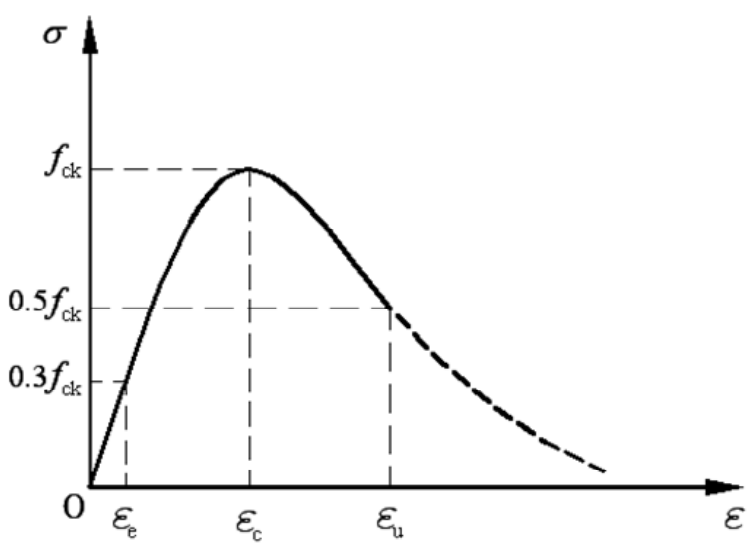

Figure 7. Compressive Stress-strain Relation of Concrete 


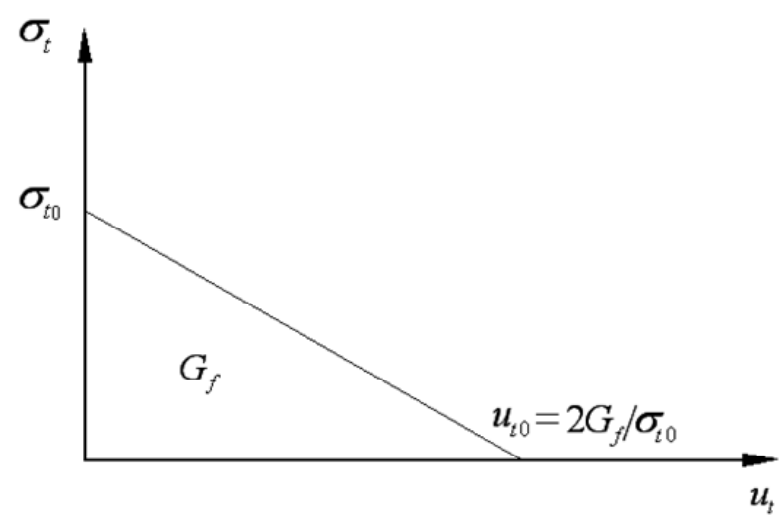

Figure 8. Tensile Softening Model of Concrete

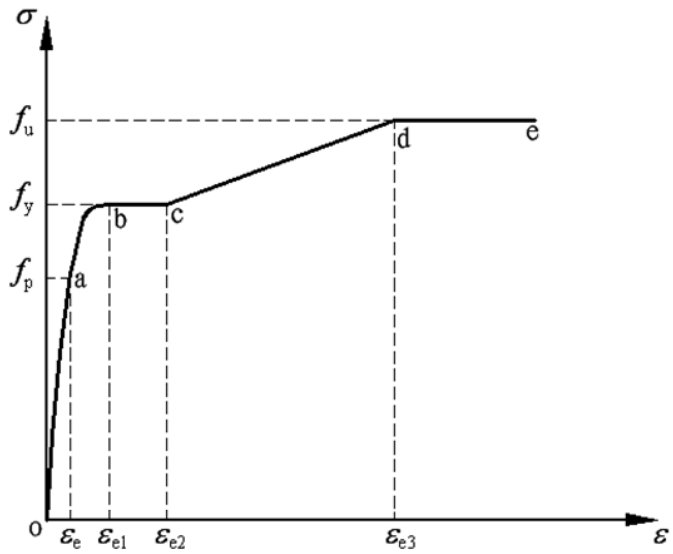

Figure 9. Stress-strain Relation of Steel

Steel axial stress-strain relation is shown in Figure 9, and the mathematical expression can be described as follows [15]:

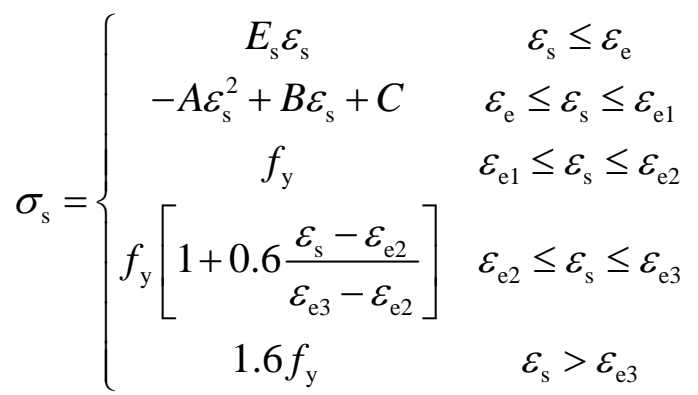

where,

$f_{\mathrm{p}}$ is proportional limit value of steel

$f_{\mathrm{y}}$ is yield strength value of steel

$f_{\mathrm{u}}$ is ultimate strength value of steel

$\varepsilon_{\mathrm{e}}=0.8 f_{\mathrm{y}} / E_{\mathrm{s}}, \varepsilon_{\mathrm{e} 1}=1.5 \varepsilon_{\mathrm{e}}, \varepsilon_{\mathrm{e} 2}=10 \varepsilon_{\mathrm{e} 1}, \varepsilon_{\mathrm{e} 3}=100 \varepsilon_{\mathrm{e} 1}, B=2 A \varepsilon_{\mathrm{e} 1}$,

$A=0.2 f_{\mathrm{y}} /\left(\varepsilon_{\mathrm{e} 1}-\varepsilon_{\mathrm{e}}\right)^{2}, C=0.8 f_{\mathrm{y}}+A \varepsilon_{\mathrm{e}}{ }^{2}-B \varepsilon_{\mathrm{e}}$.

and the details can be found in reference [15]. 
Figure 10 shows an established CFEST finite element model with solid elements for steel and concrete and there are three layers of meshed elements along the steel tube thickness direction.

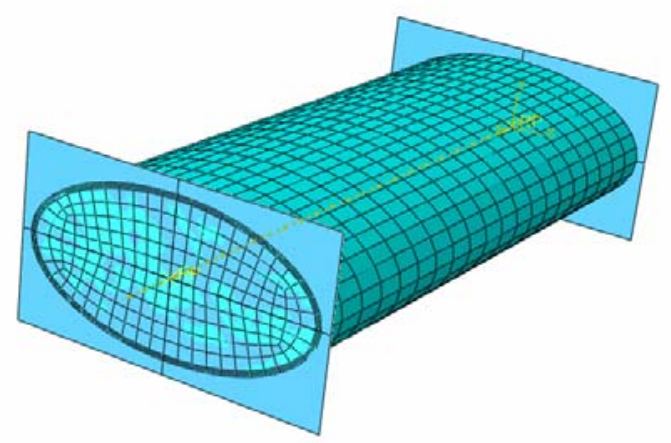

Figure 10. Finite Element Model for CFEST

The boundary condition of the CFEST columns under axial compression is simply supported. The loading condition is by displacement control. For the long column, an initial eccentricity of $e_{0}=L / 1000$ [16] (L is effective length of the column) along long and short axes of the section is applied.

Figure 11 shows the stress contour for different aspect ratios (long side length against short side length for the cross section) for concrete filled steel tubes modeled by ABAQUS. It can be seen that circular shape is a special elliptical shape with aspect ratio of 1 , and its lateral pressure is circlewise uniform. For the elliptical cross section, the lateral pressure is not uniform for core concrete, and changes with the shape of elliptical cross section. The lateral pressure distribution in core concrete is as follows: maximum at both ends of long axis of cross section, minimum at both ends of short axis of cross section.

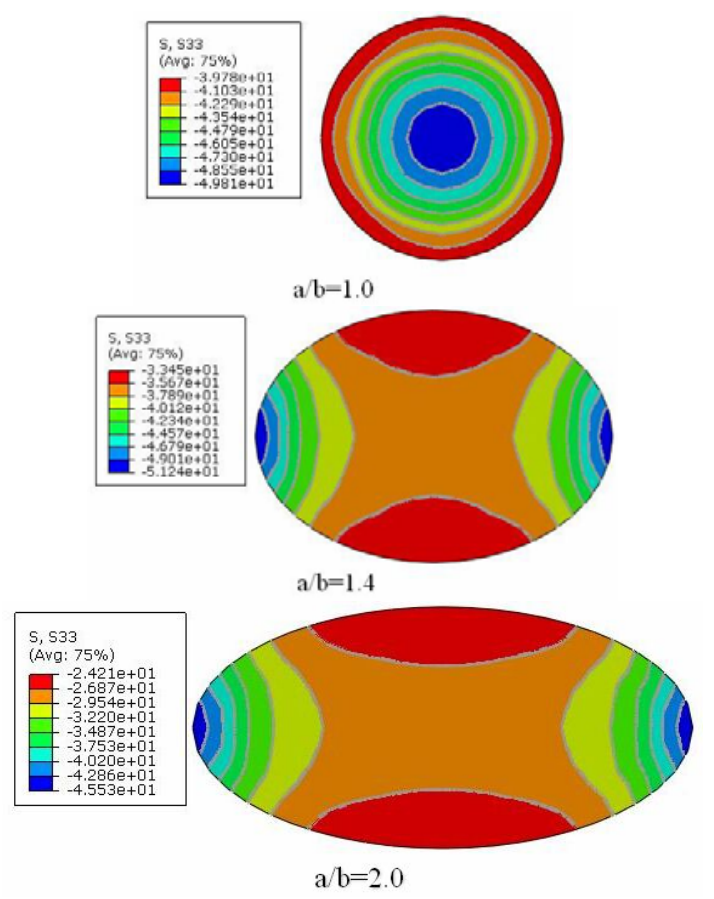




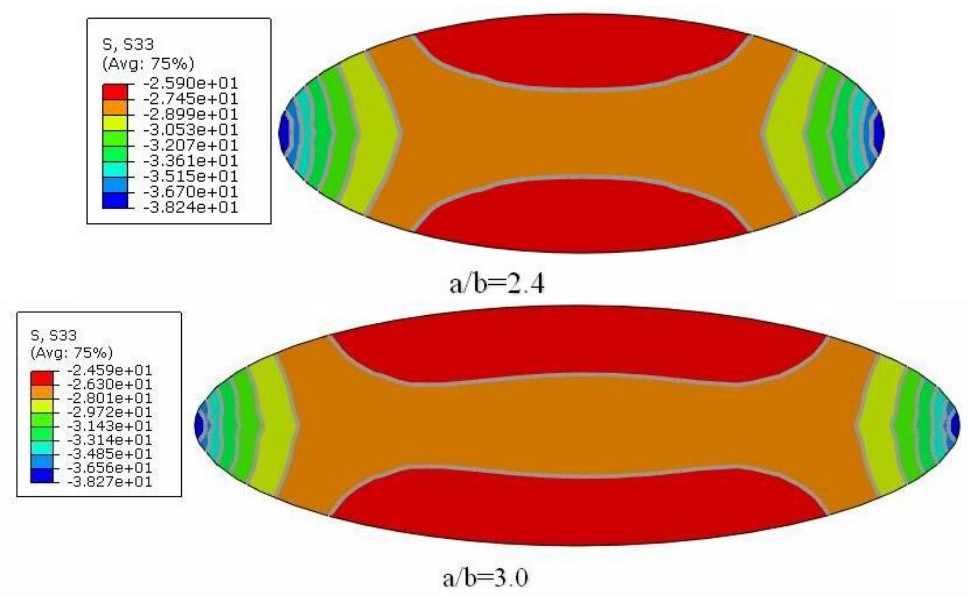

Figure 11. Stress Contour for Core Concrete

\section{AXIAL COMPRESSIVE STRENGTH FORMULA FOR CFEST SHORT COLUMNS}

In reference [1], a unified formula of axial compressive strength for concrete filled circular steel tube (CFCST) short columns is proposed, as shown in Eq. 17.

$$
f_{\mathrm{sc}}^{\mathrm{k}}=\frac{1+1.5 k \xi}{1+\frac{A_{\mathrm{s}}}{A_{\mathrm{c}}}} f_{\mathrm{ck}}
$$

where $A_{s}$ and $A_{c}$ are cross-sectional areas of steel and concrete respectively, $\xi$ is characteristic

values for the confining factor, $\xi=\frac{f_{\mathrm{y}} A_{\mathrm{s}}}{f_{\mathrm{ck}} A_{\mathrm{c}}}, f_{\mathrm{y}}$ and $f_{\mathrm{ck}}$ are the characteristic values for the yield strength of steel and cylinder strength of concrete respectively. $k$ is confining cross-section adjustment factor. In this paper, by changing the elliptical cross section aspect ratios $(a / b)$, the relation between $k$ and $a / b$ is studied.

According to previous theoretical analysis and finite element simulation results, it is assumed that stress distribution of the core concrete of CFEST is described by mathematical model as shown in Figure 12 [17-19]. The shaded area is effective distribution zone of lateral pressure, which consists of the surrounded area by two parabola lines $c_{1}, c_{2}$, and ellipse. The parabolic lines $c_{1}$ and $c_{2}$ are tangential to straight line $\mathrm{y}_{1}$ and $\mathrm{y}_{2}$ at the intersected points $\mathrm{y}_{1}, \mathrm{y}_{2}$ and ellipse, i.e. $\mathrm{A}, \mathrm{B}, \mathrm{C}$ and D. As the parabola lines $c_{1}$ and $c_{2}$ are symmetric to $\mathrm{X}$ axis, straight line $\mathrm{y}_{1}$ and $\mathrm{y}_{2}$ are symmetric to $\mathrm{X}$ and $\mathrm{Y}$ axis, only the position of $\mathrm{A}$ is required in order to determine the core concrete compressive area. 


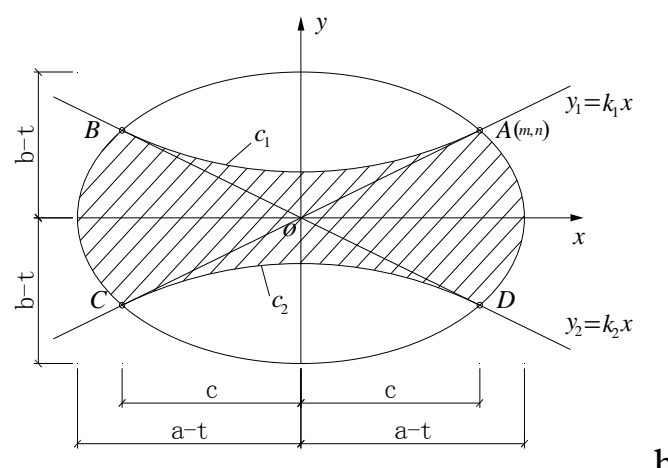

$\mathrm{h}$

Figure 12. Effective Confining Area of Core Concrete

According to the parabola $C_{1}$ and the straight line $Y_{1}$ are tangent at $A(m, n)$, simultaneous equations can be solved:

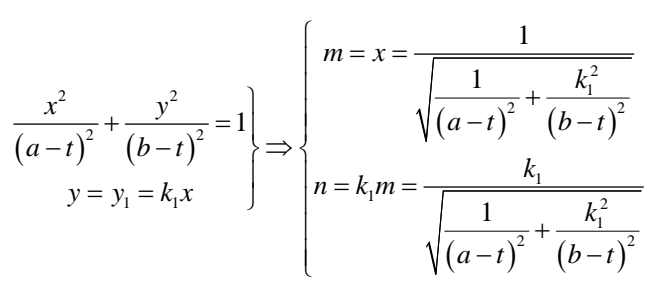

Parabola $C_{1}$ is expressed by $y=\frac{n}{2 m^{2}} x^{2}+\frac{n}{2}$, and after integration, the compressive area of the core concrete can be obtained as follows:

$$
\begin{aligned}
A_{\text {unconfined }}= & 4(a-t)(b-t)\left[\frac{m}{2(a-t)} \sqrt{1-\left(\frac{m}{a-t}\right)^{2}}\right. \\
& \left.+\frac{1}{2} \arcsin \left(\frac{m}{a-t}\right)\right]-\frac{8 m n}{3} \\
A_{\text {confined }}= & \pi(a-t)(b-t)-A_{\text {non-confined }} \\
= & \pi(a-t)(b-t)-4(a-t)(b-t)\left[\frac{m}{2(a-t)} \sqrt{1-\left(\frac{m}{a-t}\right)^{2}}\right. \\
& \left.+\frac{1}{2} \arcsin \left(\frac{m}{a-t}\right)\right]+\frac{8 m n}{3} \\
k=\frac{A_{\text {confined }}}{\pi(a-t)(b-t)} & 4\left[\frac{m}{2(a-t)} \sqrt{1-\left(\frac{m}{a-t}\right)^{2}}+\frac{1}{2} \arcsin \left(\frac{m}{a-t}\right)\right] \\
=1- & \frac{8 m n}{\pi \pi(a-t)(b-t)}
\end{aligned}
$$

Based on the fact that the compressive lateral pressure is circlewise uniform for concrete filled circular steel tube, and according to regression analysis of finite element simulations, the relation between slope of straight line $\mathrm{y}_{1}$ and $\mathrm{a} / \mathrm{b}$ is as follows:

$$
k_{1}=\frac{1}{\left(\frac{a}{b}\right)-1}
$$


Putting Eq. 22 into Eq. 18, we have:

$$
\begin{aligned}
& m=\frac{\frac{1}{\sqrt{\frac{1}{(a-t)^{2}}+\frac{b^{2}}{(a-b)^{2}(b-t)^{2}}}}}{(a-b) \sqrt{\frac{1}{(a-t)^{2}}+\frac{b}{(a-b)^{2}(b-t)^{2}}}}
\end{aligned}
$$

Considering $t<<a, t<<b$, then $a-t \approx a, b-t \approx b$, and we have:

$$
k=1-\frac{4\left[\frac{m}{2 a} \sqrt{1-\left(\frac{m}{a}\right)^{2}}+\frac{1}{2} \arcsin \left(\frac{m}{a}\right)\right]}{\pi}+\frac{8 m n}{3 \pi a b}
$$

$$
m=\frac{1}{\sqrt{\frac{1}{a^{2}}+\frac{1}{(a-b)^{2}}}}, n=\frac{b}{(a-b) \sqrt{\frac{1}{a^{2}}+\frac{1}{(a-b)^{2}}}}
$$

In this paper, the cross sections for concrete filled elliptical steel tube are mainly with change of $a / b$ at value 1.0 to 3.0. Through Eq. 25 into 21, we obtain the change of $\mathrm{k}$ to the change of a/b. As shown in Figure 13, $\mathrm{k}$ is a power function of a/b. After regression, we obtain $k=(a / b)^{-0.3}$.

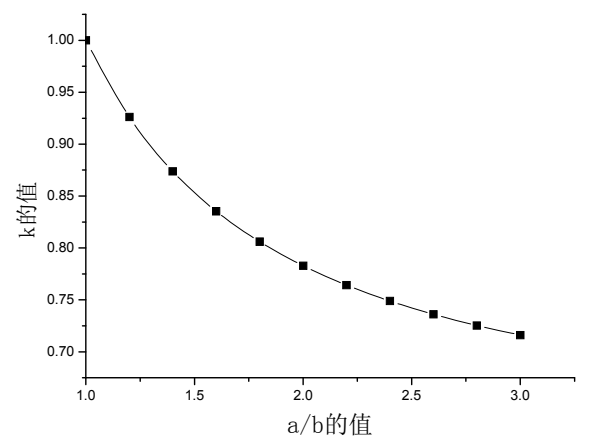

Figure 13. Confining Factor k against a/b

Therefore, axial compression formula for concrete filled elliptical steel tube short columns is as follows:

$$
f_{\mathrm{sc}}^{\mathrm{y}}=\frac{1+1.5\left(\frac{b}{a}\right)^{0.3} \xi}{1+\frac{A_{\mathrm{s}}}{A_{\mathrm{c}}}} f_{\mathrm{ck}}
$$




\section{EXPERIMENTAL VERIFICATION}

Totally six axial compression tests for CFEST short columns were performed in Shenzhen Key Laboratory of Disaster Prevention and Mitigation HIT Shenzhen Graduate School. The specimens are divided into two groups, and the two groups adopt the same type of steel and concrete. The characteristic value for axial compressive strength of concrete is $f_{\mathrm{ck}}=22.0 \mathrm{~N} / \mathrm{mm}^{2}$, and steel yield strength $f_{\mathrm{y}}=321 \mathrm{~N} / \mathrm{mm}^{2}$. The specimen ID, geometrical sizes, and number are shown in Table 1 . The setup of the specimens for the $1^{\text {st }}$ group is shown in Figure 14, where the measurement locations are focused in the middle height since the end effect is smaller in these locations. The loading device is YAS-5000 electro-hydraulic servo universal testing machine, with the loading controlled by GTC350 all-digital electro-hydraulic servo controller. The specimens' top and bottom ends are both pin supported. The displacement control is used for loading, with a constant loading speed of $4 \mathrm{kN} / \mathrm{s}$.

Table 1. Geometrical Sizes and Number for CFEST Specimens

\begin{tabular}{cccc}
\hline Group & ID & $\begin{array}{c}\text { Cross section shape } \\
\text { factor } a / b\end{array}$ & $\begin{array}{c}\text { Geometrical size } \\
(2 a \times 2 b \times t \times L) \\
(\mathrm{mm} \times \mathrm{mm} \times \mathrm{mm} \times \mathrm{mm})\end{array}$ \\
\hline \multirow{2}{*}{1} & TY2.0-1 & 2.0 & $284 \times 142 \times 6 \times 700$ \\
& TY2.0-2 & 2.0 & $284 \times 142 \times 6 \times 700$ \\
& TY2.0-3 & 2.0 & $284 \times 142 \times 6 \times 700$ \\
\hline \multirow{2}{*}{2} & TY2.5-1 & 2.5 & $300 \times 120 \times 6 \times 700$ \\
& TY2.5-2 & 2.5 & $300 \times 120 \times 6 \times 700$ \\
& TY2.5-3 & 2.5 & $300 \times 120 \times 6 \times 700$ \\
\hline
\end{tabular}
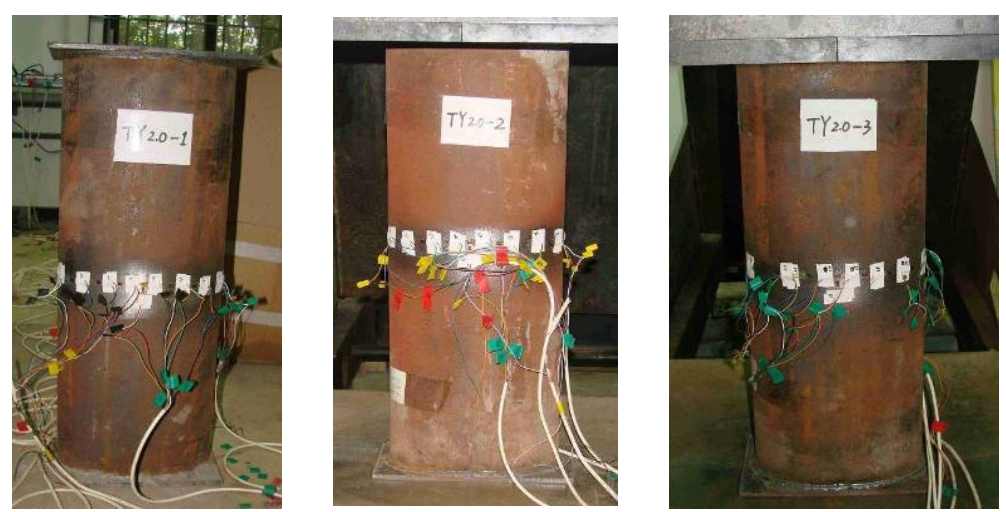

Figure 14. Setup of the $1^{\text {st }}$ Group Specimens

Figure 15 (a) and Figure 15 (b) show load-displacement curves for CFEST short columns for the $1^{\text {st }}$ and $2^{\text {nd }}$ groups respectively. It can be seen from Figure 15 that all the specimens exhibit initial elastic stage, followed by a peak, and with further loading the specimens exhibit crisp or ductile behavior, i.e. the specimens TY2.0-2, TY2.5-1 and TY2.5-2 all exhibit sudden decrease after the peak stress state (crisp behavior), while the specimens TY2.0-1, TY2.0-3 and TY2.5-3 show gradual decrease after the peak, followed by increase again. This is because during the experiments, load eccentricity is relatively larger for the specimens TY2.0-2, TY2.5-1 and TY2.5-2. The increase for TY2.0-1, TY2.0-3 and TY2.5-3 is due to the fact the confining effect of the steel tube to concrete becomes stronger, leading to the increase of load-displacement curve. 


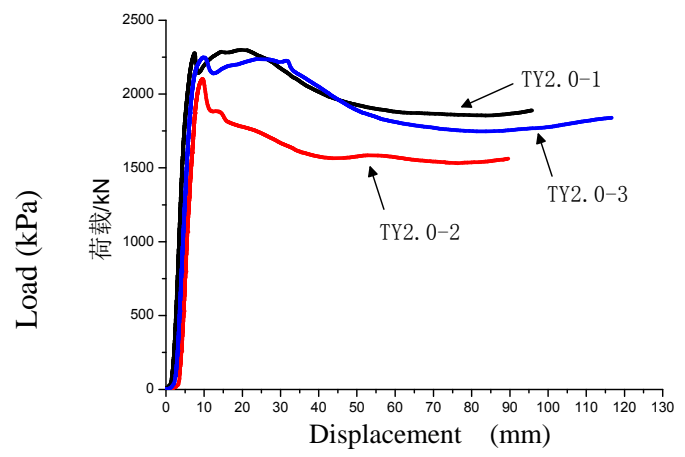

(a)

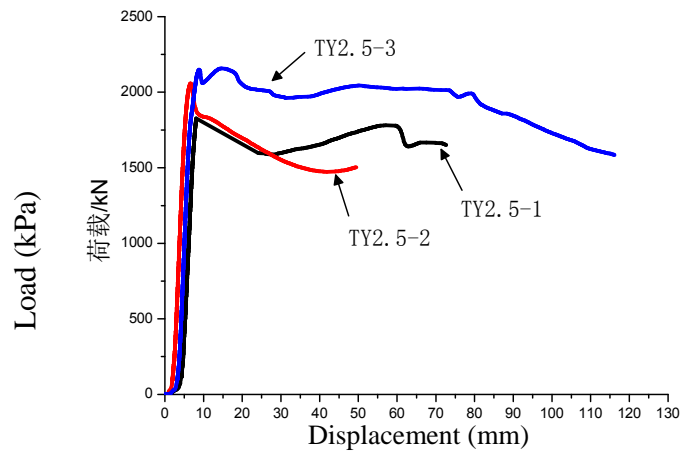

(b)

Figure 15. Load-displacement Curves for CFEST Short Columns

Figure 16 shows the pictures for the behavior of the specimens after loading of the concrete filled elliptical steel tube short columns for the $1^{\text {st }}$ and $2^{\text {nd }}$ groups respectively.
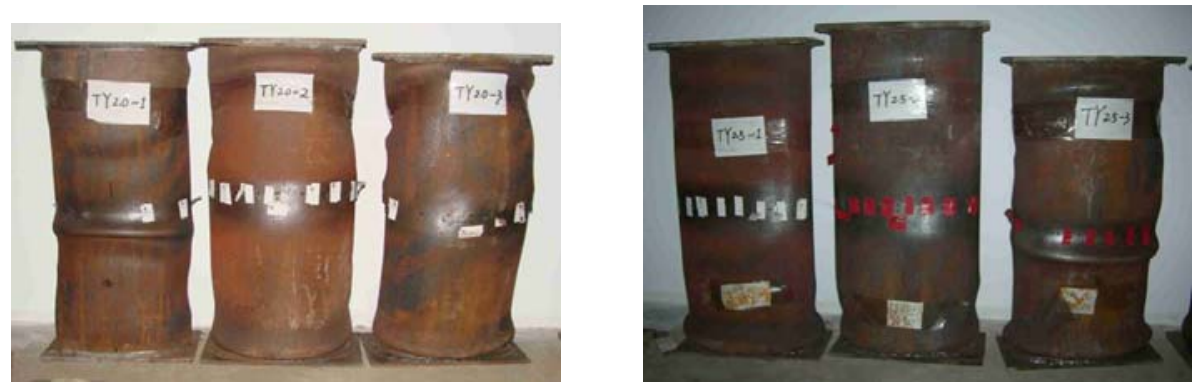

Figure 16. Behavior of the Specimens after Loading of the CFEST Short Columns

Table 2 is for test results, and table 3 is for comparison of test results and the formula-based results. Other test results are compared in Table 4 . It can be seen from the table 3 and 4 that the calculated values are in good agreement with experimental results.

Table 2. Ultimate Compressive Capacity and Combined Compressive Strength

\begin{tabular}{cccc}
\hline ID & $\begin{array}{c}\text { Composite cross section } \\
\text { area } A_{\mathrm{sc}}\left(\mathrm{mm}^{2}\right)\end{array}$ & $\begin{array}{c}\text { Ultimate compressive } \\
\text { capacity } N_{\mathrm{u}}(\mathrm{kN})\end{array}$ & $\begin{array}{c}\text { Combined compressive } \\
\text { strength } \\
f_{\mathrm{sc}}\left(\mathrm{N} / \mathrm{mm}^{2}\right)\end{array}$ \\
\hline TY2.0-1 & 31673.54 & 2299.00 & 72.62 \\
TY2.0-2 & 31673.54 & 2102.00 & 66.40 \\
TY2.0-3 & 31673.54 & 2249.00 & 71.04 \\
TY2.5-1 & 28274.33 & 1827.00 & 64.65 \\
TY2.5-2 & 28274.33 & 2059.00 & 72.86 \\
TY2.5-3 & 28274.33 & 2157.00 & 76.33 \\
\hline
\end{tabular}

Table 3. Comparison of Test Results and the Formula-based Results

\begin{tabular}{ccccc}
\hline Group & $\begin{array}{c}\text { Formula based } \\
f_{\mathrm{sc}}\left(\mathrm{N} / \mathrm{mm}^{2}\right)\end{array}$ & $\begin{array}{c}\text { Formula } \\
\text { calculated } N_{\mathrm{u}}(\mathrm{kN})\end{array}$ & $\begin{array}{c}\text { Experimental } \\
\text { averaged } N_{\mathrm{u}}(\mathrm{kN})\end{array}$ & $\begin{array}{c}\text { (Formula value)/ } \\
\text { (experimental } \\
\text { value) }\end{array}$ \\
\hline 1 & 68.25 & 2161.75 & 2216.67 & 0.975 \\
2 & 69.52 & 1965.76 & 2014.33 & 0.976 \\
\hline
\end{tabular}


Table 4. Comparison of other Test Results and the Formula-based Results

\begin{tabular}{|c|c|c|c|c|c|}
\hline Ref. & Group & $\begin{array}{l}\text { Formula } \\
\text { based } \\
f_{\mathrm{sc}}\left(\mathrm{N} / \mathrm{mm}^{2}\right)\end{array}$ & $\begin{array}{c}\text { Formula } \\
\text { calculated } N_{\mathrm{u}}(\mathrm{kN})\end{array}$ & Experimental averaged $N_{\mathrm{u}}(\mathrm{kN})$ & $\begin{array}{c}\text { (Formula value) } \\
\text { / (experimental } \\
\text { value) }\end{array}$ \\
\hline \multirow{15}{*}{ [2-3] } & 150X75X4-C30.NG/ & 94.94 & 847.82 & 839 & 1.011 \\
\hline & 150X75X4-C60 .NG/ & 111.07 & 991.90 & 974 & 1.018 \\
\hline & 150X75X4-C100 .NG/ & 140.87 & 1259.11 & 1265 & 0.995 \\
\hline & 150X75X5-C30 .NG/ & 108.12 & 964.37 & 981 & 0.983 \\
\hline & 150X75X5-C60 .NG/ & 122.81 & 1097.51 & 1084 & 1.012 \\
\hline & 150X75X5-C100 .NG/ & 151.73 & 1355.17 & 1296 & 1.046 \\
\hline & 150X75X6.3-C30 .NG/ & 136.18 & 1200.59 & 1193 & 1.006 \\
\hline & 150X75X6.3-C60 .NG/ & 152.31 & 1346.03 & 1280 & 1.052 \\
\hline & 150X75X6.3-C100 .NG/ & 176.55 & 1562.28 & 1483 & 1.053 \\
\hline & 150X75X4-C30 .G/ & 95.50 & 849.64 & 780 & 1.089 \\
\hline & 150X75X4-C60 .G/ & 111.70 & 997.84 & 961 & 1.038 \\
\hline & 150X75X4-C100 .G/ & 141.49 & 1259.90 & 1272 & 0.990 \\
\hline & 150X75X5-C30 .G/ & 107.82 & 965.67 & 988 & 0.977 \\
\hline & 150X75X5-C60 .G/ & 123.45 & 1102.61 & 1123 & 0.982 \\
\hline & 150X75X6.3-C100 .G/ & 178.40 & 1579.59 & 1160 & 1.362 \\
\hline \multirow{8}{*}{ [20] } & EHS1 - SCC-Full & 128.70 & 1141.70 & 1075 & 1.062 \\
\hline & EHS2 - SCC-Full & 133.28 & 1185.55 & 1163 & 1.019 \\
\hline & EHS3 - SCC-Full & 152.32 & 1353.85 & 1310 & 1.033 \\
\hline & EHS4 - SCC-Full & 119.50 & 1881.26 & 1598 & 1.177 \\
\hline & EHS5 - SCC-Full & 133.18 & 2099.23 & 2068 & 1.015 \\
\hline & EHS6 - SCC-Full & 150.22 & 2367.13 & 2133 & 1.110 \\
\hline & EHS7 - SCC-Full & 161.75 & 2553.59 & 2290 & 1.115 \\
\hline & EHS8 - NC-Full & 115.52 & 2216.68 & 2109 & 1.051 \\
\hline
\end{tabular}

\section{STABILITY FACTOR UNDER AXIAL COMPRESSION FOR CFEST LONG COLUMNS}

For the concrete filled steel tube, based on unified theory with considering the composite to be one material, the stability factor can be calculated as follows [1]:

$$
\varphi=\frac{1}{2 \bar{\lambda}_{\mathrm{sc}}{ }^{2}}\left\{\bar{\lambda}_{\mathrm{sc}}{ }^{2}+\left(1+\varepsilon_{\mathrm{sc}}\right)-\sqrt{\left[\bar{\lambda}_{\mathrm{sc}}{ }^{2}+\left(1+\varepsilon_{\mathrm{sc}}\right)\right]^{2}-4 \bar{\lambda}_{\mathrm{sc}}{ }^{2}}\right\}
$$

where slenderness ratio is defined as:

$$
\bar{\lambda}_{\mathrm{sc}}=\frac{\lambda}{\pi} \sqrt{\frac{f_{\mathrm{sc}}}{E_{\mathrm{sc}}}}
$$

where $\varepsilon_{\mathrm{sc}}$ is the effective initial eccentricity of concrete filled steel tube and $\varepsilon_{\mathrm{sc}}=K \bar{\lambda}_{\mathrm{sc}} ; K \quad$ is the initial eccentricity coefficient of concrete filled steel tube and $K=0.25 \alpha^{N} ; \alpha$ is steel ratio, equal to the ratio of the steel section area and the composite section area $A_{s} /\left(A_{s}+A_{c}\right) ; N$ is cross section shape factor. 
In calculating the stability factor, bending stiffness is used and the composite elastic modulus is calculated as follows:

$E_{\mathrm{sc}}=\frac{E_{\mathrm{c}} I_{\mathrm{c}}+E_{\mathrm{s}} I_{\mathrm{s}}}{I_{\mathrm{sc}}}$

In this paper, based on Eq. 27 and a number of finite element analysis, and after regression analysis, the stability factor for concrete filled elliptical steel tube short and long columns is as follows [11]:

$$
\begin{aligned}
& \varphi=\frac{1}{2 \bar{\lambda}_{\mathrm{sc}}{ }^{2}}\left\{\bar{\lambda}_{\mathrm{sc}}{ }^{2}+\left(1+\varepsilon_{\mathrm{sc}}\right)-\sqrt{\left[\bar{\lambda}_{\mathrm{sc}}{ }^{2}+\left(1+\varepsilon_{\mathrm{sc}}\right)\right]^{2}-4 \bar{\lambda}_{\mathrm{sc}}{ }^{2}}\right\} \\
& \varepsilon_{\mathrm{sc}}=K \bar{\lambda}_{\mathrm{sc}} \\
& K=0.25 \alpha^{N} \\
& N=\left(\frac{a}{b}\right)^{m}
\end{aligned}
$$

where $a$ is half the length of long axis of elliptical cross section, $b$ is half the length of short axis of elliptical cross section, $m=-6$ for action around long axis, $m=-2$ for action around short axis.

For the work reported a total of 198 finite element models are established [11]. Stability factor is analyzed for different parameters, as listed in table 4. Comparison of formula based value with the finite element results gives an average value of 1.021 and error variance is 0.002 . This indicates that the formula can describe the stability capacity for CFEST long columns.

Table 4. Parameters for Axial Compressive Long Column

\begin{tabular}{cc}
\hline Parameter & Value \\
\hline Steel yield strength $f_{\mathrm{y}} / \mathrm{MPa}$ & $235,345,90$ \\
Concrete axial compressive characteristic strength $f_{\mathrm{ck}} / \mathrm{MPa}$ & $20.1,26.8,32.4$ \\
Steel ratio $a$ & $0.098 \sim 0.160$ \\
Section shape $a / b$ & $1.0,1.2,1.4,1.6,1.8,2.0,2.2,2.4$, \\
Length $L / \mathrm{mm}$ & $2.6,3.0$ \\
\hline
\end{tabular}

\section{CONCLUDING REMARKS}

This paper presents theoretical analysis of axial compressive behavior of concrete filled elliptical steel tube members. The theoretical analysis shows the distribution rule of interaction between steel tube and core concrete for CFEST column under axial compression based on limit equilibrium, which is verified by both experimental tests and finite element simulations. A unified axial compressive strength formula and stability factor are obtained for CFEST columns. 


\section{Appendix : Notations}

$f_{l x}(x)$ : lateral pressure of concrete along $\mathrm{x}$ when abscissa is $\mathrm{x}$

$f_{l y}(y)$ : lateral pressure of concrete along $\mathrm{y}$ when ordinate is $\mathrm{y}$

$f_{y y}(0)$ : lateral pressure of concrete along $y$ when ordinate is 0

$f_{l x}(0)$ : lateral pressure of concrete along $\mathrm{x}$ when abscissa is 0

$N(x)$ : circumferential tension of steel tube when abscissa is $\mathrm{X}$

$N_{1}$ : circumferential tension of steel tube when abscissa is a

$N_{2}$ : $\quad$ circumferential tension of steel tube when $\mathrm{x}=0$

$\alpha$ : $\quad$ the angle between $\mathrm{x}$ axis and the tangential to the elliptic curve at $\mathrm{x}$

$\sigma(x)$ : circumferential tension of steel tube at $\mathrm{x}$

$\sigma_{1}$ : $\quad$ circumferential tension of steel tube at $\mathrm{x}=\mathrm{a}$

$\sigma_{2}$ : circumferential tension of steel tube at $\mathrm{x}=0$

$f_{\mathrm{ck}}: \quad$ peak value of stress of concrete

$\varepsilon_{\mathrm{e}}$ : compressive strain of concrete corresponding to stress with the value of $0.3 f_{\mathrm{ck}}$ at hardening stage

$\varepsilon_{\mathrm{c}}$ : compressive strain of concrete corresponding to stress with the peak value of $f_{\mathrm{ck}}$

$\varepsilon_{\mathrm{c}}$ : compressive strain of concrete corresponding to stress with the value of $0.5 f_{\mathrm{ck}}$ at softening stage

$\alpha_{\mathrm{a}}, \alpha_{\mathrm{d}}$ - model constants for concrete

$G_{\mathrm{f}}$ : fracture energy required to cause one continuous crack per unit area

$\sigma_{\mathrm{t} 0}: \quad$ failure stress of concrete

$f_{\mathrm{p}}$ : $\quad$ proportional limit value of steel

$f_{\mathrm{y}}$ : characteristic yield strength value of steel

$f_{\mathrm{u}}$ : ultimate strength value of steel

$E_{\mathrm{s}}$ : Young's modulus of elasticty

$\varepsilon_{\mathrm{e}}=0.8 f_{\mathrm{y}} / E_{\mathrm{s}}$

$\varepsilon_{\mathrm{e} 1}=1.5 \varepsilon_{\mathrm{e}}$

$\varepsilon_{\mathrm{e} 2}=10 \varepsilon_{\mathrm{e} 1}$

$\varepsilon_{\mathrm{e} 3}=100 \varepsilon_{\mathrm{e} 1}$

$A$ : $\quad$ model constant for steel , $A=0.2 f_{\mathrm{y}} /\left(\varepsilon_{\mathrm{e} 1}-\varepsilon_{\mathrm{e}}\right)^{2}$,

$B$ : model constant for steel, $B=2 A \varepsilon_{\mathrm{e} 1}$

$C$ : model constant for steel, $C=0.8 f_{\mathrm{y}}+A \varepsilon_{\mathrm{e}}{ }^{2}-B \varepsilon_{\mathrm{e}}$.

$e_{0}$ : initial eccentricity

$A_{s}: \quad$ cross-sectional areas of steel

$A_{c}$ : cross-sectional areas of concrete

$\xi$ : characteristic values for the confining factor, $\xi=\frac{f_{\mathrm{y}} A_{\mathrm{s}}}{f_{\mathrm{ck}} A_{\mathrm{c}}}$

$f_{\mathrm{ck}}$ : characteristic values for cylinder strength of concrete

$k$ : $\quad$ confining cross-section adjustment factor

$\varepsilon_{\mathrm{sc}}$ : effective initial eccentricity of concrete filled steel tube and $\varepsilon_{\mathrm{sc}}=K \bar{\lambda}_{\mathrm{sc}}$ 
$K: \quad$ initial eccentricity coefficient of concrete filled steel tube and $K=0.25 \alpha^{N}$

$\alpha$ : $\quad$ steel ratio, equal to $A_{s} /\left(A_{s}+A_{c}\right)$

$A_{3}$ : $\quad$ section area of steel

$A_{c}$ : $\quad$ section area of concrete

$N$ : $\quad$ cross section shape factor

a: $\quad$ half length of long axis of elliptical cross section

b : $\quad$ half length of short axis of elliptical cross section

$\mathrm{a} / \mathrm{b}: \quad$ aspect ratio

$E_{\mathrm{sc}}: \quad$ composite (steel and concrete) elastic modulus

$E_{\mathrm{c}}$ : elastic modulus of concrete

$I_{\mathrm{c}}$ : area moment of inertia for concrete

$E_{\mathrm{s}}$ : Young's modulus of elasticty

$I_{\mathrm{s}}$ : area moment of inertia for steel

$I_{\mathrm{sc}}$ : area moment of inertia for concrete and steel

\section{REFERENCES}

[1] Yu, M., Zha, X.X., Ye, J. and She, C.Y., “A Unified Formulation for Hollow and Solid Concrete-filled Steel Tube Columns under Axial Compression”, Engineering Structures, 2010, Vol. 32, No. 4, pp. 1046-1053.

[2] Manojkumar V. Chitawadagi, and Mattur C. Narasimhan1, "Strength Deformation Behavior of Circular Concrete Filled Steel Tubes Subjected to Pure Bending”, Journal of Constructional Steel Research, 2009, Vol. 65, pp. 1836-1845.

[3] Yang, H., Lam, D. and Gardner, L., "Testing and Analysis of Concrete-filled Elliptical Hollow Sections”, Engineering Structures, 2008, Vol. 30, No. 2, pp. 3771-3781.

[4] Dai, X. and Lam, D., "Numerical Modelling of the Axial Compressive Behavior of Short Concrete-filled Elliptical Steel Columns”, Journal of Constructional Steel Research, 2010, Vol. 66, No. 7, pp. 931-942.

[5] Guo, L, Zhang, S, Kim, W. and Ranzi, G., "Behavior of Square Hollow Steel Tubes and Steel Tubes Filled with Concrete”, Thin-Walled Structures, 2007, Vol. 45, pp. 961-973.

[6] Varma, A.H., Ricles, J.M., Sause, R. and Lu, L.W., "Experimental Behavior of High Strength Square Concrete-Filled Steel Tube Beam-Columns”, Journal of Structural Engineering, ASCE. 2002, Vol. 128, No. 3, pp. 309-318.

[7] Chen, B.C., Ou, Z.Q., Wang, L.Y. and Han, L.H., "Eccentric Bearing Capacity Analysis of Concrete Filled Steel Tube”, 2002, Vol. 30, No. 6, pp. 838-844. (in Chinese)

[8] Yu, Z.W. and Ding, X.F., "Mechanical Properties.of Concrete Filled Circular Steel Tube Eccentric Loaded Columns", 2008, Vol. 21, No. 1, pp. 40-46. (in Chinese)

[9] Toshiaki Fujimoto, Akiyoshi Mukai, Isao Nishiyama and Kenji Sakino, "Behavior of Eccentrically Loaded Concrete-Filled Steel Tubular Columns", Journal of Structural Engineering, ASCE. 2004, Vol. 130, No. 2, pp. 203-212.

[10] Zhong, S.T., "Unified Theory of Concrete Filled Steel Tube - Theoretical Research and Application”, Tsinghua University Press, 2006. (in Chinese)

[11] Liu, X.C., "Study of Basic Properties of Concrete Filled Elliptical Steel Tube", Master Thesis, Harbin Institute of Technology Shenzhen Graduate School, 2010, Vol. 6. (in Chinese)

[12] ABAQUS Analysis User’s Manual, Volume III: Materials, SIMULIA. 
[13] GB50010-2002, Code for Design of Xoncrete Structures”, Ministry of Construction, People's Republic of China. (in Chinese)

[14] Yao, G.H., "Research on Behaviour of Mechanism of Concrete-filled Steel Tubes Subjected to Complicated Loading States”, PhD Thesis, Fuzhou University, 2006. (in Chinese)

[15] Han, L.H., "Concrete Filled Steel Tube Structure - Theory and Practice”, Science Press, 2004. (in Chinese)

[16] GB50205-2001, Code for Acceptance of Construction Quality of Steel Structures”, Ministry of Construction, People's Republic of China. (in Chinese)

[17] Tan, T.H. and Yip, W.K., "Behavior of Axially Loaded Concrete Columns Confined by Elliptical Hoops”, ACI Structural Journal, 1999, Vol. 96, No. 6, pp. 967-973.

[18] Chung, H.S., Yang, K.H., Lee, Y.H. and Eun, H.C.,” Stress-strain Curve of Laterally Confined Concrete”, Engineering Structures, 2002, Vol. 24, No. 9, pp. 1153-1163.

[19] Razvi, S. and Saatcioglu, M., “Confinement Model for High-strength Concrete”, ASCE, Journal of Structural Engineering, 1999, Vol. 125, No. 3, pp. 281-289.

[20] Zhao, X.L. and Packer, J.A., "Tests and Design of Concrete-filled Elliptical Hollow Section Stub Columns”, Thin-Walled Structures, 2009, Vol. 47, pp. 617-628. 


\title{
STUDY ON BEHAVIOR OF CONCRETE FILLED ELLIPTICAL STEEL TUBE MEMBERS PART II : UNDER BENDING AND ECCENTRIC COMPRESSION
}

\author{
Xiaoxiong Zha ${ }^{1,}{ }^{*}$, Guobin Gong ${ }^{2}$ and Xichao Liu ${ }^{2}$ \\ ${ }^{1}$ Shenzhen Graduate School, Harbin Institute of Technology, Shenzhen 518055, China \\ 2 Shenzhen Graduate School, Harbin Institute of Technology, Shenzhen 518055, China \\ *(Corresponding author: E-mail: zhaxx@hit.edu.cn)
}

Received: 28 April 2011; Revised: 17 February 2012; Accepted: 29 February 2012

\begin{abstract}
In this paper, based on the ideology of "unified theory", the theoretical calculation equations of ultimate flexural capacity for concrete filled elliptical steel tube members (CFEST) around long and short axes are derived and compared with and verified by finite element simulations. Modified equations are then proposed for practical applications on the basis of the flexural capacity for circular concrete filled steel tube members. Under the guidance of "unified theory" and parametric analysis, the simplified practical calculation equations of capacity for CFEST members under eccentric compression are obtained, and mechanical behavior of a series of CFEST members with different section dimensions is conducted using finite element analysis.
\end{abstract}

Keywords: Elliptical concrete filled steel tube, Unified theory, Bending, Eccentric compression, Finite element, Parametric analysis

\section{INTRODUCTION}

In the framework of "unified theory" proposed by Zhong [1], the concrete filled steel tube (CFST) can be considered to be one unified material, on which the unified capacity is based rather than the simple superposition of capacity of concrete and steel tube. In other words, the unified compressive strength can be expressed by one parameter $f_{\mathrm{sc}}^{\mathrm{y}}$, which incorporates the effect of the concrete-steel interaction. According to ultimate balance theory, the ultimate flexural bending capacity is derived for CFEST members around strong and weak axes. Then the theory is modified and amended with the help of finite element simulation results, and simplified equations are obtained for ultimate flexural bending capacity for CFEST members. Based on the existing interaction equation of $N / N_{0} \sim M / M_{0}$ for flexural capacity for concrete filled circular steel tube, a series of flexural members are analyzed by using finite element simulations for different elliptical aspect ratios. And interaction equations of $N / N_{0} \sim M / M_{0}$ are obtained for the CFEST members.

\section{FINITE ELEMENT SIMULATION OF CFEST FOR COMPRESSIVE AND FLEXURAL MEMBERS}

A general-purpose finite element software ABAQUS is used for simulating CFEST members. Solid elements are used for both steel tube and concrete, and the nodes are tied together, i.e. no sliding. The concrete damaged plasticity model is employed for concrete material. The concrete axial compressive stress-strain relation is shown in Figure 1, and the mathematical equation of expression can be described as follows. More details can be found in GB50010 [2]

when $\varepsilon \leq \varepsilon_{\mathrm{e}}, \sigma=E_{\mathrm{c}} \varepsilon, E_{\mathrm{c}}=0.3 f_{\mathrm{ck}} / \varepsilon_{\mathrm{e}}$;

when $\varepsilon_{\mathrm{e}} \leq \varepsilon \leq \varepsilon_{\mathrm{c}}, \sigma=f_{\mathrm{ck}}\left[\alpha_{\mathrm{a}}\left(\frac{\varepsilon}{\varepsilon_{\mathrm{c}}}\right)+\left(3-2 \alpha_{\mathrm{a}}\right)\left(\frac{\varepsilon}{\varepsilon_{\mathrm{c}}}\right)^{2}+\left(\alpha_{\mathrm{a}}-2\right)\left(\frac{\varepsilon}{\varepsilon_{\mathrm{c}}}\right)^{3}\right]$; 
when $\varepsilon_{\mathrm{c}} \leq \varepsilon \leq \varepsilon_{\mathrm{u}}, \sigma=f_{\mathrm{ck}} \frac{\varepsilon / \varepsilon_{\mathrm{c}}}{\alpha_{\mathrm{d}}\left(\varepsilon / \varepsilon_{\mathrm{c}}-1\right)^{2}+\varepsilon / \varepsilon_{\mathrm{c}}}$;

where:

$\varepsilon_{\mathrm{e}}$ - compressive strain corresponding to stress with the value of $0.3 f_{\mathrm{ck}}$ at hardening stage

$\varepsilon_{\mathrm{c}}$ - compressive strain corresponding to stress with the peak value of $f_{\mathrm{ck}}$

$\varepsilon_{\mathrm{c}}$ - compressive strain corresponding to stress with the value of $0.5 f_{\mathrm{ck}}$ at softening stage

$\alpha_{\mathrm{a}}, \alpha_{\mathrm{d}}-$ model constants

The axial tensile stress-strain relationship is based on energy criterion of concrete, i.e. softened stress-fracture energy relation and the stress-strain curve is shown in Figure 2, with the mathematical equation of expression described as follows. $G_{\mathrm{f}}$ and $\sigma_{\mathrm{t} 0}$ are concrete fracture energy (the energy required to cause one continuous crack per unit area), and failure stress respectively. When $f_{\mathrm{ck}}=20 \mathrm{MPa}, G_{\mathrm{f}}=40 \mathrm{~N} / \mathrm{m}$; when $f_{\mathrm{ck}}=40 \mathrm{MPa}, G_{\mathrm{f}}=120 \mathrm{~N} / \mathrm{m}$, and the values of $G_{\mathrm{f}}$ can be obtained using linear interpolation corresponding to other values of $f_{\mathrm{ck}}$.

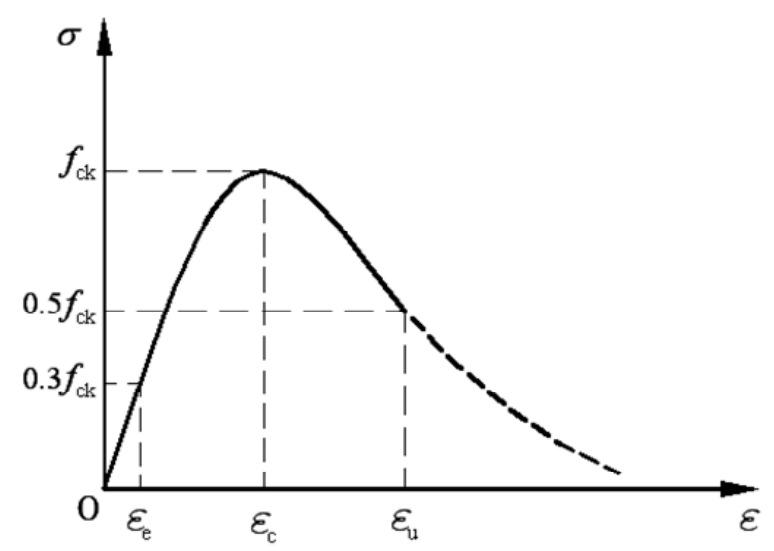

Figure 1. Concrete Compressive Stress-strain Relation of concrete

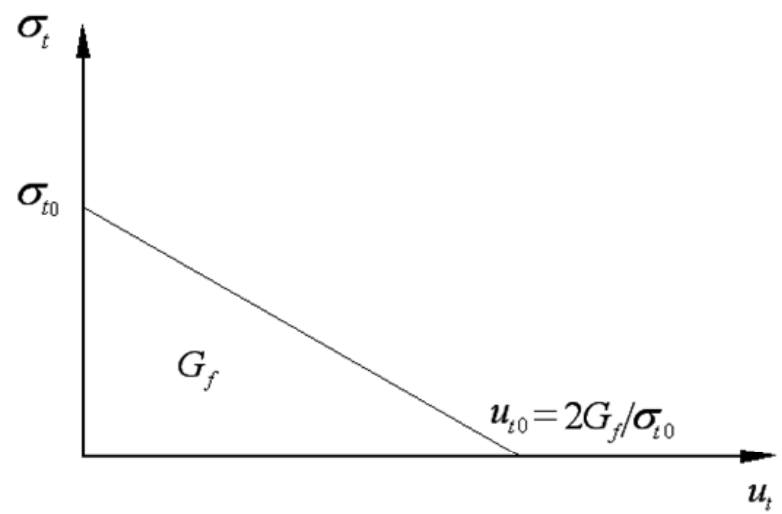

Figure 2. Concrete Tensile Softening Model of concrete 


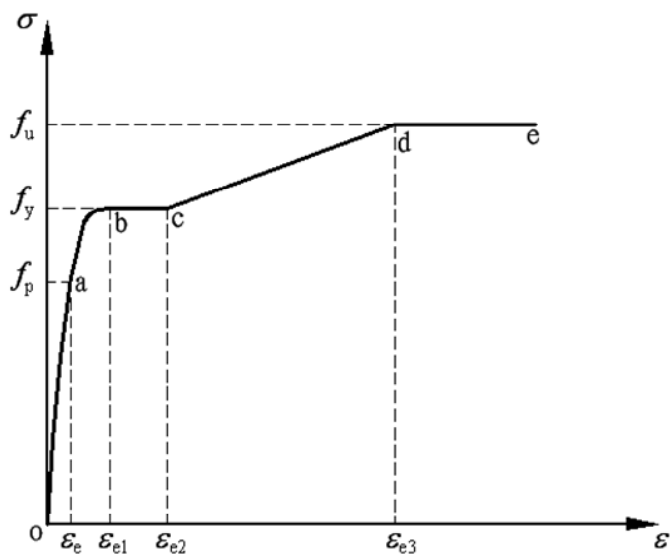

Figure 3. Steel Stress-strain Relation of steel

Axial stress-strain relation of steel is shown in Figure 3, and the mathematical expression can be described as follows :

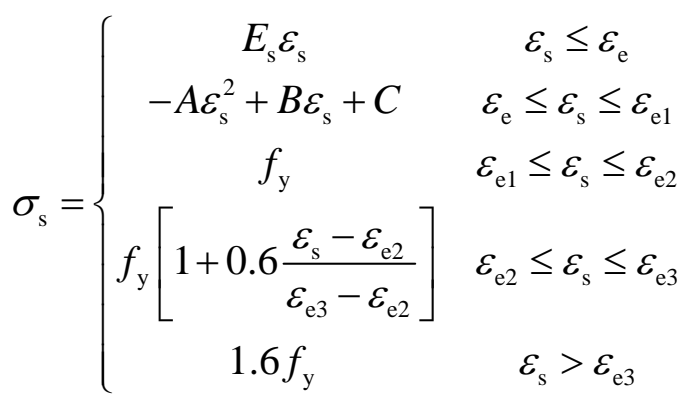

where,

$f_{\mathrm{p}}$ is proportional limit value of steel

$f_{\mathrm{y}}$ is yield strength value of steel

$f_{\mathrm{u}}$ is ultimate strength value of steel

$\varepsilon_{\mathrm{e}}=0.8 f_{\mathrm{y}} / E_{\mathrm{s}}, \varepsilon_{\mathrm{e} 1}=1.5 \varepsilon_{\mathrm{e}}, \varepsilon_{\mathrm{e} 2}=10 \varepsilon_{\mathrm{e} 1}, \varepsilon_{\mathrm{e} 3}=100 \varepsilon_{\mathrm{e} 1}, B=2 A \varepsilon_{\mathrm{e} 1}$,

$A=0.2 f_{\mathrm{y}} /\left(\varepsilon_{\mathrm{e} 1}-\varepsilon_{\mathrm{e}}\right)^{2}, C=0.8 f_{\mathrm{y}}+A \varepsilon_{\mathrm{e}}{ }^{2}-B \varepsilon_{\mathrm{e}}$.

and the details can be found in Han [3].

Figure 4 shows an established CFEST finite element model with solid elements for steel and concrete and there are three layers of meshed elements along the steel tube thickness direction.

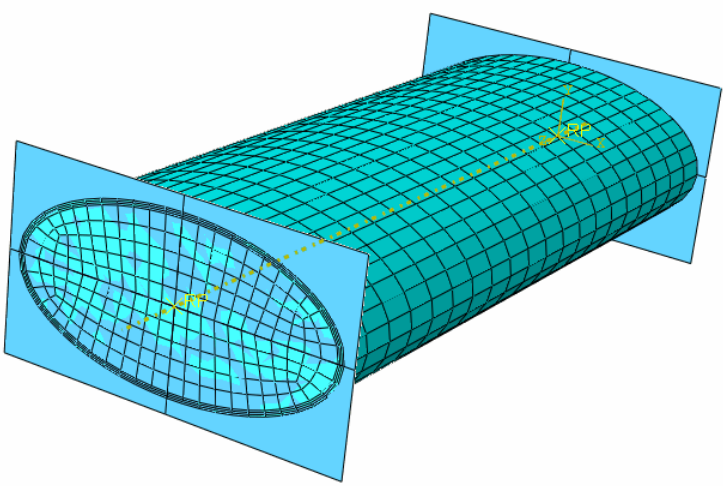

Figure 4. Finite Element Model for CFEST 
In order to verify the accuracy of the finite element model, concrete filled steel circular tube for eccentric compression is simulated using finite element in Chen et al. [4] and Yu and Ding [5], and the simulation results agree well with the test results, see Liu [6].

\section{THE FLEXURAL BEHAVIOR AROUND THE LONG/WEAK AXIS OF CONCRETE FILLED ELLIPTICAL STEEL TUBE}

\subsection{Theoretical Equation Derivation of Flexural Bending Capacity around Long Axis}

All the derivations in this paper are limited to uniaxial bending only. The stress distribution of CFEST at limit state, and the cross section dimensions are shown in Figure 5.

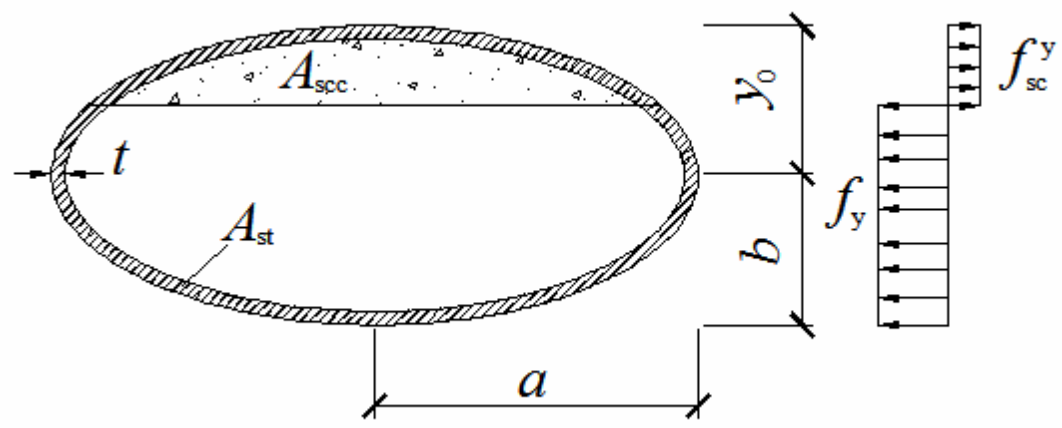

Figure 5. Stress Distribution Bent Around Long Axis for CFEST at Limit State and Section Dimensions

When the member is at limit state, the section stress distribution is as shown in Figure 5. According to static equilibrium, the location of neutral axis can be determined, i.e. y0 (distance of the section centroid to neutral axis).

. $\sum N=0=>$

$$
\begin{aligned}
& A_{\mathrm{st}} f_{\mathrm{y}}-A_{\mathrm{scc}} f_{\mathrm{sc}}^{\mathrm{y}}=0 \\
& \begin{aligned}
A_{\mathrm{st}}= & \pi a b-\pi(a-t)(b-t)-2 a b\left[\frac{\pi}{4}-\frac{1}{2} \arcsin \left(\frac{y_{0}}{b}\right)-\frac{y_{0}}{2 b} \sqrt{1-\left(\frac{y_{0}}{b}\right)^{2}}\right] \\
& +2(a-t)(b-t)\left[\frac{\pi}{4}-\frac{1}{2} \arcsin \left(\frac{y_{0}}{(b-t)}\right)-\frac{y_{0}}{2(b-t)} \sqrt{1-\left(\frac{y_{0}}{(b-t)}\right)^{2}}\right] \\
A_{\mathrm{scc}} & =2 a b\left[\frac{\pi}{4}-\frac{1}{2} \arcsin \left(\frac{y_{0}}{b}\right)-\frac{y_{0}}{2 b} \sqrt{1-\left(\frac{y_{0}}{b}\right)^{2}}\right]
\end{aligned}
\end{aligned}
$$

where $A_{\mathrm{st}}$ - section area for steel tube in tension zone;

$A_{\text {scc }}$ - combined section area in compression zone

$a$-half length of long axis for elliptical section

$b$-half length of short axis for elliptical section

$t$-steel tube thickness

$y_{0}$ - distance of the section centroid to neutral axis.

$f_{\mathrm{y}}$ - yield strength of steel 


\section{$f_{\mathrm{sc}}^{\mathrm{y}}$ —combined characteristic strength for concrete filled steel tube}

According to the location of neutral axis based on Eq. 1, the limit bending moment capacity can be obtained by taking moment about the neutral axis contributed by tensile stress and compressive stress:

$$
\begin{aligned}
M_{0}= & M_{\mathrm{s}}+M_{\mathrm{sc}} \\
M_{\mathrm{s}}= & 2 f_{\mathrm{y}}\left\{\left[\frac{\pi}{4} a b y_{0}+\frac{1}{2} a b y_{0} \arcsin \left(\frac{y_{0}}{b}\right)+\frac{1}{3} a b^{2} \sqrt{1-\left(\frac{y_{0}}{b}\right)^{2}}\right.\right. \\
& \left.+\frac{1}{6} a y_{0}^{2} \sqrt{1-\left(\frac{y_{0}}{b}\right)^{2}}\right]-\left[\frac{\pi}{4}(a-t)(b-t) y_{0}+\frac{1}{2}(a-t)(b-t) y_{0} \arcsin \left(\frac{y_{0}}{b-t}\right)\right. \\
& \left.\left.+\frac{1}{3}(a-t)(b-t)^{2} \sqrt{1-\left(\frac{y_{0}}{b-t}\right)^{2}}+\frac{1}{6}(a-t) y_{0}^{2} \sqrt{1-\left(\frac{y_{0}}{b-t}\right)^{2}}\right]\right\} \\
M_{\mathrm{sc}} & =2 f_{\mathrm{sc}}^{\mathrm{y}}\left\{\frac{1}{3} a b^{2}\left[1-\left(\frac{y_{0}}{b}\right)^{2}\right]^{\frac{3}{2}}-a b y_{0}\left[\frac{\pi}{4}-\frac{1}{2}\left(\frac{y_{0}}{b}\right) \sqrt{1-\left(\frac{y_{0}}{b}\right)^{2}}-\frac{1}{2} \arcsin \left(\frac{y_{0}}{b}\right)\right]\right\}
\end{aligned}
$$

As the tension strength of concrete is ignored in the above derivation, the actual limit bending capacity will be larger than calculated by Eq. 4. By comparison with finite element analysis results, the bending capacity of CFEST can be approximately expressed as follows:

$M=1.2 M_{0}$

From Eqs. 4, 5, 6, we know that the factors affecting the limit flexural capacity for CFEST are mainly steel strength, concrete compressive strength and member section shape. In order to verify the applicability of the theoretical Eq. 5 to 7, a total of 77 finite element models are established and the results are compared with those from the equations, with an average of 1.004 and variance of 0.0008 , see Liu [6].

\subsection{Practical Equation of Flexural Bending Capacity around Long Axis}

Comparison of theoretical results and finite element simulation results indicates that the limit state equilibrium based limit state flexural capacity for concrete filled steel tube can be reasonably used to calculate the limit flexural capacity. However, the solution procedures are quite complex and not applicable to practical engineering. With finite element analysis results, an equation of flexural bending capacity around long axis for practical purpose is obtained as follows:

$$
\begin{aligned}
& M=\gamma_{\mathrm{m}} W_{\mathrm{sc}} f_{\mathrm{sc}}^{\mathrm{y}} \\
& \gamma_{\mathrm{m}}=-0.4832 k \xi+1.9264(k \xi)^{0.5}
\end{aligned}
$$


where

$\gamma_{\mathrm{m}}$ is cross section plastic development coefficient

$W_{\mathrm{sc}}$ is modulus of the combined section

$\mathrm{k}$ is confining adjustment factor, when around long axis,

$$
k=(a / b)^{0.12}
$$

The comparison of finite element simulation results and Eq. 8 shows that an average of 1.017 and variance of 0.004, see Appendix 2 and also Liu [6]. Compared with Eq. 7, Eq. 8 gives a relatively little larger value, but the equation form is simplified, which is more suitable for practical engineering.

\section{THE FLEXURAL BEHAVIOR AROUND THE SHORT/STRONG AXIS OF CFEST [7-9]}

\subsection{Theoretical Derivation of Flexural Bending Capacity around Short Axis}

The stress distribution of CFEST at limit state, and the cross section dimensions are shown in Figure $5 . \mathrm{y}_{0}$ is the distance of the section centroid to neutral axis.

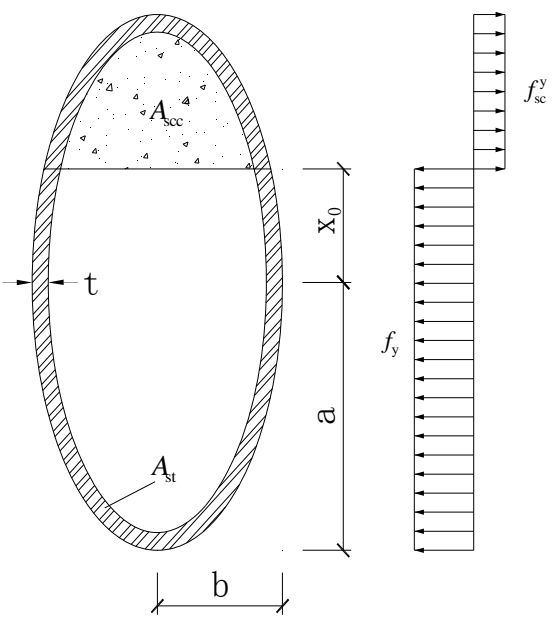

Figure 6. Stress Distribution Bent around Short Axis for CFEST at Limit State and Section Dimensions

When the member is at limit state, the section stress distribution is as shown in Figure 6. According to static equilibrium, the location of neutral axis can be determined, i.e. $\mathrm{x}_{0} \cdot \sum N=0=>$

$$
A_{\mathrm{st}} f_{\mathrm{y}}-A_{\mathrm{scc}} f_{\mathrm{sc}}^{\mathrm{y}}=0
$$

$$
\begin{aligned}
A_{\mathrm{st}}= & \pi a b-\pi(a-t)(b-t)-2 a b\left[\frac{\pi}{4}-\frac{1}{2} \arcsin \left(\frac{x_{0}}{a}\right)-\frac{x_{0}}{2 a} \sqrt{1-\left(\frac{x_{0}}{a}\right)^{2}}\right] \\
& +2(a-t)(b-t)\left[\frac{\pi}{4}-\frac{1}{2} \arcsin \left(\frac{x_{0}}{(a-t)}\right)-\frac{x_{0}}{2(a-t)} \sqrt{1-\left(\frac{x_{0}}{(a-t)}\right)^{2}}\right]
\end{aligned}
$$




$$
A_{\mathrm{scc}}=2 a b\left[\frac{\pi}{4}-\frac{1}{2} \arcsin \left(\frac{x_{0}}{a}\right)-\frac{x_{0}}{2 a} \sqrt{1-\left(\frac{x_{0}}{a}\right)^{2}}\right]
$$

According to the location of neutral axis based on Eq. 10, the limit bending moment capacity can be obtained by taking moment about the neutral axis contributed by tensile stress and compressive stress:

$$
\begin{aligned}
M_{0}= & M_{\mathrm{s}}+M_{\mathrm{sc}} \\
M_{\mathrm{s}}= & 2 f_{\mathrm{y}}\left\{\left[\frac{\pi}{4} a b x_{0}+\frac{1}{2} a b x_{0} \arcsin \left(\frac{x_{0}}{a}\right)+\frac{1}{3} b a^{2} \sqrt{1-\left(\frac{x_{0}}{a}\right)^{2}}\right.\right. \\
& \left.+\frac{1}{6} b x_{0}^{2} \sqrt{1-\left(\frac{x_{0}}{a}\right)^{2}}\right]-\left[\frac{\pi}{4}(a-t)(b-t) x_{0}+\frac{1}{2}(a-t)(b-t) x_{0} \arcsin \left(\frac{x_{0}}{a-t}\right)\right. \\
& \left.\left.+\frac{1}{3}(b-t)(a-t)^{2} \sqrt{1-\left(\frac{x_{0}}{a-t}\right)^{2}}+\frac{1}{6}(b-t) x_{0}^{2} \sqrt{1-\left(\frac{x_{0}}{a-t}\right)^{2}}\right]\right\} \\
M_{\mathrm{sc}} & =2 f_{\mathrm{sc}}^{\mathrm{y}}\left\{\frac{1}{3} b a^{2}\left[1-\left(\frac{x_{0}}{a}\right)^{2}\right]^{\frac{3}{2}}-a b x_{0}\left[\frac{\pi}{4}-\frac{1}{2}\left(\frac{x_{0}}{a}\right) \sqrt{1-\left(\frac{x_{0}}{a}\right)^{2}}-\frac{1}{2} \arcsin \left(\frac{x_{0}}{a}\right)\right]\right\}
\end{aligned}
$$

By finite element analysis, the bending capacity of CFEST can be approximately expressed as follows:

$M=1.17 M_{0}$

The theoretical results are compared with those from finite element simulations, with an average of 1.003 and variance of 0.0003 , see Liu [6].

\subsection{Practical Flexural Bending Capacity around Short Axis}

Comparison of theoretical results and finite element simulation results indicates that the limit state equilibrium based limit state flexural capacity for concrete filled steel tube can reasonably used to calculate the limit flexural capacity. However, the solution procedures are quite complex and not applicable to practical engineering. With finite element analysis results, an equation of flexural bending capacity around long axis for practical purpose is obtained as follows:

$$
\begin{aligned}
& M=\gamma_{\mathrm{m}} W_{\mathrm{sc}} f_{\mathrm{sc}}^{\mathrm{y}} \\
& \gamma_{\mathrm{m}}=-0.4832 k \xi+1.9264(k \xi)^{0.5}
\end{aligned}
$$


where

$\gamma_{\mathrm{m}}$ is cross section plastic development coefficient

$W_{\text {sc }}$ is modulus of the combined section

$\mathrm{k}$ is confining adjustment factor, when around short axis,

$$
k=(b / a)^{0.6} \text {. }
$$

The comparison of finite element simulation results and Eq. 17 shows that an average of 0.993 and variance of 0.006, see Appendix 3 and also Liu [6]. Compared with Eq. 16, Eq. 17 gives a relatively little smaller value, but the equation form is simplified, which is more suitable for practical engineering.

\section{INTERACTION EQUATIONS OF ECCENTRIC COMPRESSION CAPACITY FOR CFEST MEMBERS [9-11]}

The actions of compression and bending moment on compressive and flexural member may be caused by different loads, i.e. pressure and bending moment can be two independent variables. For the one-way compressive flexural/bending structures, there are mainly three different loading paths, as shown in Figure 7 [3].

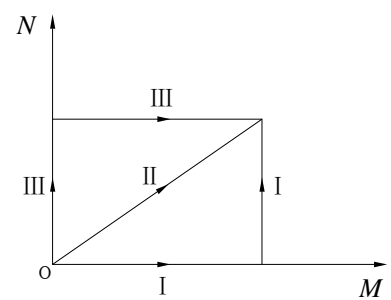

Figure 7. Loading Paths for Compressive and Flexural Member

In this paper, loading path II is adopted for finite element simulation of concrete filled elliptical steel tube, and the main concern is to analyze the concrete filled elliptical steel tube behavior with different cross sections and under different eccentricities.

\subsection{Interaction Equations of Eccentric Compression Capacity around Long Axis for CFEST Members}

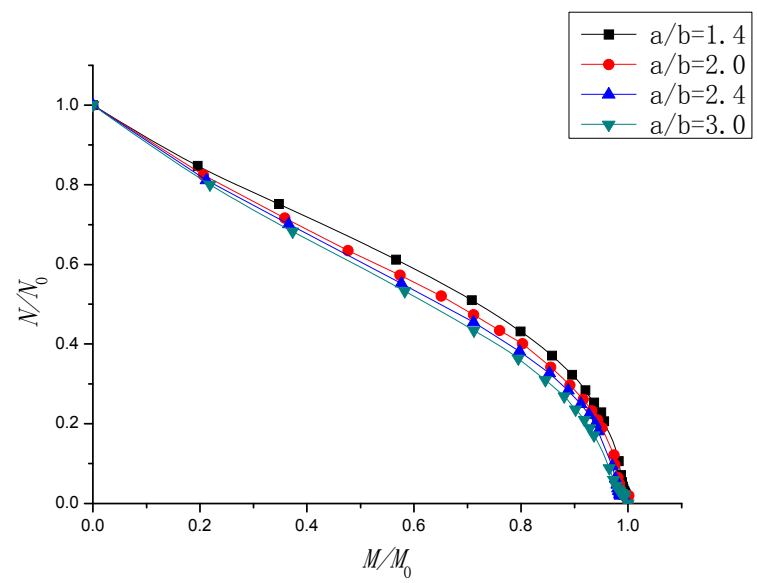

Figure 8. $N / N_{0} \sim M / M_{0}$ of Eccentric Compression Capacity around Long Axis for Concrete Filled Elliptical Steel Tube 
In this paper, finite element analysis is used for obtaining the $N / N_{0} \sim M / M_{0}$ interaction curves. In Figure 8, there are balanced points in the curve of $N / N_{0} \sim M / M_{0}$, which moves down as the increase of steel ratio. Considering that limited value range for the steel ratio, the balanced points are different curves are unified to one point $N / N_{0}=0.2$ [2]. The interaction curve is divided to two segments. Curve fitting is used for obtaining the equation. Considering safety factors, modification factor is introduced and the final interaction equations of eccentric compression capacity around long axis for CFEST is as follows

1) when $\frac{N}{\varphi A_{\mathrm{sc}}} \geq 0.2 f_{\mathrm{sc}}^{y}$

$\frac{N}{N_{0}}+\frac{\beta_{\mathrm{m}} M}{1.32\left(1-0.4 N / N_{\mathrm{E}}\right) M_{0}} \leq 1$

2) when $\frac{N}{\varphi A_{s c}}<0.2 f_{\mathrm{sc}}^{\mathrm{y}}$

$$
-\frac{N}{7 N_{0}}+\frac{\beta_{\mathrm{m}} M}{\left(1-0.4 N / N_{\mathrm{E}}\right) M_{0}} \leq 1
$$

\subsection{Interaction Equations of Eccentric Compression Capacity around Short Axis for CFEST Members}

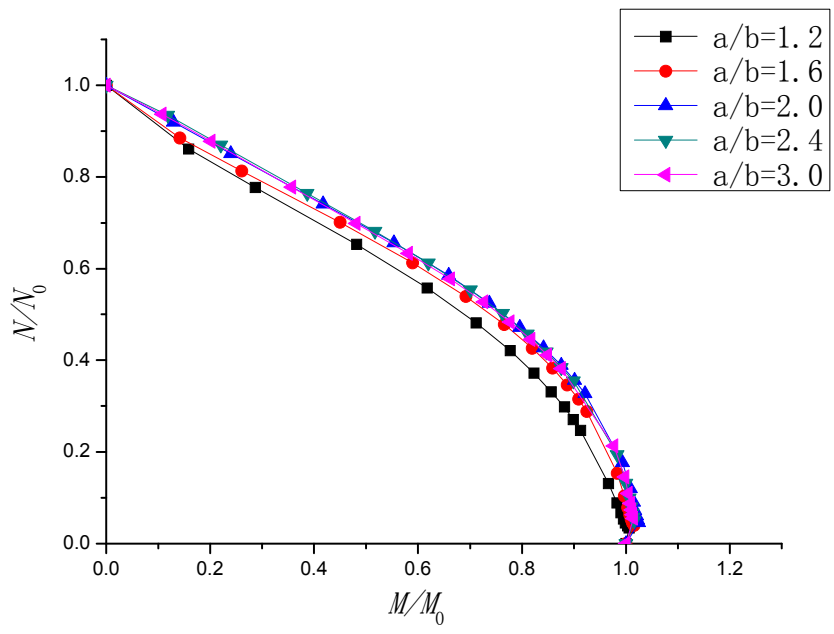

Figure 9. $N / N_{0} \sim M / M_{0}$ of Eccentric Compression Capacity around Short Axis for Concrete Filled Elliptical Steel Tube

Finite element analysis is used for obtaining the $N / N_{0} \sim M / M_{0}$ interaction curves as shown in Figure 9. Curve fitting is used for obtaining the equation. Considering safety factors, modification factor is introduced and the final interaction equations of eccentric compression capacity around short axis for CFEST is as follows

1) when $\frac{N}{\varphi A_{s c}} \geq 0.2 f_{s c}^{y}$

$\frac{N}{N_{0}}+\frac{\beta_{\mathrm{m}} M}{1.45\left(1-0.4 N / N_{\mathrm{E}}\right) M_{0}} \leq 1$ 
2) when $\frac{N}{\varphi A_{\mathrm{sc}}}<0.2 f_{\mathrm{sc}}^{\mathrm{y}}$

$-\frac{N}{7 N_{0}}+\frac{\beta_{\mathrm{m}} M}{\left(1-0.4 N / N_{\mathrm{E}}\right) M_{0}} \leq 1$

\section{CONCLUDING REMARKS}

In this paper the limit equilibrium method is used to derive theoretical bending capacity equation for elliptical concrete filled steel tube members under uniaxial bending, and the equation based results are compared with and verified by the finite element simulation results. In view of complexity in the theoretical equations, modifications are made and simplified and practical equations are obtained which are suitable for practical engineering and also verified by finite element simulation analysis.

For eccentric compression members of concrete filled steel tubes, a series of elliptical cross section, around long and short axis eccentric compression models are established based on finite element analysis. The interaction curves $N / N_{0} \sim M / M_{0}$ are obtained by finite element simulations. Finally, according to the $N / N_{0} \sim M / M_{0}$ curves for different elliptical section dimensions and for different eccentricities around long and short axes, equations are obtained which can be applied to practical engineering.

\section{REFERENCES}

[1] Zhong, S T., "Unified Theory of Concrete Filled Steel Tube - Theoretical Research and Application”, Tsinghua University Press, 2006 (in Chinese)

[2] GB50010-2002, Code for Design of Concrete Structures. Ministry of Construction, People's Republic of China. (in Chinese)

[3] Han, L.H., "Concrete Filled Steel Tube Structure - Theory and Practice”, Science Press. 2004 (in Chinese)

[4] Chen, B.C., Ou, Z.Q., Wang, L.Y. and Han, L.H., "Eccentric Bearing Capacity Analysis of Concrete Filled Steel Tube”, 2002, Vol. 30, No. 6, pp. 838-844 (in Chinese).

[5] Yu, Z.W. and Ding, X.F., "Mechanical Properties of Concrete Filled Circular Steel Tube Eccentric Loaded Columns”, 2008, Vol. 21, No. 1, pp. 40-46 (in Chinese).

[6] Liu, X.C., "Study of Basic Properties of Concrete Filled Elliptical Steel Tube”, Master Thesis, Harbin Institute of Technology Shenzhen Graduate School, 2010, Vol. 6 (in Chinese).

[7] Yang, H., Lam, D. and Gardner, L., “Testing and Analysis of Concrete-filled Elliptical Hollow Sections”, Engineering Structures, 2008, Vol. 30, No. 2, pp. 3771-3781.

[8] Eiichi Inai, Akiyoshi Mukai, Makoto Kai, Hiroyoshi Tokinoya, Toshiyuki Fukumoto, Koji Mori6, "Behavior of Concrete-Filled Steel Tube Beam Columns", ASCE, Journal of Structural Engineering, 2004, Vol. 130, No. 2, pp. 189-202.

[9] Chan, T.M. and Gardner, L., "Flexural Buckling of Elliptical Hollow Section Columns", ASCE, Journal of Structural Engineering, 2009, Vol. 135, No. 5, pp. 546-557.

[10] Amit, H., Varma, James M., Ricles, Richard Sause, Lu, L.W., "Experimental Behavior of High Strength Square Concrete-Filled Steel Tube Beam-Columns”, ASCE, Journal of Structural Engineering, 2002, Vol. 128, No. 3, pp. 309-318.

[11] Toshiaki Fujimoto, Akiyoshi Mukai, Isao Nishiyama, Kenji Sakino, "Behavior of Eccentrically Loaded Concrete-Filled Steel Tubular Columns”, ASCE, Journal of Structural Engineering, 2004, Vol. 130, No. 2, pp. 203-212. 


\section{Appendix 1: Notations}

$\varepsilon_{\mathrm{e}}: \quad$ compressive strain corresponding to stress with the value of $0.3 f_{\mathrm{ck}}$ at hardening stage

$\varepsilon_{\mathrm{c}}$ : compressive strain corresponding to stress with the peak value of $f_{\mathrm{ck}}$ or $0.5 f_{\mathrm{ck}}$ at softening stage

$\alpha_{\mathrm{a}}, \alpha_{\mathrm{d}}$ : model constants

$f_{\mathrm{p}}: \quad$ proportional limit value of steel

$f_{\mathrm{y}}$ : $\quad$ yield strength value of steel

$f_{\mathrm{u}}: \quad$ ultimate strength value of steel

$A_{\mathrm{st}}: \quad$ section area for steel tube in tension zone

$A_{\text {scc }}: \quad$ combined section area in compression zone

$a: \quad$ half length of long axis for elliptical section

$b$ : half length of short axis for elliptical section

$t: \quad$ steel tube thickness

$y_{0}$ : distance of the section centroid to neutral axis.

$f_{\mathrm{sc}}^{\mathrm{y}}$ : combined characteristic strength for concrete filled steel tube

$\gamma_{\mathrm{m}}$ : cross section plastic development coefficient

$W_{\text {sc }}$ : section modulus of the combined section

$\mathrm{k}$ : $\quad$ confining adjustment factor

Appendix 2: Comparison of Finite Element Analysis and Theoretical Equation for Flexural Capacity for CFEST Members Bent around Long Axis

\begin{tabular}{cccccccc}
\hline $\begin{array}{c}2 a \\
(\mathrm{~mm})\end{array}$ & $\begin{array}{c}2 b \\
(\mathrm{~mm})\end{array}$ & $\begin{array}{c}t \\
(\mathrm{~mm})\end{array}$ & $\begin{array}{c}f_{\mathrm{ck}} \\
\left(\mathrm{N} / \mathrm{mm}^{2}\right)\end{array}$ & $\begin{array}{c}f_{\mathrm{y}} \\
\left(\mathrm{N} / \mathrm{mm}^{2}\right)\end{array}$ & $\begin{array}{c}M_{\mathrm{c}} \\
(\mathrm{kN} \times \mathrm{m})\end{array}$ & $\begin{array}{c}M_{\text {FEM }} \\
(\mathrm{kN} \times \mathrm{m})\end{array}$ & $\begin{array}{c}M_{\mathrm{c}} \\
M_{\mathrm{FEM}}\end{array}$ \\
\hline 151.79 & 94.87 & 2.91 & 20.1 & 235 & 14.86 & 15.06 & 0.987 \\
161.00 & 89.44 & 2.87 & 20.1 & 235 & 15.20 & 15.80 & 0.962 \\
169.71 & 84.85 & 2.82 & 20.1 & 235 & 15.52 & 16.46 & 0.943 \\
151.79 & 94.87 & 2.91 & 26.8 & 235 & 15.55 & 15.70 & 0.990 \\
161.00 & 89.44 & 2.87 & 26.8 & 235 & 15.89 & 16.50 & 0.963 \\
169.71 & 84.85 & 2.82 & 26.8 & 235 & 16.20 & 17.22 & 0.941 \\
151.79 & 94.87 & 2.91 & 20.1 & 345 & 21.34 & 20.92 & 1.020 \\
161.00 & 89.44 & 2.87 & 20.1 & 345 & 21.91 & 21.90 & 1.000 \\
151.79 & 94.87 & 2.91 & 32.4 & 235 & 16.16 & 16.19 & 0.998 \\
161.00 & 89.44 & 2.87 & 32.4 & 235 & 16.51 & 17.04 & 0.969 \\
169.71 & 84.85 & 2.82 & 20.1 & 345 & 22.44 & 22.78 & 0.985 \\
177.99 & 80.90 & 2.77 & 20.1 & 345 & 22.92 & 23.82 & 0.962 \\
185.90 & 77.46 & 2.72 & 20.1 & 345 & 23.37 & 24.78 & 0.943 \\
151.79 & 94.87 & 2.91 & 20.1 & 390 & 24.12 & 23.25 & 1.037 \\
161.00 & 89.44 & 2.87 & 20.1 & 390 & 24.81 & 24.33 & 1.020 \\
169.71 & 84.85 & 2.82 & 20.1 & 390 & 25.45 & 25.28 & 1.006 \\
177.99 & 80.90 & 2.77 & 20.1 & 390 & 26.03 & 26.43 & 0.985 \\
185.90 & 77.46 & 2.72 & 20.1 & 390 & 26.58 & 27.49 & 0.967 \\
193.49 & 74.42 & 2.67 & 20.1 & 390 & 27.09 & 28.41 & 0.954 \\
200.80 & 71.71 & 2.63 & 20.1 & 390 & 27.58 & 29.16 & 0.946 \\
207.85 & 69.28 & 2.58 & 20.1 & 390 & 28.04 & 30.27 & 0.926
\end{tabular}




\begin{tabular}{lccccccc}
141.99 & 101.42 & 3.94 & 20.1 & 345 & 26.74 & 25.02 & 1.069 \\
151.79 & 94.87 & 3.88 & 20.1 & 345 & 27.74 & 26.41 & 1.050 \\
161.00 & 89.44 & 3.82 & 20.1 & 345 & 28.64 & 27.70 & 1.034 \\
169.71 & 84.85 & 3.76 & 20.1 & 345 & 29.46 & 28.92 & 1.019 \\
177.99 & 80.90 & 3.69 & 20.1 & 345 & 30.22 & 30.02 & 1.007 \\
185.90 & 77.46 & 3.62 & 20.1 & 345 & 30.94 & 31.20 & 0.992 \\
193.49 & 74.42 & 3.56 & 20.1 & 345 & 31.61 & 32.12 & 0.984 \\
200.80 & 71.71 & 3.50 & 20.1 & 345 & 32.25 & 33.19 & 0.972 \\
207.85 & 69.28 & 3.43 & 20.1 & 345 & 32.86 & 34.30 & 0.958 \\
151.79 & 94.87 & 4.85 & 20.1 & 345 & 33.79 & 31.66 & 1.067 \\
161.00 & 89.44 & 4.77 & 20.1 & 345 & 35.08 & 33.16 & 1.058 \\
169.71 & 84.85 & 4.69 & 20.1 & 345 & 36.26 & 34.73 & 1.044 \\
177.99 & 80.90 & 4.61 & 20.1 & 345 & 37.37 & 36.05 & 1.037 \\
185.90 & 77.46 & 4.52 & 20.1 & 345 & 38.40 & 37.35 & 1.028 \\
193.49 & 74.42 & 4.44 & 20.1 & 345 & 39.38 & 38.65 & 1.019 \\
200.80 & 71.71 & 4.36 & 20.1 & 345 & 40.32 & 39.90 & 1.011 \\
207.85 & 69.28 & 4.28 & 20.1 & 345 & 41.22 & 41.11 & 1.003 \\
\hline
\end{tabular}

Appendix 3: Comparison of Finite Element Analysis and Theoretical Equation for Flexural Capacity for CFEST Members Bent around Short Axis

\begin{tabular}{|c|c|c|c|c|c|c|c|c|}
\hline $\begin{array}{c}2 a \\
(\mathrm{~mm})\end{array}$ & $\begin{array}{c}2 b \\
(\mathrm{~mm})\end{array}$ & $\begin{array}{c}t \\
(\mathrm{~mm})\end{array}$ & $\begin{array}{c}f_{\mathrm{ck}} \\
\left(\mathrm{N} / \mathrm{mm}^{2}\right)\end{array}$ & $\begin{array}{c}f_{\mathrm{y}} \\
\left(\mathrm{N} / \mathrm{mm}^{2}\right)\end{array}$ & $\begin{array}{c}x_{0} \\
(\mathrm{~mm})\end{array}$ & $\begin{array}{c}M_{\mathrm{c}} \\
(\mathrm{kN} \times \mathrm{m})\end{array}$ & $\begin{array}{c}M_{\mathrm{FEM}} \\
(\mathrm{kN} \times \mathrm{m})\end{array}$ & $\frac{M_{\mathrm{c}}}{M_{\mathrm{FEM}}}$ \\
\hline 131.45 & 109.54 & 2.99 & 20.1 & 235 & 22.64 & 11.57 & 13.19 & 1.004 \\
\hline 169.71 & 84.85 & 2.82 & 20.1 & 235 & 26.42 & 9.09 & 16.46 & 0.993 \\
\hline 200.80 & 71.71 & 2.63 & 20.1 & 235 & 29.28 & 7.76 & 19.08 & 0.987 \\
\hline 207.85 & 69.28 & 2.58 & 20.1 & 235 & 29.99 & 7.50 & 19.81 & 0.977 \\
\hline 131.45 & 109.54 & 2.99 & 26.8 & 235 & 26.05 & 11.96 & 13.71 & 1.001 \\
\hline 141.99 & 101.42 & 2.96 & 26.8 & 235 & 27.42 & 11.13 & 14.69 & 0.998 \\
\hline 151.79 & 94.87 & 2.91 & 26.8 & 235 & 28.77 & 10.42 & 15.70 & 0.986 \\
\hline 161.00 & 89.44 & 2.87 & 26.8 & 235 & 29.88 & 9.87 & 16.50 & 0.987 \\
\hline 169.71 & 84.85 & 2.82 & 26.8 & 235 & 30.98 & 9.39 & 17.22 & 0.989 \\
\hline 177.99 & 80.90 & 2.77 & 26.8 & 235 & 32.01 & 8.97 & 18.07 & 0.981 \\
\hline 185.90 & 77.46 & 2.72 & 26.8 & 235 & 32.99 & 8.60 & 18.84 & 0.976 \\
\hline 193.49 & 74.42 & 2.67 & 26.8 & 235 & 33.94 & 8.27 & 19.50 & 0.975 \\
\hline 200.80 & 71.71 & 2.63 & 26.8 & 235 & 34.74 & 8.00 & 20.05 & 0.980 \\
\hline 207.85 & 69.28 & 2.58 & 26.8 & 235 & 35.64 & 7.73 & 20.84 & 0.970 \\
\hline 207.85 & 69.28 & 2.58 & 32.4 & 235 & 39.70 & 7.89 & 21.64 & 0.963 \\
\hline 131.45 & 109.54 & 2.99 & 20.1 & 345 & 19.03 & 16.39 & 18.42 & 1.017 \\
\hline 141.99 & 101.42 & 2.96 & 20.1 & 345 & 19.78 & 15.26 & 19.65 & 1.014 \\
\hline 185.90 & 77.46 & 2.72 & 20.1 & 345 & 22.92 & 11.84 & 24.78 & 1.000 \\
\hline 193.49 & 74.42 & 2.67 & 20.1 & 345 & 23.48 & 11.40 & 25.61 & 1.000 \\
\hline 185.90 & 77.46 & 2.72 & 20.1 & 390 & 21.72 & 13.28 & 27.49 & 1.008 \\
\hline 193.49 & 74.42 & 2.67 & 20.1 & 390 & 22.25 & 12.79 & 28.41 & 1.008 \\
\hline 200.80 & 71.71 & 2.63 & 20.1 & 390 & 22.52 & 12.36 & 29.16 & 1.014 \\
\hline 207.85 & 69.28 & 2.58 & 20.1 & 390 & 23.20 & 11.96 & 30.27 & 1.005 \\
\hline 131.45 & 109.54 & 3.98 & 20.1 & 345 & 16.32 & 20.96 & 23.37 & 1.024 \\
\hline 141.99 & 101.42 & 3.94 & 20.1 & 345 & 16.89 & 19.53 & 25.02 & 1.018 \\
\hline 185.90 & 77.46 & 3.62 & 20.1 & 345 & 19.41 & 15.20 & 31.20 & 1.015 \\
\hline
\end{tabular}




\begin{tabular}{lllllllll}
\hline 193.49 & 74.42 & 3.56 & 20.1 & 345 & 19.82 & 14.66 & 32.12 & 1.020 \\
200.80 & 71.71 & 3.50 & 20.1 & 345 & 20.24 & 14.17 & 33.19 & 1.019 \\
151.79 & 94.87 & 4.85 & 20.1 & 345 & 15.23 & 22.19 & 31.66 & 1.024 \\
161.00 & 89.44 & 4.77 & 20.1 & 345 & 15.69 & 21.02 & 33.16 & 1.026 \\
169.71 & 84.85 & 4.69 & 20.1 & 345 & 16.10 & 20.04 & 34.73 & 1.023 \\
177.99 & 80.90 & 4.61 & 20.1 & 345 & 16.49 & 19.19 & 36.05 & 1.026 \\
185.90 & 77.46 & 4.52 & 20.1 & 345 & 16.97 & 18.42 & 37.35 & 1.026 \\
193.49 & 74.42 & 4.44 & 20.1 & 345 & 17.39 & 17.76 & 38.65 & 1.026 \\
200.80 & 71.71 & 4.36 & 20.1 & 345 & 17.82 & 17.16 & 39.90 & 1.026 \\
207.85 & 69.28 & 4.28 & 20.1 & 345 & 18.28 & 16.62 & 41.11 & 1.025 \\
\hline
\end{tabular}

Appendix 4: Comparison of Finite Element Analysis and Theoretical Equation for CFEST Members under Eccentric Compression around Long Axis

\begin{tabular}{|c|c|c|c|c|c|c|c|c|}
\hline $\begin{array}{c}2 a \\
(\mathrm{~mm})\end{array}$ & $\begin{array}{c}2 b \\
(\mathrm{~mm})\end{array}$ & $\begin{array}{c}t \\
(\mathrm{~mm})\end{array}$ & $\begin{array}{c}L \\
(\mathrm{~mm})\end{array}$ & $\lambda$ & $\begin{array}{c}e_{0} \\
(\mathrm{~mm})\end{array}$ & $\begin{array}{c}N \\
(\mathrm{kN})\end{array}$ & $\begin{array}{c}M \\
(\mathrm{kN} \times \mathrm{m})\end{array}$ & $\begin{array}{c}\text { Interaction } \\
\text { equation }\end{array}$ \\
\hline 141.99 & 101.42 & 2.96 & 1000 & 39.44 & 5 & 411.66 & 2.06 & 1.001 \\
\hline 141.99 & 101.42 & 2.96 & 1000 & 39.44 & 10 & 365.14 & 3.65 & 1.023 \\
\hline 141.99 & 101.42 & 2.96 & 1000 & 39.44 & 50 & 180.26 & 9.01 & 1.031 \\
\hline 141.99 & 101.42 & 2.96 & 1000 & 39.44 & 60 & 156.85 & 9.41 & 1.010 \\
\hline 141.99 & 101.42 & 2.96 & 1000 & 39.44 & 70 & 138.14 & 9.67 & 0.990 \\
\hline 141.99 & 101.42 & 2.96 & 1000 & 39.44 & 80 & 122.98 & 9.84 & 0.970 \\
\hline 141.99 & 101.42 & 2.96 & 1000 & 39.44 & 90 & 110.90 & 9.98 & 0.955 \\
\hline 141.99 & 101.42 & 2.96 & 1000 & 39.44 & 200 & 51.62 & 10.32 & 0.972 \\
\hline 141.99 & 101.42 & 2.96 & 1000 & 39.44 & 300 & 34.57 & 10.37 & 0.980 \\
\hline 141.99 & 101.42 & 2.96 & 1000 & 39.44 & 400 & 25.97 & 10.39 & 0.983 \\
\hline 141.99 & 101.42 & 2.96 & 1000 & 39.44 & 500 & 20.81 & 10.40 & 0.986 \\
\hline 141.99 & 101.42 & 2.96 & 1000 & 39.44 & 600 & 17.37 & 10.42 & 0.988 \\
\hline 141.99 & 101.42 & 2.96 & 1000 & 39.44 & 700 & 14.91 & 10.43 & 0.990 \\
\hline 141.99 & 101.42 & 2.96 & 1000 & 39.44 & 800 & 13.06 & 10.45 & 0.992 \\
\hline 141.99 & 101.42 & 2.96 & 1000 & 39.44 & 900 & 11.62 & 10.46 & 0.993 \\
\hline 141.99 & 101.42 & 2.96 & 1000 & 39.44 & 1000 & 10.47 & 10.47 & 0.994 \\
\hline 169.71 & 84.85 & 2.82 & 1000 & 47.14 & 5 & 375.22 & 1.88 & 0.988 \\
\hline 169.71 & 84.85 & 2.82 & 1000 & 47.14 & 10 & 325.95 & 3.26 & 0.999 \\
\hline 169.71 & 84.85 & 2.82 & 1000 & 47.14 & 15 & 288.90 & 4.33 & 1.009 \\
\hline 169.71 & 84.85 & 2.82 & 1000 & 47.14 & 20 & 260.83 & 5.22 & 1.022 \\
\hline 169.71 & 84.85 & 2.82 & 1000 & 47.14 & 25 & 236.73 & 5.92 & 1.028 \\
\hline 207.85 & 69.28 & 2.58 & 1000 & 57.74 & 900 & 8.63 & 7.77 & 0.991 \\
\hline 207.85 & 69.28 & 2.58 & 1000 & 57.74 & 1000 & 7.79 & 7.79 & 0.993 \\
\hline 169.71 & 84.85 & 2.82 & 1000 & 47.14 & 30 & 215.50 & 6.47 & 1.026 \\
\hline 169.71 & 84.85 & 2.82 & 1000 & 47.14 & 35 & 197.42 & 6.91 & 1.023 \\
\hline 169.71 & 84.85 & 2.82 & 1000 & 47.14 & 40 & 182.42 & 7.30 & 1.022 \\
\hline 169.71 & 84.85 & 2.82 & 1000 & 47.14 & 50 & 155.60 & 7.78 & 1.002 \\
\hline 169.71 & 84.85 & 2.82 & 1000 & 47.14 & 500 & 17.91 & 8.95 & 0.981 \\
\hline 169.71 & 84.85 & 2.82 & 1000 & 47.14 & 600 & 14.94 & 8.97 & 0.983 \\
\hline 169.71 & 84.85 & 2.82 & 1000 & 47.14 & 700 & 12.82 & 8.97 & 0.984 \\
\hline 169.71 & 84.85 & 2.82 & 1000 & 47.14 & 800 & 11.22 & 8.98 & 0.985 \\
\hline 169.71 & 84.85 & 2.82 & 1000 & 47.14 & 900 & 9.98 & 8.99 & 0.986 \\
\hline 169.71 & 84.85 & 2.82 & 1000 & 47.14 & 1000 & 9.02 & 9.10 & 1.000 \\
\hline
\end{tabular}




\begin{tabular}{lllllcccl}
\hline 185.90 & 77.46 & 2.72 & 1000 & 51.64 & 5 & 394.42 & 1.80 & 0.981 \\
185.90 & 77.46 & 2.72 & 1000 & 51.64 & 10 & 340.65 & 3.11 & 0.992 \\
185.90 & 77.46 & 2.72 & 1000 & 51.64 & 20 & 268.37 & 4.90 & 1.006 \\
185.90 & 77.46 & 2.72 & 1000 & 51.64 & 30 & 220.76 & 6.04 & 1.010 \\
185.90 & 77.46 & 2.72 & 1000 & 51.64 & 40 & 185.50 & 6.77 & 1.002 \\
185.90 & 77.46 & 2.72 & 1000 & 51.64 & 50 & 158.89 & 7.25 & 0.988 \\
185.90 & 77.46 & 2.72 & 1000 & 51.64 & 60 & 137.81 & 7.54 & 0.970 \\
185.90 & 77.46 & 2.72 & 1000 & 51.64 & 70 & 121.21 & 7.74 & 0.952 \\
185.90 & 77.46 & 2.72 & 1000 & 51.64 & 200 & 45.17 & 8.24 & 0.963 \\
185.90 & 77.46 & 2.72 & 1000 & 51.64 & 300 & 30.30 & 8.30 & 0.972 \\
185.90 & 77.46 & 2.72 & 1000 & 51.64 & 400 & 22.79 & 8.32 & 0.976 \\
185.90 & 77.46 & 2.72 & 1000 & 51.64 & 500 & 18.27 & 8.33 & 0.978 \\
185.90 & 77.46 & 2.72 & 1000 & 51.64 & 600 & 15.25 & 8.35 & 0.980 \\
185.90 & 77.46 & 2.72 & 1000 & 51.64 & 700 & 13.10 & 8.37 & 0.983 \\
185.90 & 77.46 & 2.72 & 1000 & 51.64 & 800 & 11.46 & 8.36 & 0.983 \\
185.90 & 77.46 & 2.72 & 1000 & 51.64 & 900 & 10.19 & 8.37 & 0.984 \\
185.90 & 77.46 & 2.72 & 1000 & 51.64 & 1000 & 9.18 & 8.38 & 0.984 \\
207.85 & 69.28 & 2.58 & 1000 & 57.74 & 5 & 342.73 & 1.71 & 0.977 \\
207.85 & 69.28 & 2.58 & 1000 & 57.74 & 10 & 292.18 & 2.92 & 0.980 \\
207.85 & 69.28 & 2.58 & 1000 & 57.74 & 20 & 228.25 & 4.57 & 0.993 \\
207.85 & 69.28 & 2.58 & 1000 & 57.74 & 30 & 185.83 & 5.57 & 0.991 \\
207.85 & 69.28 & 2.58 & 1000 & 57.74 & 40 & 155.62 & 6.22 & 0.982 \\
207.85 & 69.28 & 2.58 & 1000 & 57.74 & 50 & 132.42 & 6.62 & 0.965 \\
207.85 & 69.28 & 2.58 & 1000 & 57.74 & 200 & 37.77 & 7.55 & 0.958 \\
207.85 & 69.28 & 2.58 & 1000 & 57.74 & 300 & 25.41 & 7.62 & 0.969 \\
207.85 & 69.28 & 2.58 & 1000 & 57.74 & 400 & 19.14 & 7.66 & 0.974 \\
207.85 & 69.28 & 2.58 & 1000 & 57.74 & 500 & 15.37 & 7.69 & 0.979 \\
207.85 & 69.28 & 2.58 & 1000 & 57.74 & 600 & 12.85 & 7.71 & 0.982 \\
207.85 & 69.28 & 2.58 & 1000 & 57.74 & 700 & 11.05 & 7.73 & 0.985 \\
207.85 & 69.28 & 2.58 & 1000 & 57.74 & 800 & 9.69 & 7.75 & 0.988 \\
\hline & & & & & & & & \\
\hline
\end{tabular}

Appendix 5: Comparison of Finite Element Analysis and Theoretical Equation for CFEST Members under Eccentric Compression around Short Axis

\begin{tabular}{ccccccccc}
\hline $\begin{array}{c}2 a \\
(\mathrm{~mm})\end{array}$ & $\begin{array}{c}2 b \\
(\mathrm{~mm})\end{array}$ & $\begin{array}{c}t \\
(\mathrm{~mm})\end{array}$ & $\begin{array}{c}L \\
(\mathrm{~mm})\end{array}$ & $\lambda$ & $\begin{array}{c}e_{0} \\
(\mathrm{~mm})\end{array}$ & $\begin{array}{c}N \\
(\mathrm{kN})\end{array}$ & $\begin{array}{c}M \\
(\mathrm{kN} \times \mathrm{m})\end{array}$ & $\begin{array}{c}\text { Interaction } \\
\text { equation }\end{array}$ \\
\hline 131.45 & 109.54 & 2.99 & 1200 & 36.51 & 5 & 585.14 & 2.93 & 0.975 \\
131.45 & 109.54 & 2.99 & 1200 & 36.51 & 20 & 443.82 & 8.88 & 0.997 \\
131.45 & 109.54 & 2.99 & 1200 & 36.51 & 40 & 327.63 & 13.11 & 0.985 \\
131.45 & 109.54 & 2.99 & 1200 & 36.51 & 60 & 252.69 & 15.16 & 0.951 \\
131.45 & 109.54 & 2.99 & 1200 & 36.51 & 80 & 202.93 & 16.23 & 0.916 \\
131.45 & 109.54 & 2.99 & 1200 & 36.51 & 100 & 168.09 & 16.81 & 0.885 \\
131.45 & 109.54 & 2.99 & 1200 & 36.51 & 300 & 60.32 & 18.10 & 0.974 \\
131.45 & 109.54 & 2.99 & 1200 & 36.51 & 500 & 36.67 & 18.33 & 0.991 \\
131.45 & 109.54 & 2.99 & 1200 & 36.51 & 800 & 23.17 & 18.53 & 1.003 \\
141.99 & 101.42 & 2.96 & 1200 & 33.81 & 5 & 592.22 & 3.86 & 1.021 \\
141.99 & 101.42 & 2.96 & 1200 & 33.81 & 20 & 461.12 & 12.02 & 1.044 \\
141.99 & 101.42 & 2.96 & 1200 & 33.81 & 40 & 348.06 & 18.14 & 1.037 \\
141.99 & 101.42 & 2.96 & 1200 & 33.81 & 60 & 270.80 & 21.17 & 0.998 \\
\hline
\end{tabular}




\begin{tabular}{|c|c|c|c|c|c|c|c|c|}
\hline 141.99 & 101.42 & 2.96 & 1200 & 33.81 & 80 & 217.95 & 22.72 & 0.957 \\
\hline 141.99 & 101.42 & 2.96 & 1200 & 33.81 & 500 & 39.41 & 25.68 & 0.997 \\
\hline 141.99 & 101.42 & 2.96 & 1200 & 33.81 & 800 & 24.86 & 25.91 & 1.008 \\
\hline 151.79 & 94.87 & 2.91 & 1200 & 31.62 & 5 & 593.99 & 2.42 & 0.987 \\
\hline 151.79 & 94.87 & 2.91 & 1200 & 31.62 & 20 & 470.49 & 7.67 & 1.021 \\
\hline 151.79 & 94.87 & 2.91 & 1200 & 31.62 & 40 & 361.87 & 11.79 & 1.027 \\
\hline 151.79 & 94.87 & 2.91 & 1200 & 31.62 & 60 & 285.87 & 13.98 & 1.001 \\
\hline 151.79 & 94.87 & 2.91 & 1200 & 31.62 & 80 & 231.97 & 15.12 & 0.966 \\
\hline 151.79 & 94.87 & 2.91 & 1200 & 31.62 & 300 & 69.53 & 17.00 & 0.987 \\
\hline 151.79 & 94.87 & 2.91 & 1200 & 31.62 & 500 & 42.13 & 17.16 & 1.001 \\
\hline 151.79 & 94.87 & 2.91 & 1200 & 31.62 & 800 & 26.56 & 17.31 & 1.012 \\
\hline 161.00 & 89.44 & 2.87 & 1200 & 29.81 & 5 & 590.54 & 2.95 & 0.984 \\
\hline 161.00 & 89.44 & 2.87 & 1200 & 29.81 & 20 & 472.05 & 9.44 & 1.015 \\
\hline 161.00 & 89.44 & 2.87 & 1200 & 29.81 & 40 & 368.56 & 14.74 & 1.028 \\
\hline 161.00 & 89.44 & 2.87 & 1200 & 29.81 & 100 & 202.05 & 20.20 & 0.947 \\
\hline 161.00 & 89.44 & 2.87 & 1200 & 29.81 & 300 & 73.06 & 21.92 & 0.989 \\
\hline 161.00 & 89.44 & 2.87 & 1200 & 29.81 & 500 & 44.24 & 22.12 & 1.003 \\
\hline 161.00 & 89.44 & 2.87 & 1200 & 29.81 & 800 & 27.85 & 22.28 & 1.013 \\
\hline 169.71 & 84.85 & 2.82 & 1200 & 28.28 & 5 & 589.02 & 2.95 & 1.011 \\
\hline 169.71 & 84.85 & 2.82 & 1200 & 28.28 & 20 & 474.82 & 9.50 & 1.036 \\
\hline 169.71 & 84.85 & 2.82 & 1200 & 28.28 & 40 & 375.13 & 15.01 & 1.049 \\
\hline 169.71 & 84.85 & 2.82 & 1200 & 28.28 & 60 & 302.11 & 18.13 & 1.029 \\
\hline 169.71 & 84.85 & 2.82 & 1200 & 28.28 & 80 & 249.31 & 19.94 & 1.001 \\
\hline 169.71 & 84.85 & 2.82 & 1200 & 28.28 & 100 & 209.88 & 20.99 & 0.970 \\
\hline 169.71 & 84.85 & 2.82 & 1200 & 28.28 & 300 & 76.57 & 22.97 & 0.995 \\
\hline 169.71 & 84.85 & 2.82 & 1200 & 28.28 & 800 & 29.17 & 23.34 & 1.020 \\
\hline 177.99 & 80.90 & 2.77 & 1200 & 26.97 & 40 & 379.04 & 13.94 & 1.026 \\
\hline 177.99 & 80.90 & 2.77 & 1200 & 26.97 & 60 & 307.78 & 16.98 & 1.012 \\
\hline 177.99 & 80.90 & 2.77 & 1200 & 26.97 & 80 & 255.06 & 18.77 & 0.987 \\
\hline 177.99 & 80.90 & 2.77 & 1200 & 26.97 & 100 & 215.63 & 19.83 & 0.960 \\
\hline 177.99 & 80.90 & 2.77 & 1200 & 26.97 & 300 & 79.41 & 21.91 & 0.987 \\
\hline 177.99 & 80.90 & 2.77 & 1200 & 26.97 & 500 & 48.10 & 22.12 & 1.002 \\
\hline 177.99 & 80.90 & 2.77 & 1200 & 26.97 & 700 & 34.51 & 22.21 & 1.008 \\
\hline 177.99 & 80.90 & 2.77 & 1200 & 26.97 & 800 & 30.24 & 22.25 & 1.011 \\
\hline 185.90 & 77.46 & 2.72 & 1200 & 25.82 & 5 & 586.42 & 2.93 & 1.018 \\
\hline 185.90 & 77.46 & 2.72 & 1200 & 25.82 & 60 & 314.95 & 18.90 & 1.035 \\
\hline 185.90 & 77.46 & 2.72 & 1200 & 25.82 & 80 & 262.34 & 20.99 & 1.009 \\
\hline 185.90 & 77.46 & 2.72 & 1200 & 25.82 & 100 & 222.74 & 22.27 & 0.981 \\
\hline 185.90 & 77.46 & 2.72 & 1200 & 25.82 & 500 & 50.06 & 25.03 & 1.001 \\
\hline 193.49 & 74.42 & 2.67 & 1200 & 24.81 & 40 & 388.17 & 15.53 & 1.033 \\
\hline 193.49 & 74.42 & 2.67 & 1200 & 24.81 & 60 & 320.32 & 19.22 & 1.026 \\
\hline 193.49 & 74.42 & 2.67 & 1200 & 24.81 & 80 & 267.92 & 21.43 & 1.003 \\
\hline 193.49 & 74.42 & 2.67 & 1200 & 24.81 & 100 & 228.16 & 22.82 & 0.978 \\
\hline 193.49 & 74.42 & 2.67 & 1200 & 24.81 & 300 & 85.37 & 25.61 & 0.984 \\
\hline 193.49 & 74.42 & 2.67 & 1200 & 24.81 & 500 & 51.74 & 25.87 & 1.001 \\
\hline 193.49 & 74.42 & 2.67 & 1200 & 24.81 & 800 & 32.53 & 26.02 & 1.010 \\
\hline 200.80 & 71.71 & 2.63 & 1200 & 23.90 & 5 & 585.58 & 2.84 & 0.997 \\
\hline 200.80 & 71.71 & 2.63 & 1200 & 23.90 & 20 & 483.37 & 9.39 & 1.016 \\
\hline 200.80 & 71.71 & 2.63 & 1200 & 23.90 & 80 & 272.66 & 21.19 & 1.004 \\
\hline
\end{tabular}




\begin{tabular}{lcccccccc}
\hline 200.80 & 71.71 & 2.63 & 1200 & 23.90 & 100 & 232.85 & 22.62 & 0.980 \\
200.80 & 71.71 & 2.63 & 1200 & 23.90 & 300 & 87.74 & 25.57 & 0.982 \\
200.80 & 71.71 & 2.63 & 1200 & 23.90 & 800 & 33.43 & 25.99 & 1.009 \\
207.85 & 69.28 & 2.58 & 1200 & 23.09 & 5 & 586.52 & 2.93 & 1.013 \\
207.85 & 69.28 & 2.58 & 1200 & 23.09 & 20 & 486.68 & 9.73 & 1.028 \\
207.85 & 69.28 & 2.58 & 1200 & 23.09 & 80 & 278.69 & 22.30 & 1.014 \\
207.85 & 69.28 & 2.58 & 1200 & 23.09 & 100 & 238.93 & 23.89 & 0.991 \\
207.85 & 69.28 & 2.58 & 1200 & 23.09 & 300 & 90.78 & 27.23 & 0.980 \\
207.85 & 69.28 & 2.58 & 1200 & 23.09 & 800 & 34.60 & 27.68 & 1.008 \\
\hline
\end{tabular}




\title{
NONLINEAR FINITE ELEMENT ANALYSIS ON LONG COLUMNS OF HIGH-STRENGTH CONCRETE-FILLED SQUARE STEEL TUBE WITH INNER CFRP CIRCULAR TUBE UNDER AXIAL LOAD
}

\author{
G.C. $\mathrm{Li}^{1{ }^{1,}, \text { C.Y. } \mathrm{Di}^{2}}{ }^{2}$, L. Tian ${ }^{2}$ and C. Fang ${ }^{2}$ \\ ${ }^{1}$ Professor, School of Civil Engineering, Shenyang Jianzhu University, Shenyang, China \\ ${ }^{2}$ Postgraduate, School of Civil Engineering, Shenyang Jianzhu University, Shenyang, China \\ *(Corresponding author: E-mail: liguochang0604@sina.com)
}

Received: 13 December 2011; Revised: 18 May 2012; Accepted: 23 May 2012

\begin{abstract}
The concrete-filled square steel tubular structure has been applied wildly in the practical projects around the world. To install CFRP into the column is beneficial not only to overcome the disadvantages of the high-strength concrete, but also to improve the bearing capacity and the stability of the concrete-filled square steel tube. This paper adopts finite element analysis software ABAQUS 6.7 to make nonlinear finite element analysis on a large number of long columns of high-strength concrete-filled square steel tube with inner CFRP circular tube subjected to axial compression. The analysis results are verified by the tests. In addition, the load-axial strain curves in the whole process are calculated and analyzed, and they are divided into 4 segments: elastic phase, plastic phase, descending phase and rebound phase. Based on the curves of load-axial strain, the stresses analysis on the core concrete, CFRP tube and square steel tube are conducted. The results of finite element simulation analysis show the destruction of long columns subjected to axial compression are all buckling failure. It indicates that slenderness ratios are the key to decide the type of buckling failure for long columns under axial compressive loading. The boundary slenderness ratio between elastic buckling and plastic buckling is discussed.
\end{abstract}

Keywords: ABAQUS finite element, inner CFRP circular tube, axial compression, working mechanism, boundary slenderness ratio.

\section{INTRODUCTION}

Many advantages, such as high bearing capacity, good stability, and simple type of joint available in the structure, can be shown in the concrete-filled square steel tube structure, so it is widely applied in practical engineering. Especially, the simple type of joint turns the concrete-filled square steel tubular column into a good component in frame structure. Some relative researches have been accomplished before, as shown in Cai and $\mathrm{Gu}$ [1] and Tan et al. [2]. On the basis of the theory in Han [3] and Zhong [4], some new materials are used and analyzed in the papers. Liang et al. [5] [7] investigated the strengths and behavior of short concrete filled thin-walled steel box columns with local buckling effects by nonlinear fiber element analysis, with the study of several essential effects on the stiffness, strength and ductility of high strength thin-walled CFST beam columns under combined axial load and biaxial bending, and studied the critical local and post-local buckling behavior of steel plates in concrete-filled thin-walled steel tubular beam-columns. Mohanad and Uy [8] [9] presented the experimental and theoretical studies of the behavior of hollow and concrete filled steel columns fabricated with high strength structural steel plate and subjected to biaxial bending. With the continuous development of concrete technology and new material, high-strength concrete and CFRP are used to cooperate with the steel tube and then the high-strength concrete-filled square steel tube with built-in CFRP circular tube is formed. According to $\mathrm{Li}$ et al. [10], this method can overcome effectively the weaknesses of brittleness of high-strength concrete and improve the bearing capacity and stability of concrete-filled steel tubular column. 
The CFRP circular steel tube is installed into the high-strength concrete filled square steel tube to form a new type of composite component. With the development of society and economy, there are a large number of high-rise buildings and the constructional members with big slenderness ratio which have been and will be used in practice engineering, so it is necessary to study further in the mechanical properties of the long columns. By the finite element analysis software ABAQUS 6.7, the entire process analysis on long columns $(\lambda>45)$ of concrete-filled square steel tube with inner CFRP circular tube under axial load is conducted and the working mechanism of the long columns is deeply investigated in the paper.

\section{FINITE ELEMENT MODEL}

\subsection{Constitutive Model of Materials}

\subsubsection{Steel}

In the paper, the elastic-plastic material behavior provided by ABAQUS 6.7 is applied to emulate the steel. Since the cold-formed steel tube which is divided into the corner zone and the plate zone with the different residual stress is adopted in the research, an idealized multi-liner stress-strain model proposed by Abdel-Rahman and Sivakumaran [11] is used to simulate the constitutive relation of the steel, as shown in the Figure 1. The first part of the curve is defined as the elastic stage with the Young's modulus $E_{s}=206000 \mathrm{MPa}$, and Poisson's ratio $(v)$ is taken as 0.3 .

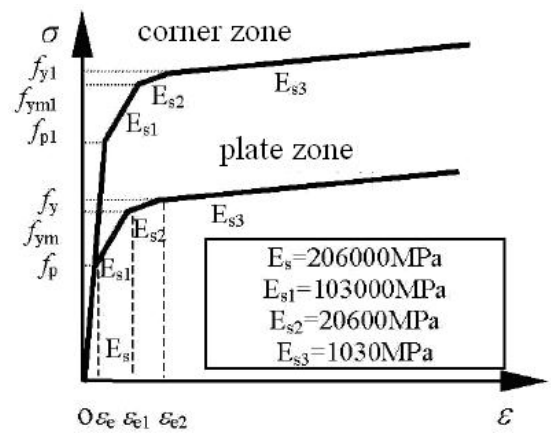

Figure 1. Idealized stress-strain curves of cold-formed steel

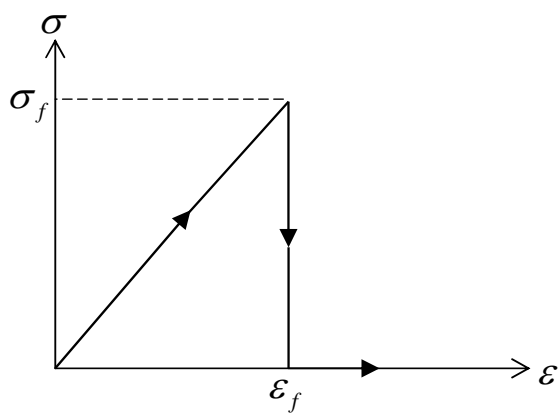

Figure 2. Stress-strain curve of CFPR

\subsubsection{CFRP}

The Lamina model provided by ABAQUS 6.7 is elected to simulate the mechanical performance of the CFPR in the elastic stage. The Hashin damage model is applied to emulation of the abrupt fracture behavior. On the basis of the previous researches, the interaction between CFRP and concrete can be neglected, since the bonding strength between CFRP and concrete is less than the strength of CFRP. Therefore, CFRP is assumed to be in the elastic state before its failure, and CFRP is ruptured and removed from the analysis owing to disability to bear load when CFRP reaches the ultimate strain. Figure 2 shows the stress-stain curve of the CFRP and the formulas of the constitutive relation are as follows:

$\varepsilon \leq \varepsilon_{\mathrm{f}}, \quad \sigma_{\mathrm{f}}=E_{\mathrm{f}} \varepsilon$

$\varepsilon>\varepsilon_{\mathrm{f}}, \quad \sigma_{\mathrm{f}}=0$ 
Where, $\sigma_{\mathrm{f}}$ is the ultimate stress of the fiber; $E_{\mathrm{f}}$ is the modulus of elasticity; $\varepsilon_{\mathrm{f}}$ is the ultimate strain.

\subsubsection{Concrete}

In the paper, the damage plastic model provided by ABAQUS 6.7 is used to emulate the concrete material. Since taking into consideration the confinement effects of the CFPR tube and steel tube on the core concrete, the stress-strain relationship of the high-strength concrete developed by Liu [12] is applied to emulate the concrete in the analysis.

\subsection{Element}

For taking into consideration the shear deformation along the thickness direction, the shell element of four nodes reduced integration scheme (S4R) is used to simulate steel. With the change of shell thickness, the method will automatically fit to the thick or thin shell theory. In order to satisfy the required accuracy, 9 integration points of Simpson theory along the thickness direction in the shell element are needed. The composite shell element of four nodes reduced integration scheme (S4R) is applied to emulate CFRP with 3 integration points of Simpson theory along the thickness direction in the shell element. The three-dimensional solid element (C3D8R) of eight nodes reduced integration scheme is used as the element model to emulate the concrete and the loading plate. In addition, the loading plate can be seen as rigid body, because it almost has no distortion in the process of experiment. The elastic modulus of the loading plate should be set largely enough and the Poisson ratio is set diminutively enough in the material properties to emulate the rigid body.

\subsection{Boundary Conditions and Mode of Loading}

For the symmetry of cylinder geometry and boundary conditions of the model, a quarter of the actual component is selected to simulate. There are symmetric boundary conditions on the two symmetric planes in the components of concrete-filled steel tube, as shown in Figure 3(a). When making nonlinear finite element analysis on long columns of concrete-filled square steel tube under axial compression, initial defects of specimen should be taken into consideration due to its large effect on the mechanical properties of long columns of high-strength concrete-filled square steel tube with built-in CFRP circular tube under axial compression. The initial defects in columns of concrete-filled steel tube belong to small eccentricity, so loading cannot be completely exerted on axle center in the process of simulation on components. The initial deflection of components should be set as thousandth length of rod (taking initial eccentricity $\mathrm{e}_{0}=\mathrm{L} / 1000$ ). The loading path is that when fixing the displacement of $\mathrm{X}, \mathrm{Z}$ direction, the line load is applied on the loading plate (the loading program is the displacement.), as shown in Figure 3 (b). 


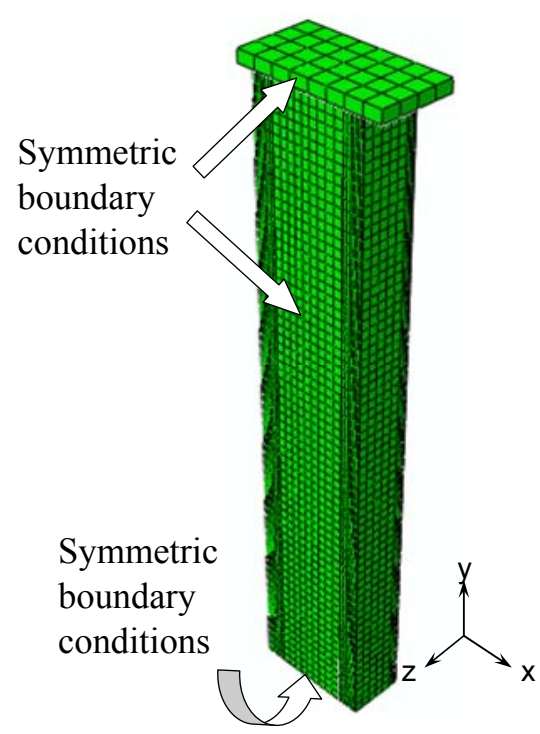

(a) Analysis Model

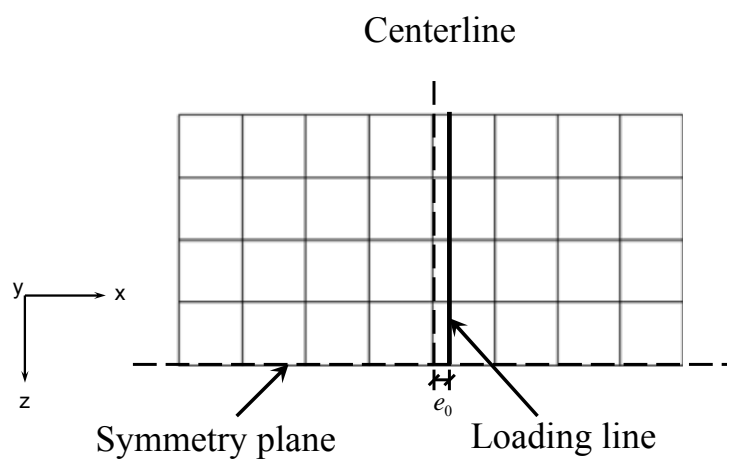

(b) Loading Path

Figure 3. Axial Compression Model of Long Columns Considering Initial Defects

\subsection{Contact}

Owing to analysis on three materials, including steel, concrete and carbon fiber, the columns of high-strength concrete-filled square steel tube with built-in CFRP circular tube studied in this paper are relatively special. Therefore, on the basis of the practical situation, the contact relation that is as simple as possible to avoid complicated contact among different materials is emulated in the paper.

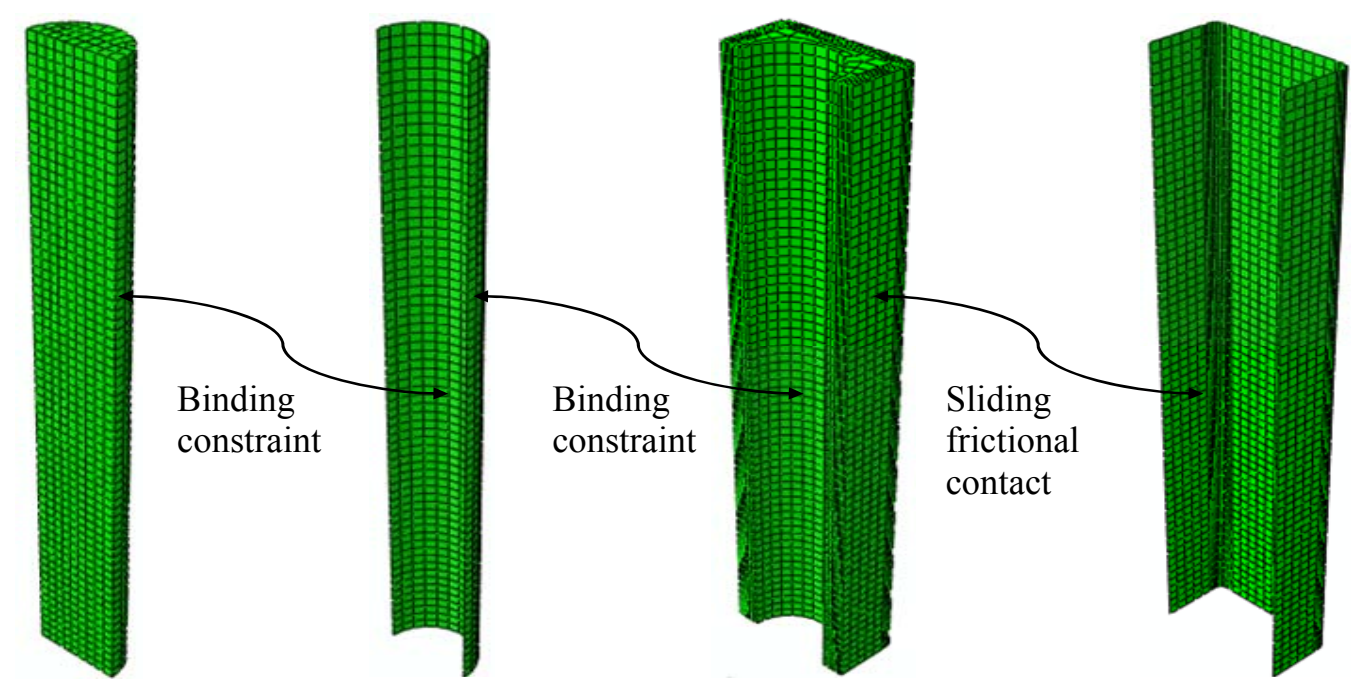

Core concrete

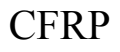

Sandwich concrete

Steel tube

Figure 4. Finite Element Model of Specimen

Since the contacts between the loading plates and the top zones of the concrete are only considered in the normal direction, "hard" contact (hard contact) is used to simulate to transmit the reaction force perpendicular to the loading plate between the interfaces. "Shell to solid" provided by ABAQUS 6.7 is applied to contact between steel tube and the loading plate, for the steel tube is simulated by shell element model. Taking into account cooperative deformation of CFRP with core concrete or sandwich concrete, binding constraints (tie) is used to emulate both the interface 
between core concrete and CFRP tube and interface between sandwich concrete and CFRP tube. The model proposed by Liu [12] is applied to simulation of the contact between steel tube and concrete. The contact along the normal direction is hard contact and that along the tangent direction is sliding frictional contact. The friction coefficient is 0.6 and the contact relations among materials are shown in the Figure 4.

\section{RESULTS OF THE ANALYSIS}

\subsection{Comparison of the Ultimate Bearing Capacity.}

Table 1. Comparison of the Ultimate Bearing Capacity

\begin{tabular}{|c|c|c|c|c|c|c|c|c|c|c|}
\hline number & $\begin{array}{c}B \\
(\mathrm{~mm})\end{array}$ & $\begin{array}{c}L \\
(\mathrm{~mm})\end{array}$ & $\begin{array}{c}t \\
(\mathrm{~mm})\end{array}$ & $\begin{array}{c}f_{y} \\
(\mathrm{MPa})\end{array}$ & $\lambda$ & $\alpha$ & $\begin{array}{c}\delta_{c f p} \\
(\mathrm{~mm})\end{array}$ & $\begin{array}{c}N_{u} \\
(\mathrm{kN})\end{array}$ & $\begin{array}{c}N_{u}^{\prime} \\
(\mathrm{kN})\end{array}$ & $\frac{N_{u}^{\prime}}{N_{u}}$ \\
\hline 2600AL50 & 200 & 2600 & 5 & 320 & 45.033 & 0.108 & 0 & 3950 & 3920 & 0.992 \\
\hline 2800AL50 & 200 & 2800 & 5 & 320 & 48.497 & 0.108 & 0 & 3900 & 3889 & 0.997 \\
\hline 3000AL50 & 200 & 3000 & 5 & 320 & 51.962 & 0.108 & 0 & 3750 & 3848 & 1.026 \\
\hline 3200AL50 & 200 & 3200 & 5 & 320 & 55.426 & 0.108 & 0 & 3687 & 3801 & 1.031 \\
\hline 2600AL52 & 200 & 2600 & 5 & 320 & 45.033 & 0.108 & 0.334 & 4086 & 3943 & 0.965 \\
\hline 2800AL52 & 200 & 2800 & 5 & 320 & 48.497 & 0.108 & 0.334 & 3934 & 3901 & 0.992 \\
\hline 3000AL52 & 200 & 3000 & 5 & 320 & 51.962 & 0.108 & 0.334 & 3795 & 3852 & 1.015 \\
\hline 3200AL52 & 200 & 3200 & 5 & 320 & 55.426 & 0.108 & 0.334 & 3690 & 3809 & 1.032 \\
\hline
\end{tabular}

\section{Note:}

The first letter A of specimen No. means axial compression;

The second letter L means long column;

The first Roman numbers 5 behind letters represents that thickness of tube wall is $5 \mathrm{~mm}$;

The second Roman numbers 0, 2 under letters represent that the number of carbon fiber layers around CFRP circular tube is 0 and 2 respectively.

$\mathrm{B}$ represents the outside length of square specimen section,

$\mathrm{L}$ represents the length of the specimen,

$\mathrm{t}$ represents the thickness of steel tube wall,

$f_{y}$ represents the yield strength of steel tube,

$\lambda=2 \sqrt{3} L / B$ represents the slenderness ratios,

$\alpha$ represents steel radio;

$\delta_{c f r p}$ represents the thickness of carbon fiber cloth,

$N_{u}$ and $N_{u}^{\prime}$ represent ultimate compressive strength obtained from specimen experiments and from the finite element method separately.

Table 1 shows the detailed information and ultimate bearing capacity value of specimens of long columns of high-strength concrete filled square steel tube with CFRP circular tube under axial compression corresponding to the experiment. The results of analysis show that the error between calculated values and experimental values of ultimate bearing capacity obtained by nonlinear finite element analysis is less than $10 \%$. The mean and variance of the $N_{u}^{\prime} / N_{u}$ value of concrete filled 
square steel tubes are 1.006 and 0.005 respectively. It shows that the calculated results agree well with the experimental results. Thus, the calculation method which analyzed the mechanical property on long column of high-strength concrete-filled square steel tube with internal CFRP circular tube under axial compression is reliable.

\subsection{Full Range Analysis on Load-Axial Strain}

To study the working mechanism of long columns of concrete-filled square steel tube with inner CFRP circular tube under axial compression, it is essential to analyze the typical curve of load $(\mathrm{N})$-average longitudinal strain $(\varepsilon)$ of long columns under axial compression separately, shown in Figure 5. The curve is divided into four sections: OA segment (elastic stage), AB segment (plastic stage), BC segment (descending stage), and CD segment (rebounding stage). Point A in the curve is the beginning point in which steel tube goes into the plastic stage. Point $\mathrm{B}$ is the point in which the component reaches its ultimate bearing capacity. Point $\mathrm{C}$ is the point in which the role of CFRP is clearly starting to act on the mechanical prosperity of the column. Point D' means a sudden rupture of CFRP circular tube. When the function of core concrete in the finite element method process is extremely unstable, axial deformation of the specimen is comparatively large and there is a large buckling in steel wall. The point $\mathrm{D}$ (the corresponding strain is about $3.5 \varepsilon_{0}-5 \varepsilon_{0}$ ) before point $\mathrm{D}$ is elected to investigate the mechanical properties of concrete before the rupture of CFRP circular tube.

The typical example of long columns of high-strength concrete-filled square steel tube with inner CFRP circular tube under axial compression and that of normal long columns of concrete filled steel tube under axial load are used to compare and analyze the changes in stress and strains of core concrete, steel tube and CFRP circular tube in the whole process so as to investigate their working principles. The calculation parameters of these typical examples are as the follows : $\mathrm{L}=3000 ; \mathrm{B}=$ $200 \mathrm{~mm} ; \mathrm{t}=5 \mathrm{~mm} ; \delta_{c f r p}=0.334$; Steel $Q_{235}$ and concrete $\mathrm{C} 90$ are used.

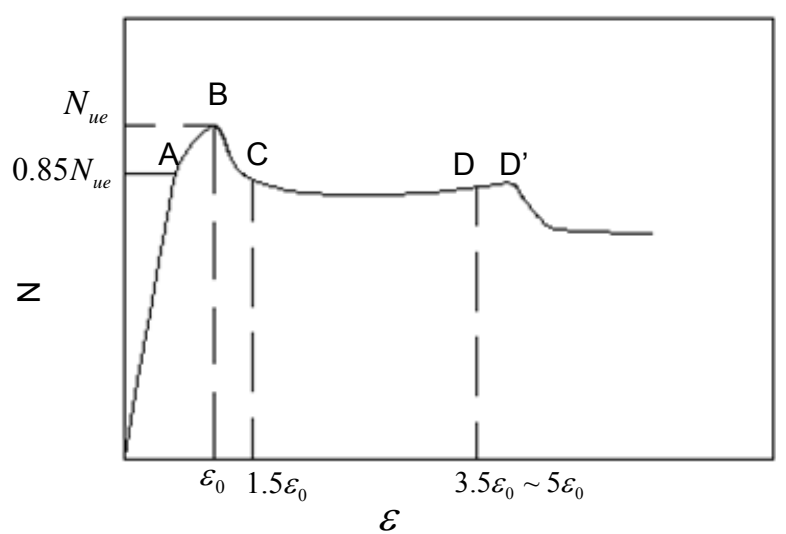

Figure 5. Typical N-e Relation Curve

\subsection{Stress and Strain Analysis of the Core Concrete.}

Figure 6 shows the longitudinal stress (S22) distribution of the core concrete section corresponding to points $\mathrm{A}, \mathrm{B}, \mathrm{C}$ and $\mathrm{D}$ on typical $\mathrm{N}-\varepsilon$ relation curves. The results show that, in the whole process, the core concrete of long columns of high-strength concrete-filled square steel tube with inner CFRP circular tube are subjected to pressure in the total cross section. When the load is small (point A), the steel has no confinement effects on the concrete due to relatively larger Poisson ratio of steel than that of concrete. When the load reaches the ultimate bearing capacity (B point) of the column, the lateral deformation coefficient of concrete is larger than that of steel, because the 
plastic deformation of concrete was formed. The confinement effect of steel on concrete mainly concentrates on the corner of steel tube. Then the load begins to decrease and the confinement performed by steel begins to expand to the flat region. When the load drops to point $C$, the difference of longitudinal stress distribution between core concrete and sandwich concrete starts to be obvious. The longitudinal stress distribution is uneven and the stress of core concrete significantly increases. When arriving at point $\mathrm{D}$, the difference is more obvious and the stress of core concrete continues increasing.

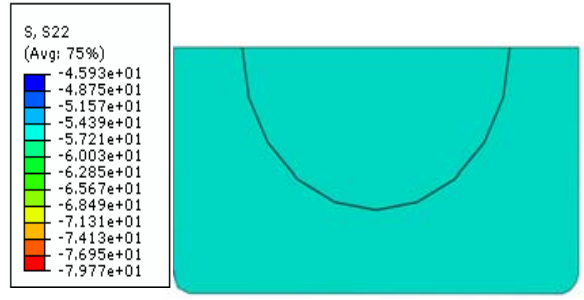

Point A
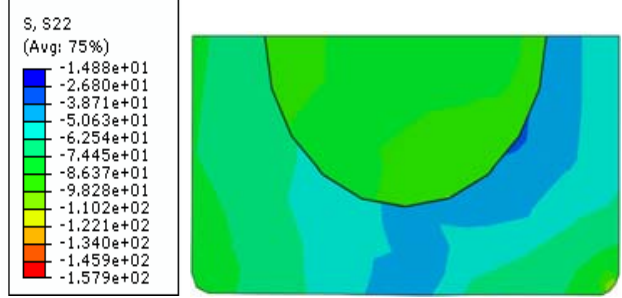

Point C

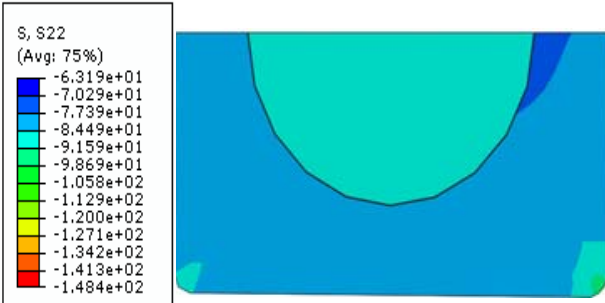

Point B
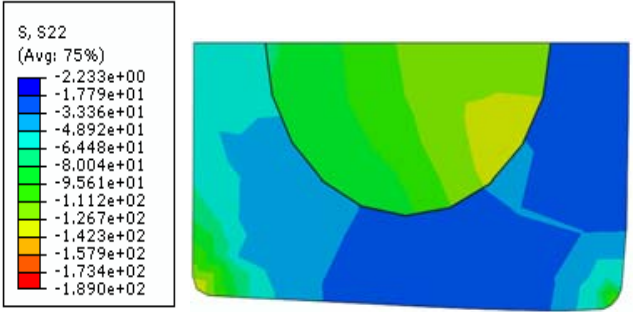

Point D

Figure 6. The Longitudinal Stress Distribution of Sectional Core Concrete in Concrete Filled Square Steel Tube with Inner CFRP Circular Tube

In order to facilitate comparison with ordinary concrete-filled square steel tube similar to the method proposed in Gu et al. [13], Figure 7 shows the longitudinal stress distribution in the cross section of square steel tube concrete columns corresponding to points $\mathrm{A}, \mathrm{B}, \mathrm{C}$ and $\mathrm{D}$. The stress of the core concrete of concrete filled square steel tube is generally less than that of the core concrete of concrete-filled square steel tube with inner CFRP circular tube and CFRP tube played an important role in the Constraint effect on the core concrete.

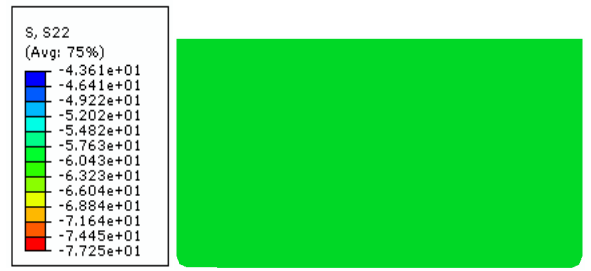

Point A
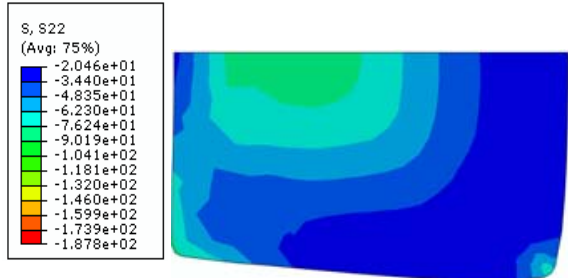

Point C

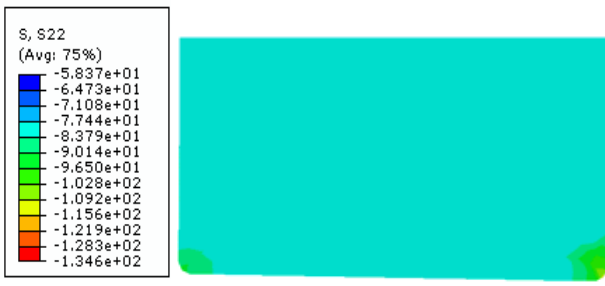

Point B

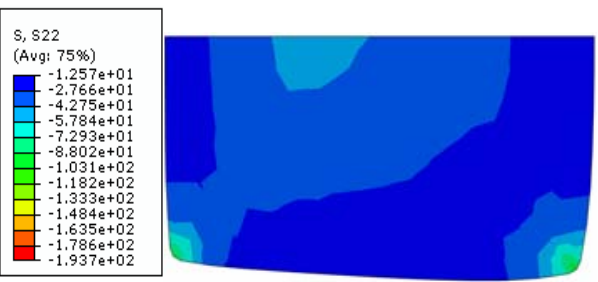

Point D

Figure 7. The Longitudinal Stress Distribution of Sectional Core Concrete in Concrete-Filled Square Steel Tube 
In order to reflect the plastic development of cross section of core concrete directly, Figure 8 and Figure 9 show the longitudinal plastic strain distribution of core concrete of axial long column components. The results show that the plastic development of concrete filled square steel tube with inner CFRP circular tube is slower and the plastic strain at both ends gradually spreads into the mid-span. At point $\mathrm{D}$, the large plastic deformation is formed in the middle of the core concrete section. But the plasticity of core concrete of concrete filled square steel tube developed rapidly, the longitudinal plastic strain in the section begins to be brought forth obviously at point B. It continues to increase and the rate of the increase speeds up at point $\mathrm{C}$.

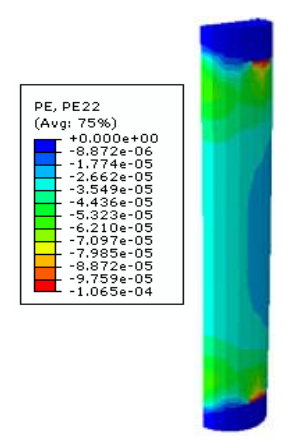

Point A

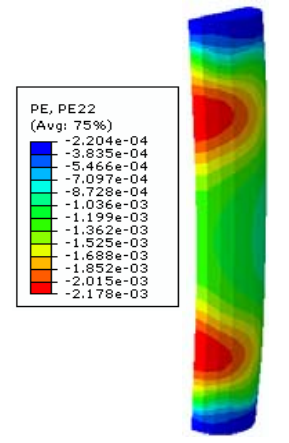

Point B

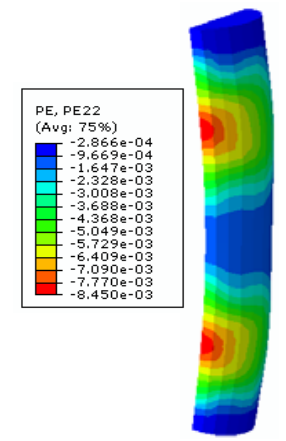

Point C

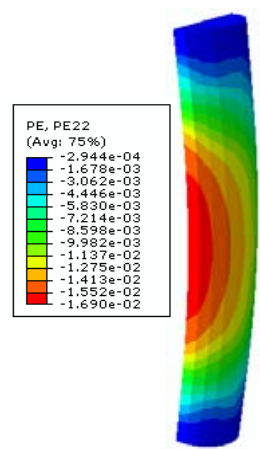

Point D

The Longitudinal Plastic Strain Distribution of Core Concrete
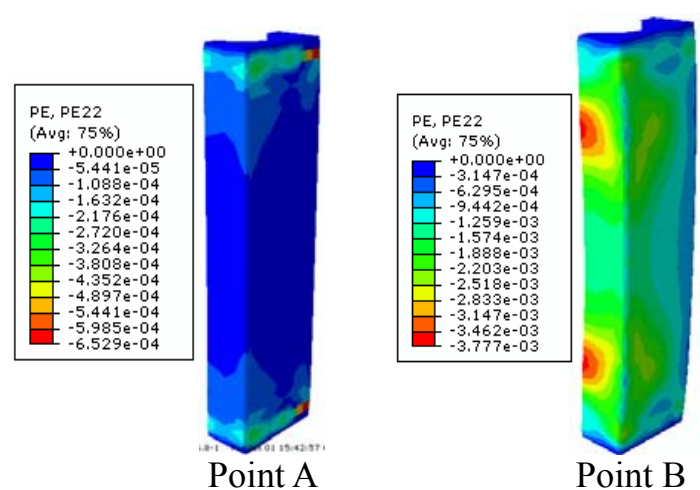

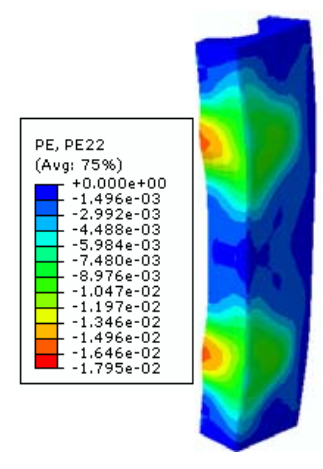

Point C

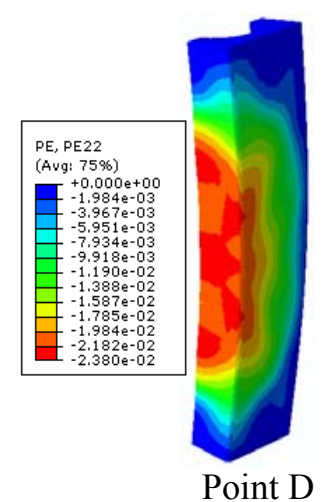

Point D

The Longitudinal Plastic Strain Distribution of Sandwich Concrete

Figure 8. The Longitudinal Plastic Strain Distribution of Sectional Core Concrete in Concrete Filled Square Steel Tube with Inner CFRP Circular Tube

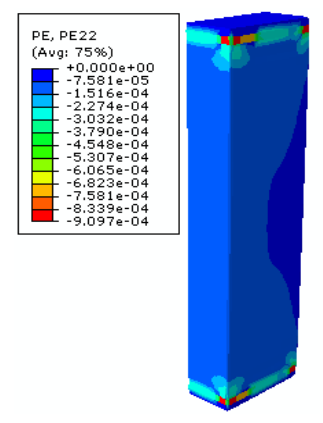

Point A

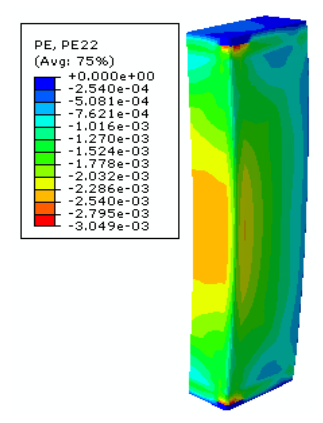

Point B

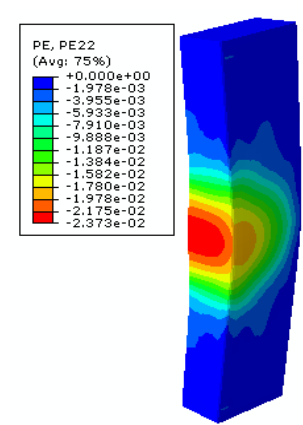

Point C

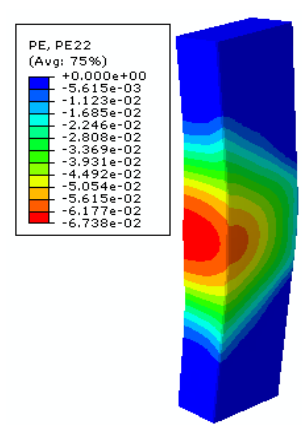

Point D

Figure 9. The Longitudinal Plastic Strain Distribution of Sectional Core Concrete in Concrete Filled Square Steel Tube 


\subsection{Stress Analysis of Steel Tube.}

Since the cold-bending steel tube is used in this paper, the increase of yield strength of steel in corner part of the steel tube is taken into consideration, with its cross section divided into corner region and flat region. Different yield strength and the relevant parameters of plastic development are set to each region. Figure 10 shows the Mises stress distribution of steel of concrete filled square steel tube with internal CFRP circular tube in the whole process of steel under load. The results demonstrate that steel tube does not produce the confinement effect on concrete due to its relatively large Poisson radio when the load is small (point A). As a result, the entire section of steel tube is basically in the elastic state while the strain values of corner region and flat region have reached proportional ultimate value. As steel tube reaches its ultimate bearing capacity (point B), what can be seen from the Mises output values is that the maximum value in corner region has reached the yield value of steel. With the increase of load, the steel tube goes into plastic state and its strain is still rising slowly, while the plastic strain develops fast. So there is the plastic failure in the axial compressive component.
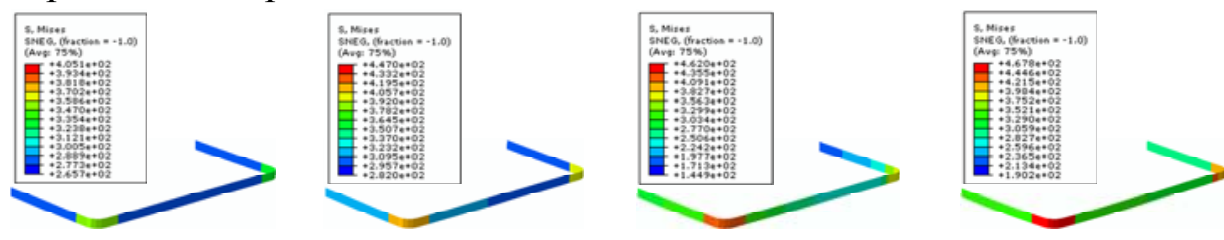

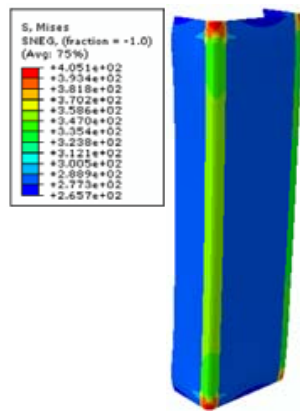

Point A

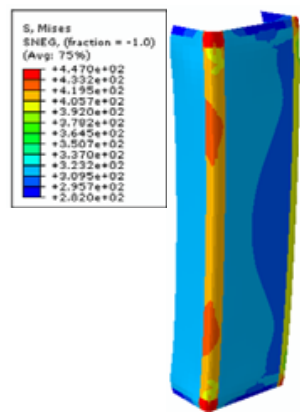

Point B

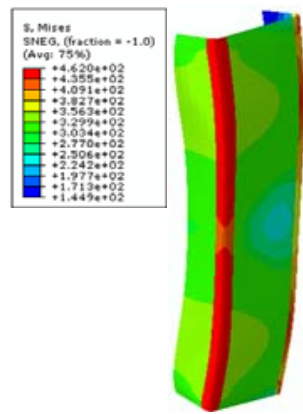

Point C

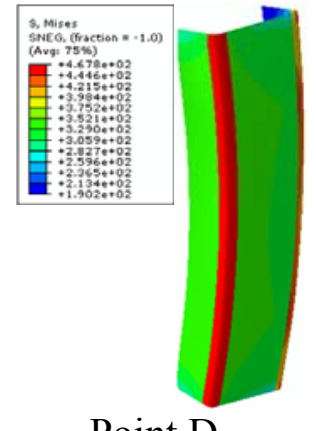

Point D

Figure 10. Mises Stress Distribution of Steel of Concrete Filled Square Steel

Tube with Inner CFRP Circular Tube 


\subsection{Strain Analysis of CFRP}

Figure 11 shows the principal stress vector of CFRP circular tube. It can be seen that the direction of maximum principal stress vector in CFRP is along the longitudinal direction of circular tube. Figure 12 gives the distribution figure of maximum principal stress of CFRP circular tube and the results show that, when the load is small (point A), the distribution of maximum principal stress along longitudinal is uneven. The maximum principal stress is not more than $93.8 \mathrm{Mpa}$ from the output values of principal stress when the CFRP circular tube is under small load. When arriving at its ultimate bearing capacity (point B), the maximum principal stress value of CFRP is $695.3 \mathrm{MPa}$, only one-sixth of its ultimate bearing capacity. CFRP does not play a significant role in the core concrete when the component reaches its ultimate bearing capacity. When the load drops to point $\mathrm{C}$, maximum principal stress of CFRP gradually moves closer to the middle of the span and it also reaches its maximum value $1875 \mathrm{MPa}$. It shows that CFRP circular tube starts to have a significant confinement effect on core concrete. Figure 5 indicates that $\mathrm{N} \sim \varepsilon$ curve starts to rebound from this point $(\mathrm{C})$. As the load increases, the maximum principal stress is also increasing correspondingly and the confinement effect of steel tube on core concrete becomes increasing apparently. When CFRP reaches its ultimate bearing capacity at point $\mathrm{D}$, the confinement effect comes to its extreme.

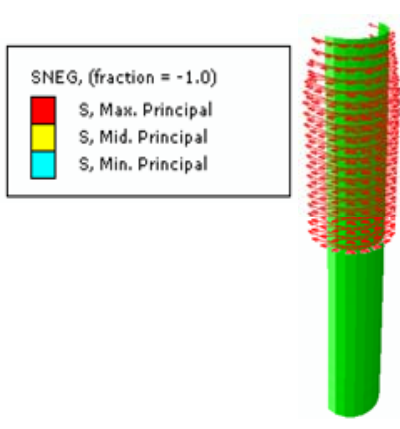

Point A

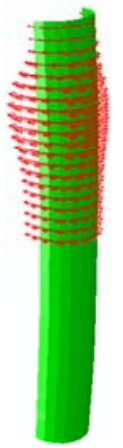

Point B

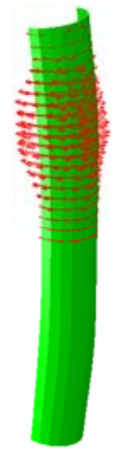

Point C

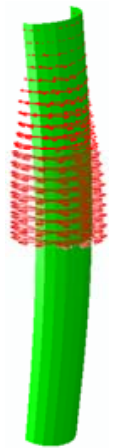

Point D

Figure 11. Distribution of the Principal Stress Vector of CFRP

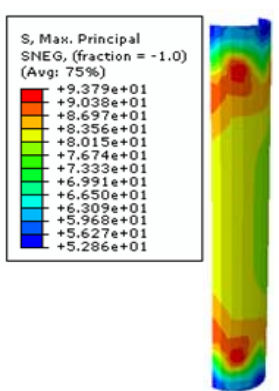

Point A

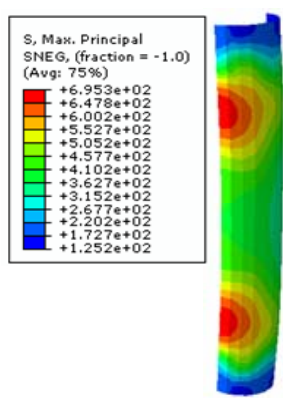

Point B

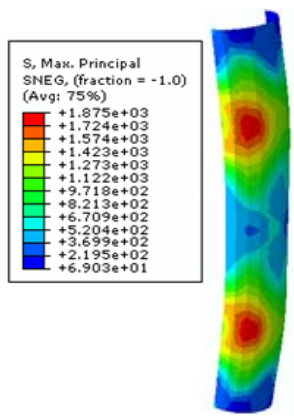

Point C

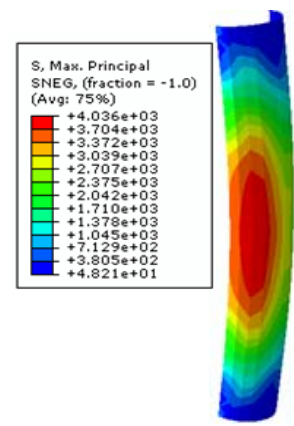

Point D

Figure 12. Distribution of the Maximum Principal Stress of CFRP 


\section{BOUNDARY SLENDERNESS RATIO OF ELASTIC BUCKLING}

\subsection{Calculation of the Bound Slenderness Ratio}

The destruction of concrete-filled steel tubular short column under axial load is the strength failure and the destruction of long concrete-filled steel tubular column is the buckling failure. Buckling failure can be divided into elastic-plastic failure and elastic buckling failure. When the buckling failure occurs and the compression stress is less than the yield strength of the steel, the failure can be defined as the elastic buckling failure. The capacity of components with relatively large slenderness ratio under axial load often depends on stability because of the initial defects. In order to receive the boundary slenderness ratio of elastic buckling of long column, the finite element simulation on long columns (the slenderness ratio $\lambda \leq 138.5$ ) of high-strength concrete-filled square steel tube with inner CFRP circular tube under axial compression is performed in the paper. Because the boundary slenderness ratio is related with the ultimate load and the load-deformation curve after the ultimate load is not a main task of the study, the figure of the load-deformation curve is only included a certain portion after the ultimate load of the specimen. Figure 13 shows the loads $(\mathrm{N})$-the average longitudinal strain $(\varepsilon)$ curve of strength concrete-filled square steel tubular long columns. And its slenderness ratio is less than 138.6. Figure 14 shows the load $(\mathrm{N})$-the average longitudinal strain $(\varepsilon)$ curve of high-strength concrete filled square steel tubular long columns with inner CFRP circular tube with the slenderness ratio corresponding to concrete-filled square steel tube.

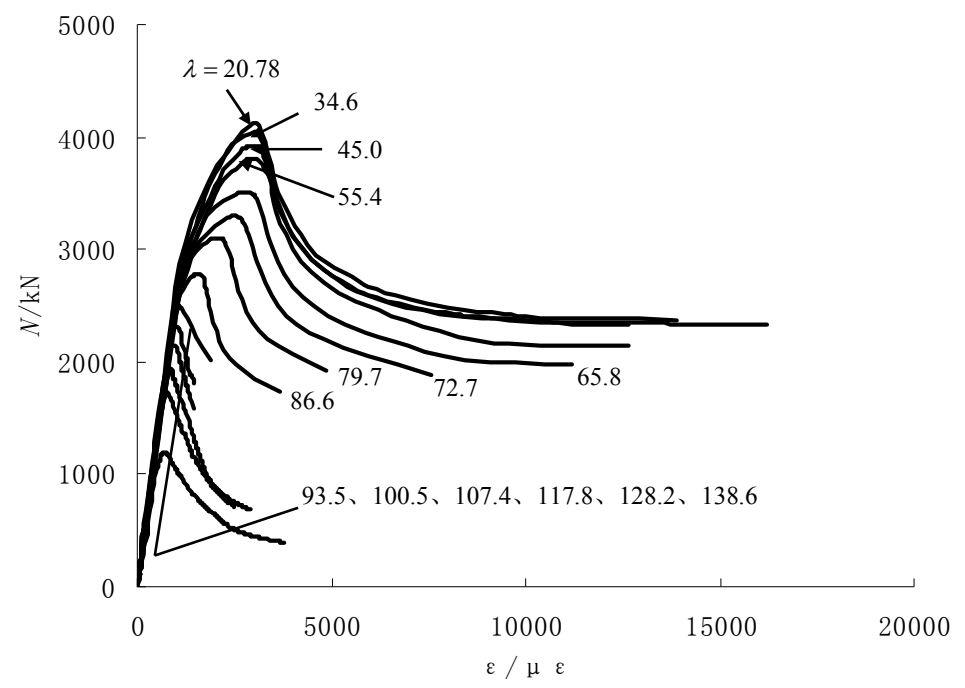

Figure 13. $N-\varepsilon$ Curve of High-Strength Concrete-Filled Square Steel Tubular Long Columns

The ultimate bearing capacity of high-strength concrete-filled steel tubular long columns is defined as the critical force when buckling failure occurs. Figure 13 and Figure 14 show that critical forces of all specimens under axial compression have much to do with slenderness ratio. The smaller the slenderness ratio $\lambda$ is, the greater the critical force is and the greater the limit deformation is. The greater the slenderness ratio $\lambda$ is, the smaller the ultimate deformation is and the critical force smaller is. It is can be seen from Figure 13 when $\lambda$ is $20.78 \sim 86.6$, the columns of concrete-filled square steel tube reach a critical state in the plastic phase of the $\mathrm{N}-\varepsilon$ curve. When $\lambda=93.5 \sim 138.6$, it reaches a critical state in the elastic stage of the $\mathrm{N}-\varepsilon$ curve. So the boundary slenderness ratio of high-strength concrete-filled square steel tubular long columns under axial compression is 93.5 when elastic buckling occurs $(\mathrm{L}=5400 \mathrm{~mm})$. 


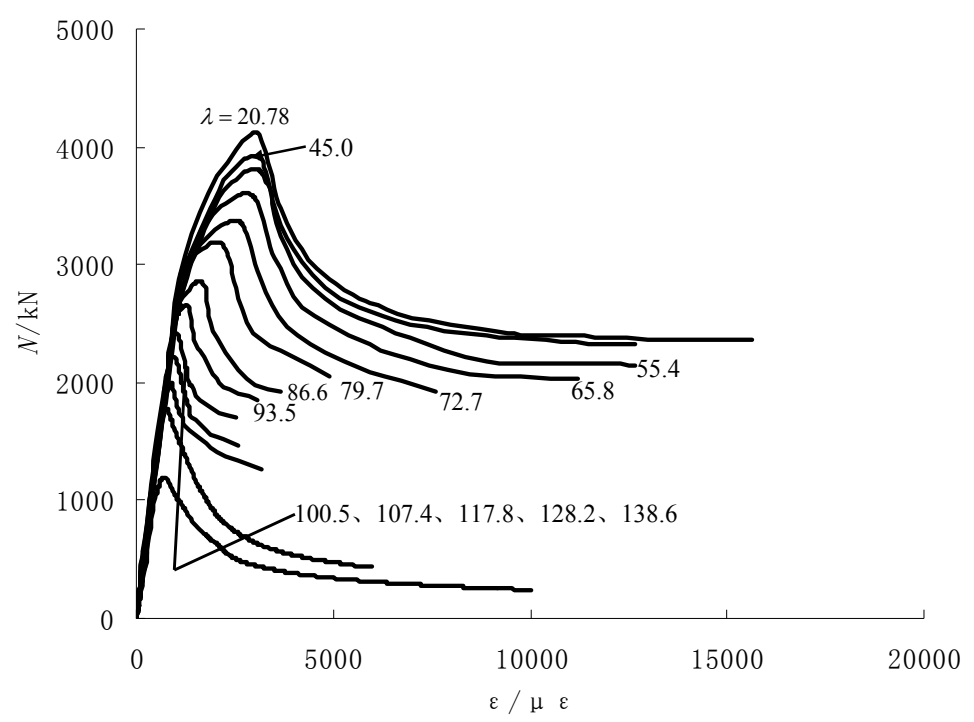

Figure 14. $N-\varepsilon$ Curve of High-Strength Concrete Filled Square Steel Tube with Inner 2 Layers CFRP Circular Tubular Long Columns

It can be seen from Figure 14, when $\lambda=20.78 \sim 93.5$, the columns of high-strength concrete-filled square steel tube with inner CFRP circular tube reach critical state in the plastic phase of the N- $\varepsilon$ curve. When $\lambda=100.5 \sim 138.6$, the specimens reach critical state in the elastic stage of the N- $\varepsilon$ curve. So the boundary slenderness ratio of columns studied in the paper under axial compression is 100.5 when elastic buckling occurs $(\mathrm{L}=5800 \mathrm{~mm})$.

Figure 15 shows the load $(\mathrm{N})$-deflection of mid-span $(\Delta)$ relationship curve of components of high-strength concrete-filled square steel tube under axial compression. It is shown in Figure 15 that, as slenderness ratio increases, the deflection $(\Delta)$ gradually increases, when the components reach its critical state. The anti-lateral stiffness and stability of components of high-strength concrete-filled square steel tube under axial compression decrease as slenderness ratio increases. At the same time, the deflection $(\Delta)$ of components $(\lambda \leq 86.6)$ with plastic buckling begins to span obviously when it arrives at $60 \% \sim 70 \%$ of critical force, while the deflection $(\Delta)$ of components $(\lambda \geq 93.5)$ with elastic buckling starts at the beginning of loading.

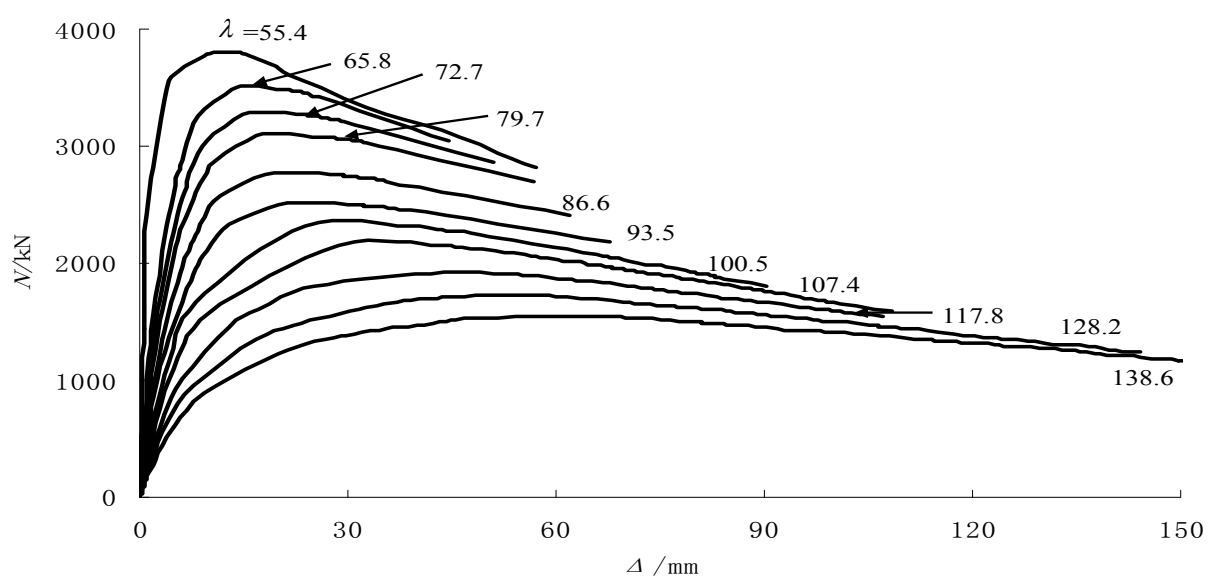

Figure 15. N- $\Delta$ Relationship Curve of High-Strength Concrete Filled Square Steel Tubular Columns 


\subsection{Theoretical Validation of Boundary Slenderness Ratio}

Zhong and Han [14] adopted numerical methods to calculate the load-deformation curve of the components under axial load and defined that the strength in the end of elastic stage of the curve is combinational proportional limit $f_{s c p}$. The reduced stress of steel has reached its proportional limit and the strain of component is proportional strain $\varepsilon_{s c p}$. It is defined that $f_{s c y}$ is the standard strength value when the component reaches its ultimate bearing capacity. These parameters $f_{s c p} / f_{s c y}$ and $\varepsilon_{s c p}$ do not depend on steel ratio and strength grade of concrete, but on the yield point of steel. It is due to the one-way force to which the steel and concrete at this stage are subjected, without the confining force, as shown in Han [3].

According to analysis results by numerical calculation of Zhong and Han [14], the expression of parameters can be calculated as follows:

$$
\begin{aligned}
& f_{s c y}=\left(1.212+B \xi+C \xi^{2}\right) f_{c k} \\
& f_{s c p}=\left[0.263\left(f_{y} / 235\right)+0.365\left(30 / f_{c u}\right)+0.104\right] f_{s c y} \\
& \varepsilon_{s c p}=3.01 \times 10^{-6} f_{y}
\end{aligned}
$$

Among: $\mathrm{B}=0.131 f_{y} / 235+0.723, \mathrm{C}=-0.07 f_{c k} / 20+0.0262$

$\xi$ is confine coefficient of the concrete-filled steel tube

The article defines that the combinational proportional load $N_{s c p}$ is equal to the $f_{s c p} \times A_{s c}$ (multiplication of combinational proportional limit and the cross-sectional area of the component). If the critical force in damage is greater than the combinational proportional load of components under axial load, the damage belongs to the plastic buckling. While the critical force in buckling damage is less than the combinational proportional load of component under axial load, the damage belongs to elastic buckling. The calculated values can be obtained from interrelated values of examples in this paper.

$$
\begin{array}{ll}
f_{s c y}=106.085 \mathrm{MPa}, & f_{s c p}=62.463 \mathrm{MPa}, \\
\varepsilon_{s c p}=978.25 \times 10^{-6}, & N_{s c p}=2498.5 \mathrm{KN}
\end{array}
$$

The critical force of components of high-strength concrete-filled square steel tube with the buckling failure is $2483 \mathrm{KN}$ in this article when the slenderness ratio is $93.5(\mathrm{~L}=5400 \mathrm{~mm})$ which is less than the combinational proportional load $N_{s c p}$ obtained by theoretical calculation. The proportional strain is $993.47 \times 10^{-6}$ equivalent to the theoretical calculation value. It proves the correctness of the calculation. The critical force of columns of high-strength concrete-filled square steel tube with internal CFRP circular tube with the buckling failure is $2419 \mathrm{KN}$ in this paper when the slenderness ratio is 100.5 ( $\mathrm{L}=5800 \mathrm{~mm}$ which is less than the theoretical calculation value. The proportional strain is $957.47 \times 10^{-6}$. It indicates that the buckling damage is elastic buckling. 
The theoretical formula of limit slenderness radio of long columns of concrete-filled steel tube proposed by Zhong and Han [14] when elastic buckling occurs is shown as follows:

$$
\lambda_{p}=1811 / \sqrt{f_{y}}
$$

To put the yield strength of steel into the expression can be obtained that the theoretical limit slenderness ratio of elastic buckling is $\lambda_{p}=101.2$. In the paper, the limit slenderness ratio is 93.5 when elastic buckling occurs on long column of concrete-filled square steel tube under axial compression. The limit slenderness ratio is 100.5 when elastic buckling occurs on long column of concrete-filled square steel tube with inner CFRP circular tube under axial compression. The difference between the calculated limit slenderness ratio and that of finite element simulated is small and shows the accuracy of the calculation.

\section{CONCLUSIONS}

(1) The finite element analysis on long columns of high-strength concrete-filled square steel tube with inner CFRP circular tube under axial load can be conducted by ABAQUS 6.7 perfectly. And the results of finite element analysis show a good agreement with the experimental results.

(2)According to the analysis on the core concrete stress of long columns of high-strength concrete-filled square steel tube with internal CFRP circular tube under axial compression, when the columns achieve the ultimate bearing capacity, the longitudinal stress distribution of sandwich concrete and that of core concrete are uneven and the core concrete is the primary part to bear the load.

(3)When long columns of high-strength concrete-filled square steel tube with internal CFRP circular tube reaches the ultimate bearing capacity, steel tube has reached its yield limits.

(4)The analysis results of long columns of high-strength concrete-filled square steel tube with inner CFRP circular tube under axial compressive show that, the confinement effect of CFRP on core concrete is small before components reach the ultimate bearing capacity. After the ultimate bearing capacity, CFRP circular tube begins to play a significant role in confinement effect on the core concrete.

(5)According to the results of finite element simulation on the specimens, the critical forces of all specimens under axial compression are depended on the slenderness ratio. The smaller the slenderness ratio $\lambda$ is, the greater the critical force is and the greater the limit deformation is.

(6) The limit slenderness ratio is 93.5 when elastic buckling occurs on the long column of concrete-filled square steel tube under axial compression. The limit slenderness ratio is 100.5 when elastic buckling occurs on the long column of concrete-filled square steel tube with inner CFRP circular tube under axial compression. These results have been verified by theoretical calculation. 


\section{ACKNOWLEDGEMENTS}

This project was supported by National Science Foundation of China (50678106), Shenyang Talent Development Fund (2009140403038), Liaoning BaiQianWan Talents Program (2010921001), Liaoning Talents Program (LR2011014) and Technology Development Program of Ministry of Housing and Urban-Rural Development (2011-k3-23).

\section{REFERENCES}

[1] Cai, S.H. and Gu, W.L., "Behaviour and Ultimate Strength of Long Concrete-Filled Steel Tubular Columns", Journal of Building Structures, 1985, Vol. 6, No. 1, pp. 32-40.

[2] Tan, K.F., Pu, X.C. and Cai, S.H., "The Study of Mechanics and Ultimate Bearing Intensity of Super High-strength Concrete Filled Steel Tube", Architecture Structure Journal, 1999, Vol. 20, No. 1, pp. 10-11.

[3] Han, L.H., "Technology of Modern Concrete Filled Steel Tube", China Architecture \& Building Press, 2007.

[4] Zhong, S.T., "Research and Application of Unified Theory of Steel Concrete", Tsinghua University Press, 2006.

[5] Liang, Q.Q., Uy, B. and Liew, J.Y.R., "Strength and Ductility of Concrete-filled Thin-walled Steel Box Columns with Local Buckling Effects", Special Issue Australian Journal of Structural Engineering, 2007, Vol. 7, No. 2, pp. 145-156.

[6] Liang, Q.Q., Uy, B. and Liew, J.Y.R., "Local Buckling of Steel Plates in Concrete-filled Thin-walled Steel Tubular Beam-columns", Journal of Constructional Steel Research, 2007, Vol. 63, No. 3, pp. 396-405.

[7] Liang, Q.Q., Uy, B. and Liew, J.Y.R., "Nonlinear Analysis of Concrete-filled Thin-walled Steel Box Columns with Local Buckling Effects", Journal of Constructional Steel Research, 2006, Vol. 62, No. 6, pp. 581-591.

[8] Mursi, M. and Uy, B., "Behaviour and Design of Fabricated High Strength Steel Columns Subjected to Biaxial Bending, Part 1: Experiments", Journal of Advanced Steel Construction, Hong Kong Institute of Steel Construction, 2006a, Vol. 2, No. 4, pp. 286-315.

[9] Mursi, M. and Uy, B., "Behaviour and Design of Fabricated High Strength Steel Columns Subjected to Biaxial Bending, Part 2: Analysis and Design Codes", Journal of Advanced Steel Construction, Hong Kong Institute of Steel Construction, 2006b, Vol. 2, No. 4, pp. 316-354.

[10] Li, G.C., Ma, L. and Yang, J.L., "Bearing Capacity of Short Columns of High-Strength Concrete Filled Square Steel Tubular with Inner CFRP Circular Tubular under Axially Compressive Load", Natural Science, Journal of Shenyang Jianzhu University, 2008, Vol. 24, No. 1, pp. 62-64.

[11] Abdel-Rabman and Sivakumaran, K.S., "Material Properties Models for Analysis of Cold-formed Steel Members", Journal of Structural Engineering, 1997, Vol. 123, No. 9, pp. 113-1143.

[12] Liu, W., "The Study of Working Mechanism of Concrete Filled Steel Tube under Partial Compression", Journal of Harbin Institute of Technology, 2003, Vol. 35, pp. 63-66.

[13] Gu, W.P., Cai, S.H. and Feng, W.L., "The Study of Function and Ultimate Bearing Intensity of High-strength Concrete Filled Steel Tube", Architecture Science, 1991, Vol. 7, No. 1, pp. 23-24.

[14] Zhong, S.T. and Han, L.H., "Steel Tube Concrete Mechanic", Dalian University of Technology Press, 1996. 


\title{
PUSH-OUT EXPERIMENTS OF HEADED SHEAR STUDS IN GROUP ARRANGEMENTS
}

\author{
Milan Spremic ${ }^{1 *}$, Zlatko Markovic ${ }^{1}$, Milan Veljkovic ${ }^{2}$ and Dragan Budjevac ${ }^{3}$ \\ ${ }^{1}$ Faculty of Civil Engineering, University of Belgrade, Bulevar kralja Aleksandra 73, 11000 Belgrade, Serbia \\ ${ }^{2}$ Department of Civil, Environmental and Natural Resources Engineering, Luleå University of Technology, \\ S-97187 Luleå, Sweden \\ ${ }^{3}$ Faculty of Civil Engineering University of Belgrade, Bulevar kralja Aleksandra 73, 11000 Belgrade, Serbia \\ *(Corresponding author: E-mail: spremic@imk.grf.bg.ac.rs)
}

Received: 2 March 2012; Revised: 13 May 2012; Accepted: 23 July 2012

\begin{abstract}
Precast concrete slabs connected to the steel beams by headed shear studs arranged in groups may be used in high-rise office buildings to speed up construction process and improve quality by increasing the grade of industrialization. The paper presents experimental research performed on push-out tests at the Faculty of Civil Engineering University in Belgrade. The main goal has been to investigate possible reductions (if any) of shear stiffness and strength of five group arrangements consisting always of four headed shear studs, the shank diameter 16 $\mathrm{mm}$ and $100 \mathrm{~mm}$ height. A shape of group arrangement and its orientation to the applied load, and distance between the studs were variables considered. Intention was to have as small as possible holes in precast concrete slabs so the distance between studs was lower than minimum required in Eurocode 4 [1]. Comparison is made with results obtained on specimen with uniformly distributed shear studs, according to requirements of the standard arrangement [1]. Material characteristics were obtained and push-out tests were preformed in procedures that fully comply with Eurocode 4.
\end{abstract}

Experimental results were evaluated according to the design models in Eurocode 4 and available literature, Okada-Yoda-Lebet [2]. Recommendations for use of the group arrangements were proposed.

Keywords: Headed studs, Group arrangement of stud connectors, Steel-concrete composite beams, Prefabricated concrete slab

\section{INTRODUCTION}

Devices used to establish transfer of longitudinal shear force between the steel beam and concrete slab strongly influence structural characteristics of a composite structure. In composite floors of high-rise buildings, the headed shear studs welded to a steel flange and encased in concrete is the most common way to insure composite action. Continuous and uniform distribution of headed studs on the flange of the steel beam results in considerable limitations for use of prefabricated composite floors. Groups of headed studs placed at the predefined positions matching openings of the prefabricated reinforced concrete slab are often used for insuring the effective composite action. In Eurocode 4, for the composite bridges EN1994-2 [3] design of discontinuously placed headed studs is allowed. A group of headed studs is allowed in the most heavily loaded zones of beams (close to the supports).

If the recommendation of the minimum spacing between the individual headed studs $(5 d$ in the force direction) is strictly considered, a larger number of grouped shear studs would require larger dimensions of openings in the prefabricated slab. The minimum allow space between the headed studs in the direction perpendicular to the force $(2,5 d)$ is practically equal to the minimum spacing due to the welding. This is defined by the dimensions of equipment for automatic welding. For this reason, a possibility of reducing the distance between the headed studs in the force direction is analyzed. 
Shim et al. [4] analyzed the shear resistance of the group of 9 headed studs $25 \mathrm{~mm}$ in diameter as a function of the distance between the studs which are smaller than the stipulated distance of the $5 d$. Josef Hegger et al. [5] considered shear resistance of two headed studs placed at the distance of $2 d$, in the force direction and a comparison with the shear resistance of specimens with two studs at the distance $2,5 d$ was presented. For the sake of comparison, in experiments shown in this paper the concrete with lower strength and headed studs with the higher ratio $h_{\mathrm{sc}} / d$ are used.

Shim et al. [4] propose reduction for the shear resistance of studs in a group compare to the sum of shear resistance of individual studs. This reduction of $30 \%$ for a group of headed studs at a distance of $3 d$ in the force direction is certainly a function of the distance between them. However, Hegger et al. [5] presented results of the experiment where they concluded that the shear resistance of two headed studs at the distance of $2 d$ in the force direction was only $5.4 \%$ lower than the sum of individual shear resistances. Hegger et al. [5] used high strength concrete which gave smaller reduction of the shear resistance. Okada et al. [2] analyzed group of 9 studs with different distances between studs (from $3 d$ to $13 d$ ) in force direction and with various concrete strength. The interaction of reinforcement layout and shear resistance was experimentally analyzed, as well. In our experiments, the specimens were made of the standard concrete strength.

Load-slip characteristic of single headed stud in the shear connection is rather well known and described in literature, [6] and [7], but there are no many data on load-slip characteristics of the group of studs. No information and recommendations on the relationship between the load-slip characteristic of individual headed stud and the load-slip characteristic of the group of studs with nominally identical resistance are available.

The shear resistance of studs is dependent on several parameters, such as: the stud material, diameter of the stud, strength and elasticity modulus of concrete in which the stud is installed. Experiments on the shear resistance of an individual stud, which have been conducted for decades, have demonstrated that the strength of concrete, height of headed studs, i.e. height/diameter ratio of studs $\left(h_{\mathrm{sc}} / d\right)$ are the most influential parameters for the shear resistance. Current design codes [1], [3], [8] take into account the effects of height/diameter ratio $\left(h_{\mathrm{sc}} / d\right)$ explicitly on the shear resistance.

This paper provides information on experimental part of the ongoing research project on headed shear stud behavior in a composite structure with a prefabricated concrete slab.

The main goal of these experiments is to investigate potential of reducing spacing between the headed studs, less than the minimum recommended value of $5 d$ in the force direction. The specimens with groups of 4 headed studs $d=16 \mathrm{~mm}$ in diameter and the height $h_{\mathrm{sc}}=100 \mathrm{~mm}$ have been used. In total, 25 specimens have been tested on the standard push-out test. The arrangement of headed studs within a group, as well as the orientation of the group to the direction of the load action, have been varied.

\section{TEST SET-UP}

The specimens included in this research are made and tested in accordance with the Annex B of Eurocode 4. They consist of: two prefabricated reinforced concrete slabs and the steel beam HEB260 with groups of headed studs welded by standard automatic procedure (Drawn Arc Stud Welding). Three types of prefabricated slabs have been used (Figure 1). All concrete slabs have standard dimensions, 600x650 mm, and they have openings for accommodating the groups of headed studs, which are located almost in the middle of the slab. Slab Type 1 has a standard 
dimensions acc. to the Annex B of the Eurocode4 [1] and the opening 240x240 mm. Type 2 is modified, a reduced size of the opening to $140 \times 240 \mathrm{~mm}$ (Figure 1b). Type 3 has same dimensions (the same opening) as the Type 2, but without transversal reinforcement passing through the opening (Figure 1c). This modification is done to analyze possible effect of the reinforcement on the behavior of the group of studs in the shear connection. All slabs are constructed with concrete of the C30/37 class and reinforced by the ribbed reinforcement $\varnothing 10 \mathrm{~mm}$ of the class B500. The production of precast concrete slabs was realized in precast concrete elements workshop. Three standard cubes $150 \mathrm{~mm}$ were used for compressive strength test for each concrete mixture. Tension strength was determined by bending test on prisms $100 \times 100 \times 400 \mathrm{~mm}$, also for each concrete mixture.

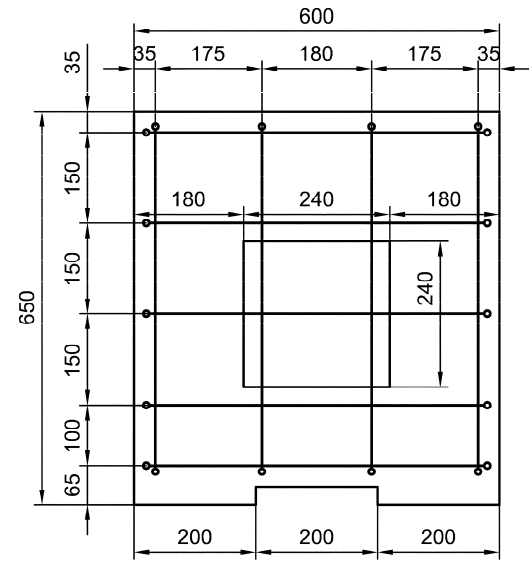

a) Type 1

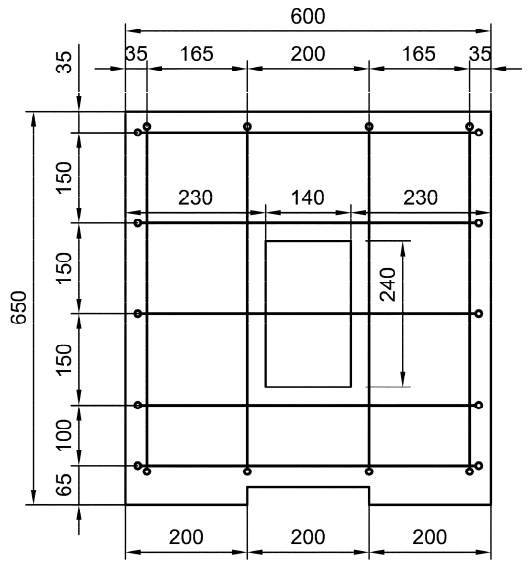

a) Type 2

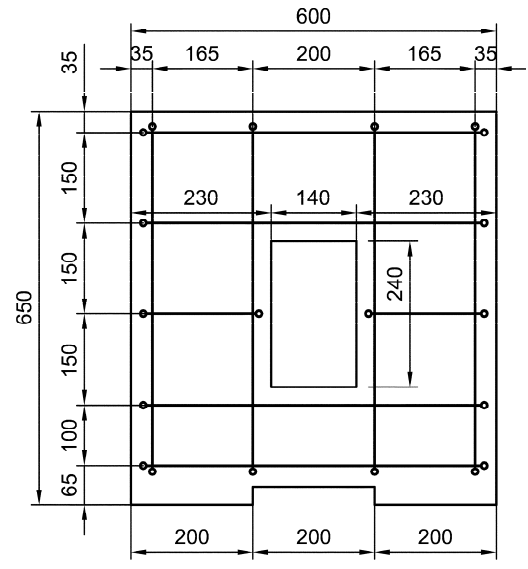

a) Type 3

Figure 1. Types of Reinforced Concrete slabs

Specimens were casted in the laboratory. After assembling of prefabricated RC slabs into precisely defined positions, the slab openings were filled in. The in-fill material was concrete with strength ranging from $f_{\mathrm{ck}}=32-40 \mathrm{MPa}$, and with small shrinking dilatation. Mix proportion for infill concrete is presented in Table 1 . The water-cement ratio was 0.52 . For infill concrete, three grain size of river aggregate and two admixtures were used (shrinkage-reducing and super-plasticizer) as presented in Table 1.

Table 1. Mix Proportion for Infill Concrete

\begin{tabular}{|c|c|c|c|c|c|c|}
\hline \multicolumn{9}{|c|}{ Mixture components [kg/m3] } \\
\hline \multirow{2}{*}{$\begin{array}{c}\text { Cement } \\
\text { 42,5R }\end{array}$} & \multirow{2}{*}{ Water } & Sand & \multicolumn{2}{c|}{$\begin{array}{c}\text { Rounded (River) } \\
\text { gravel aggregate }\end{array}$} & \multicolumn{2}{c|}{ Admixtures } \\
\cline { 3 - 7 } & & $0-4$ & $4-8$ & $8-16$ & shrinkage-reducing & super-plasticizer \\
\hline 320 & 162 & 822 & 478 & 611 & 6.4 & 1.92 \\
\hline
\end{tabular}

According to Eurocode 2, the maximum diameter of an aggregate is in relation with the minimum clear distance between rebar (in this case headed studs). The minimum clear distance between headed studs is $29 \mathrm{~mm}$. For the development of an adequate bond between the concrete and rebar, and satisfactorily placed and compacted concrete between headed studs, the maximum nominal aggregate size $16 \mathrm{~mm}$ was adopted.

Using concrete shrinkage reduction admixtures, 20\% smaller shrinkage dilatation have been obtained than the design values according to the Eurocode 2 [9], see Figure 2. By measuring the shrinkage on the control prisms, shrinkage dilatation of 250x10-6, have been obtained for the age of concrete of 45 days at the air temperature of $20-25{ }^{\circ} \mathrm{C}$ and the relative humidity of $23 \pm 2 \%$. 

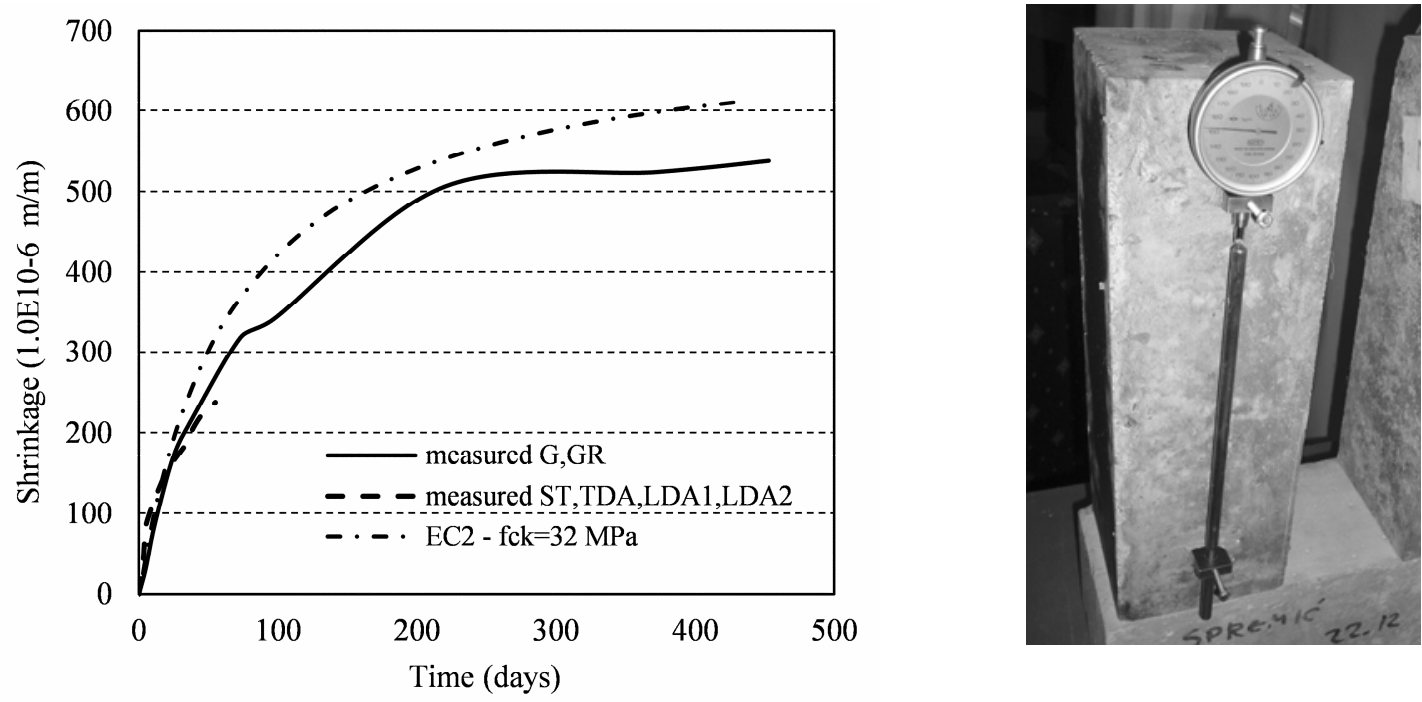

Figure 2. a) Shrinkage dilatation of the concrete in time, b) The Test Layout

Okada et al. [2] has analyzed the bond-friction effects between steel section and concrete slab. Their conclusion is that about $10 \%$ of total shear resistance of headed studs is achieved by bond-friction stresses.

The unreliable and brittle failure mode of the chemical bond between steel and concrete are reasons not to take the bond-friction stresses in design of composite beam. In our research, the chemical bond force between the concrete and steel beam was eliminated, as suggested in Eurocode 4 [1] in B.2.3(2). The surface of the steel beam was oiled prior to the assembling, to prevent chemical bond between the concrete and the steel beam. Just prior to the monolitization, surfaces of prefabricated slabs, which are in direct contact with fresh infill concrete, have been painted with the coating for contact joints between old and fresh concrete. Filling of concrete was performed in a position as shown in Figure 3. Three days after concreting of one side of the specimen, the specimens were reversed, and the other side of the specimens was completed. The infill concrete achieved full design strength 14 days after concreting (Figure 4). The samples are tested 21 days after placing concrete on the reverse side, meaning 24 days after placing concrete on the first side of the specimen. From the concrete strength diagram as the function of the concrete age (Figure 4) it can be seen that no significant increase of the concrete strength occurred after 21 days.

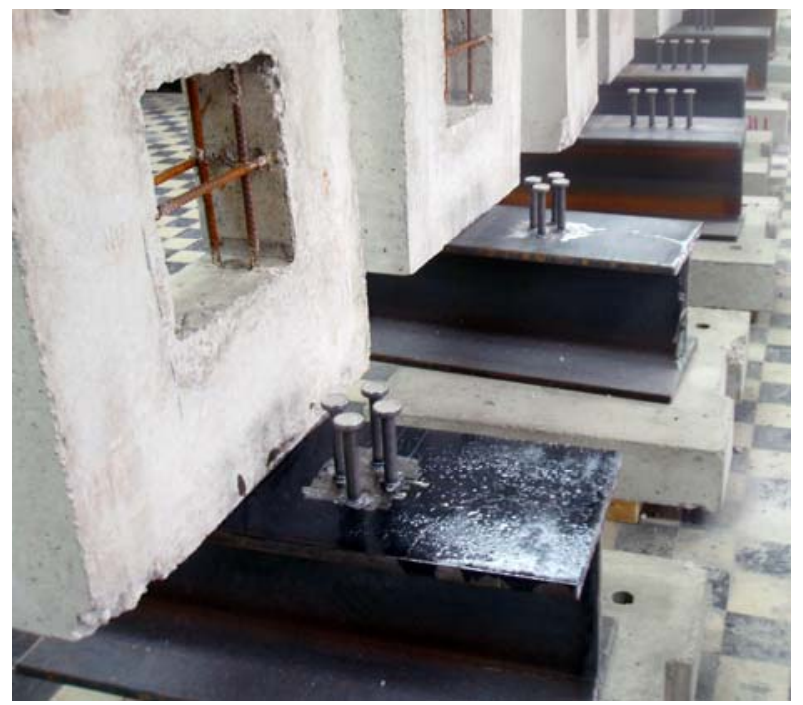

Figure 3. The Slabs Prior to Assembling 


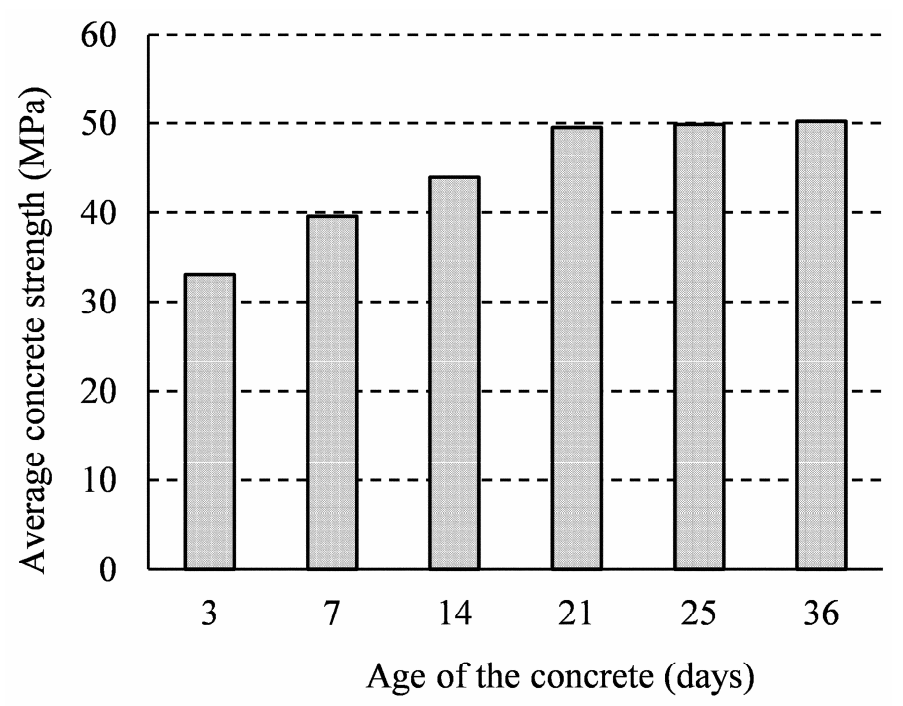

Figure 4. Increase of the Concrete Strength

The vertical force was applied by the hydraulic jack having the capacity of $3500 \mathrm{kN}$, in displacement control. In the first phase of testing, the specimens were loaded with cyclic loading. The load was applied in 26 cycles. In the first cycle, the load was applied incrementally, in three steps from $90 \mathrm{kN}$ to the force of $270 \mathrm{kN}$, which is around $40 \%$ of the expected value at failure. Then the specimen is unloaded to $32 \mathrm{kN}$. The remaining 25 cycles comprised of loading of the specimen to $270 \mathrm{kN}$ and it's unloading to $32 \mathrm{kN}$. After the last cycle of the first phase, the load was applied continually until failure, ensuring that specimen failure occurs 20-25 minutes since the start of load application in the last cycle. In order to reduce eccentricity, and to provide good contact of the specimen and the jack, the specimen was placed into the layer of fresh gypsum prior to mounting on the press. The jack headed is equipped by a spherical bearing. The force was monitored via the control board of the hydraulic jack and with the aid of load cells for measuring pressure force, manufactured by "Hottinger" having measuring range up to $1000 \mathrm{kN}$. During the test, slip of the steel beam in respect to the concrete slabs was monitored in four points, two points per each concrete slab, by the Linear Variable Displacement Transducer (LVDT sensors) no. 1, 2, 6, 7 from the Figure 5a. The transversal deflection - separation of the concrete slabs from the steel beam was also monitored in two points (LVDT sensors no. 3 and 4). Positions of the measuring points 3 and 4 are approximately at the location of the stud group. Horizontal separation between concrete slabs was monitored too. One sensor for monitoring of the slabs separation was placed at the location of the stud's group (sensor 8) while the other one, sensor number 5, was placed at 150 $\mathrm{mm}$ from the lower edge of the specimen. For LVDT sensor layout see Figure 5a. The deflections were monitored by inductive deflectometers "Hottinger". Data acquisition was performed continually by MGC+ "Hottinger" with the data recording frequency of $0,5 \mathrm{~Hz}$ and $1,0 \mathrm{~Hz}$. 

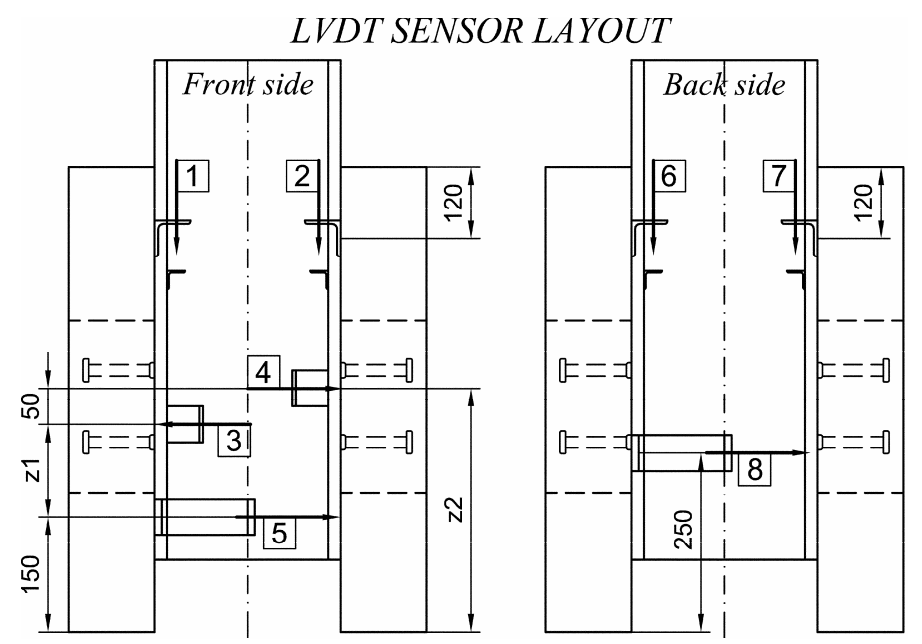

1,2,6,7 - LVDT sensors for longitudinal slip

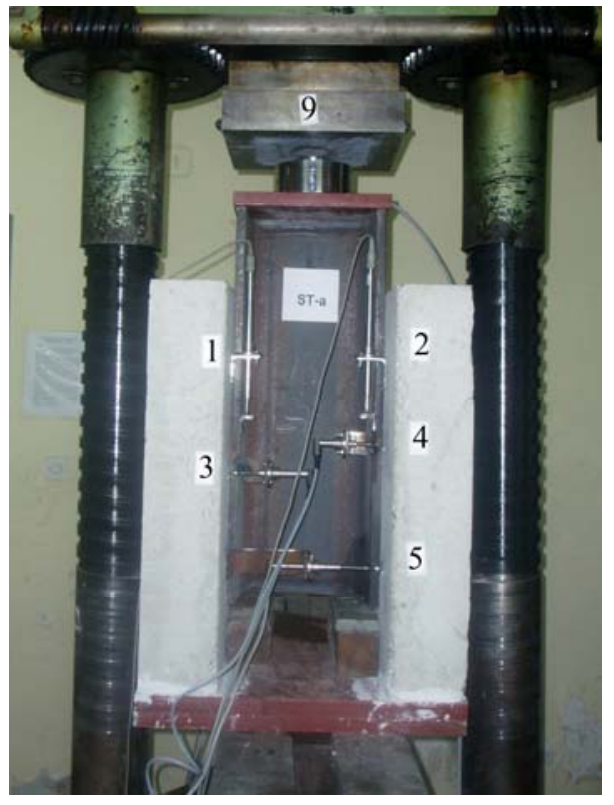

3,4 - LVDT sensors for transverse separation between the steel section and concrete slab 5,8 - LVDT sensors for transverse separation between the concrete slabs

Figure 5. a) Layout of Measuring Points, b) Equipped Specimen Ready for Testing

\section{THE GROUP ARRANGEMENTS}

As the initial data for the analysis of shear resistance of the group of elastic headed studs, the shear resistance of the single headed stud was adopted. The shear resistance of headed stud having diameter $d=16 \mathrm{~mm}$ and the height $h_{\mathrm{sc}}=100 \mathrm{~mm}$ as the function of concrete strength is presented by the diagram of the Figure 6.

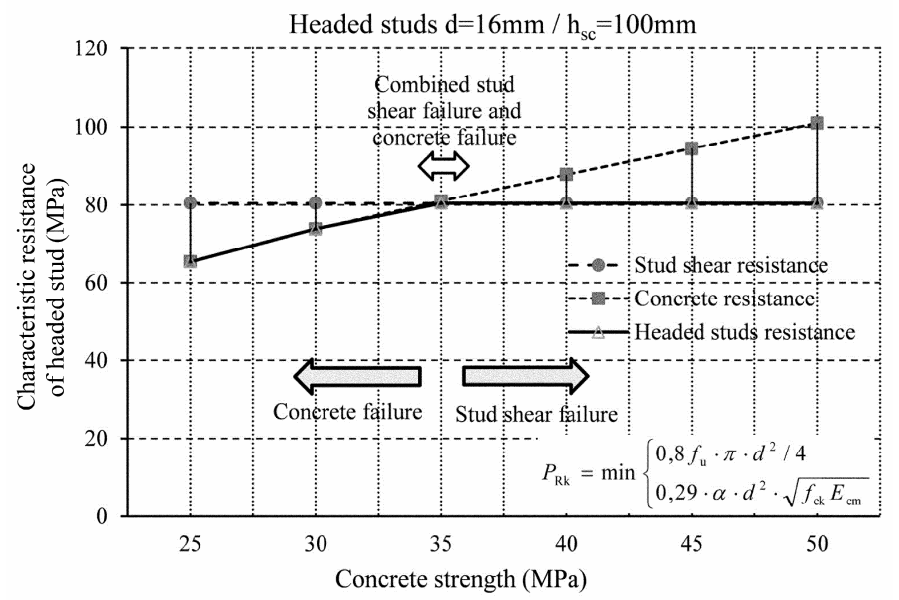

Figure 6. Resistance of Headed Studs as the Function of Nominal Concrete Strength [1]

Analyzing characteristic shear resistance of headed studs as the function of the concrete strength, (Figure 6), three failure modes can be observed: the shear stud failure, the concrete failure, and a combined failure mode. The combined failure mode is characterized by the crushing failure of concrete in the zone around the studs along with the shear failure of headed studs. If the characteristic strength of concrete has lower values $\left(f_{\mathrm{ck}}<35 \mathrm{MPa}\right)$, the failure of the concrete around the headed studs is expected. For the characteristic concrete strength of around $f_{\mathrm{ck}}=35 \mathrm{MPa}$, concrete failure around the connector and stud shear failure are approximately equal, so the combined failure is expected, while for the concrete strengths higher than $f_{\mathrm{ck}}=40 \mathrm{MPa}$ stud shear failure can be expected. 
To determine the expected shear resistance of a group of headed studs, the mechanical properties of the headed stud material were examined, the properties of the concrete used for monolitization of specimens. A characteristic stress-strain diagram of a shear stud was obtained using the coupon test, see Figure 7. Mechanical properties of concrete are given in Table 2.
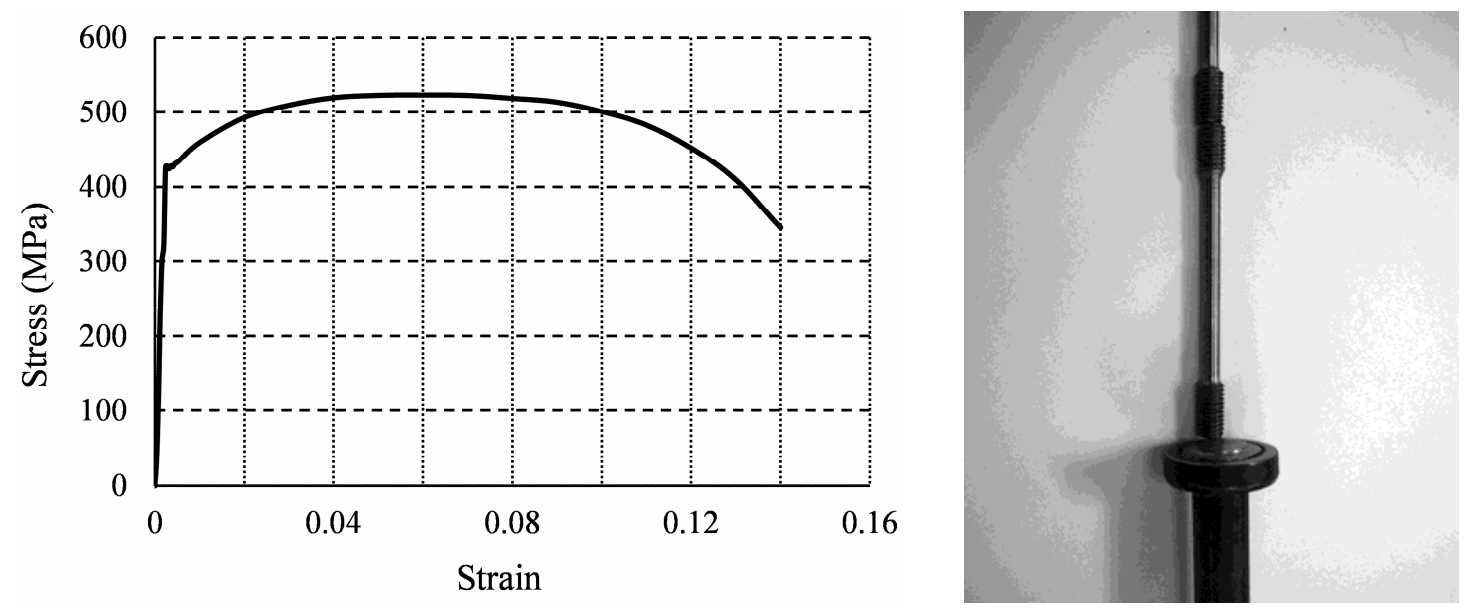

Figure 7. Characteristic Stress-strain Diagram for the Headed Stud Material

Experiment study included a total of 5 arrangements of studs. All the specimens were constructed with a total of 8 studs, four studs on each side. In the first phase of testing, four different layouts of headed studs groups were constructed. The standard specimen ST (standard test) consists of the group of four studs, $16 \mathrm{~mm}$ in diameter, on one side of the specimen. It has the arrangement which is fully according to Eurocode 4 (Figure 8a). The TDA (transversal distance arrangement) specimen types (Figure 8b) include the case when the same number of headed studs is placed in one row transversally in relation to the direction of the load, with the distance equal to the minimum distance [1] of $40 \mathrm{~mm}(2,5 d)$. In the group with LDA1 (longitudinal distance arrangement - type 1) specimens, there are four studs in the group, also placed in one row along the direction of the load, at a distance of $50 \mathrm{~mm}(\approx 3 d)$, which is less than the required minimal distance between the headed studs according to design codes (EC4). The last group specimens - LDA2 (longitudinal distance arrangement -type 2) was constructed using the rhomboid arrangement of four studs. The distance in the direction of the load is smaller than with those stipulated by design codes (Figure 8c).

The second phase of research included two new layouts of specimens: type G1 (group arrangement without reinforcement) (Figure 8e) and type GR1 (group arrangement with reinforcement) (Figure $8 \mathrm{f})$. Since obtained values of the shear resistance of specimens in the first phase of the experiment were higher than expected, the distance between studs were reduced to $45 \mathrm{~mm}(\approx 2,5 d)$ in the second phase. Type G1 specimens were formed with Type 3 concrete slabs (Figure 1c) with no reinforcement in the opening. GR1 specimens were formed with Type 2 concrete slabs. Considering that the headed stud shear failure was relevant for all the tested specimens in the first phase, the specimens in the second phase were monolitized with a slightly lower strength concrete instead of one having $f_{\mathrm{ck}}=40 \mathrm{MPa}$ (see Table 2 ). In the second phase, it was also analyzed to what extent the reinforcement in the opening affects the shear resistance of the headed studs group. 


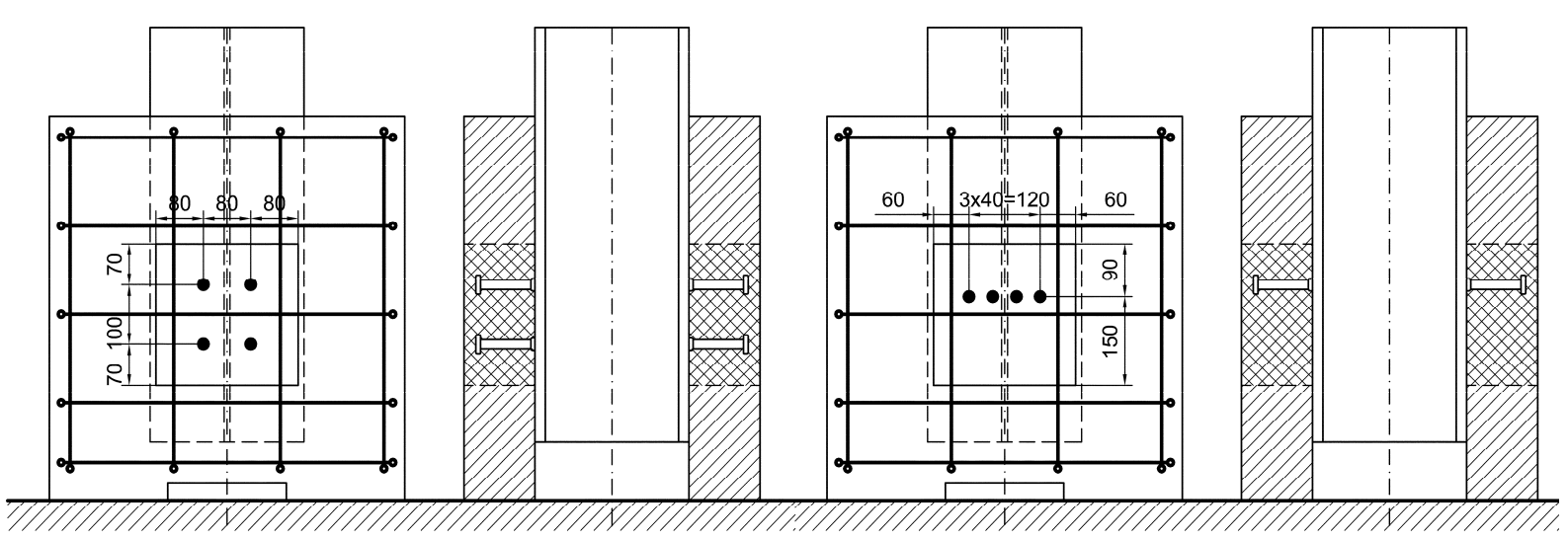

a) Specimens type $S T$ - studs $4 \circ \varnothing 16$

b) Specimens type TDA - studs $4 \circ \varnothing 16$

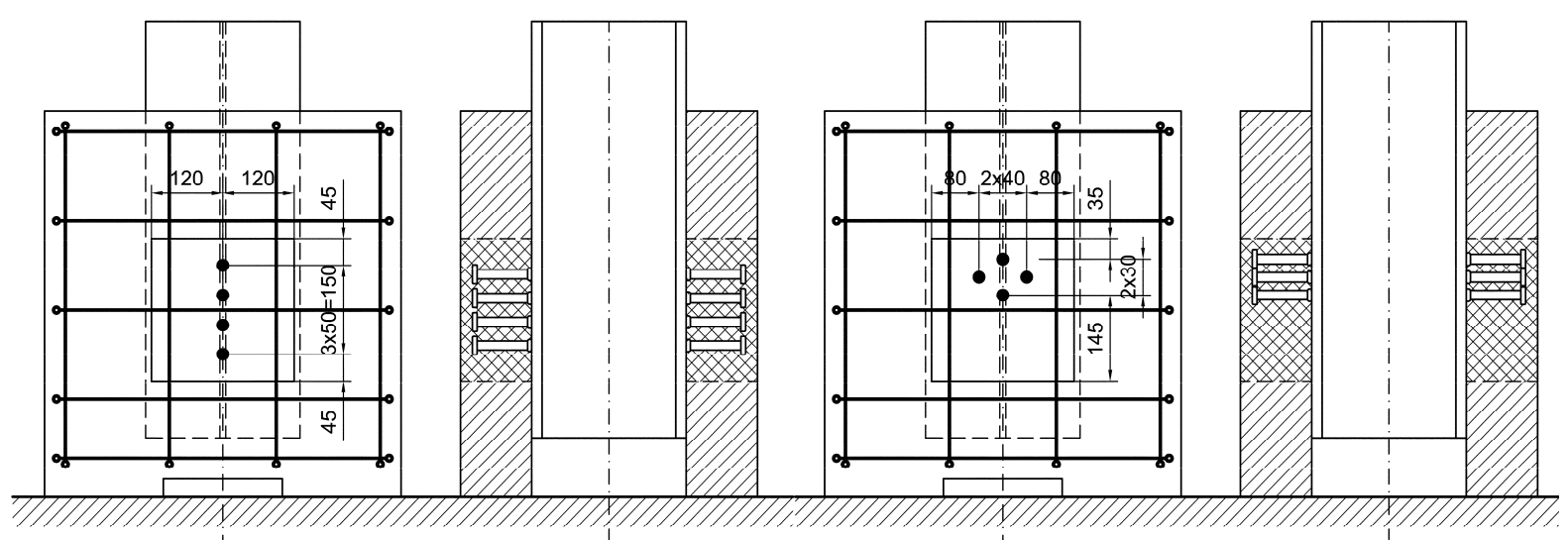

d) Specimens type LDA1 - studs $4 \circ \varnothing 16$

c) Specimens type LDA2 - studs $4 \circ \varnothing 16$

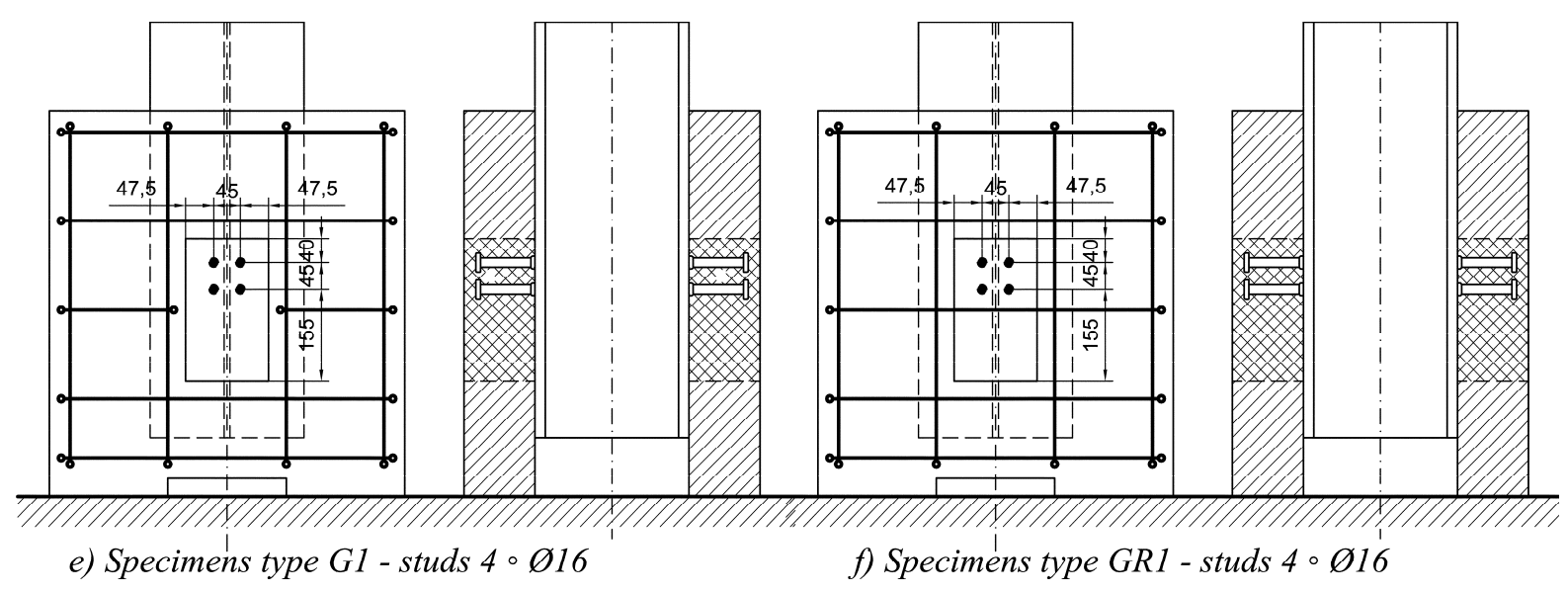

Figure 8. Layout of Specimens

\section{TEST RESULTS}

An overview of experimental results is shown in Table 2. In the column (2) and (3) are presented the strengths of infill concrete of the front/back side of the specimen. The average value of maximum slip at failure $\delta_{\max }$, between the concrete slab and steel flange, is presented in the column (7). In the column (8) is presented slip which corresponding the force value of $500 \mathrm{kN}$. The force of $500 \mathrm{kN}$ is slightly higher than the force which corresponds to the service load (limit state of serviceability). The stiffness of shear connection $k_{\mathrm{sc}}$ (for eight studs) is also presented in the table for all 25 tested specimens (9). Column (10) of Table 2 presents the ratio of measured shear resistance of specimens $\left(F_{\mathrm{u}}\right)$ and characteristic design shear resistance in accordance with [1], which was determined on the basis of actual experimental characteristics of the material $F_{\text {Rk,exp. }}$. 
$F_{R k, \text { exp }}=8 \cdot\left[0,29 \cdot 1,0 \cdot(16 \mathrm{~mm})^{2} \cdot \sqrt{f_{\mathrm{ck}} \cdot E_{\mathrm{cm}}}\right] \leq 8 \cdot\left[0,8 \cdot 523 \mathrm{MPa} \cdot \frac{\pi \cdot(16 \mathrm{~mm})^{2}}{4}\right]$

Table 2. Shear Resistance of Specimens

\begin{tabular}{|c|c|c|c|c|c|c|c|c|c|}
\hline \multirow{2}{*}{ Specimen } & $f_{\mathrm{c}, \text { cube,infill }}$ & $f_{\text {ck,infill }}$ & $f_{\text {ck,plate }}$ & $E_{\mathrm{cm}}$ & $F_{\mathrm{u}}$ & $\delta_{\max }$ & $\delta(500 \mathrm{kN})^{*}$ & $k_{\mathrm{sc}}$ & $F_{\mathrm{u}} / F_{\mathrm{Rk}, \exp }$ \\
\hline & {$[\mathrm{MPa}]$} & {$[\mathrm{MPa}]$} & {$[\mathrm{MPa}]$} & [MPa] & {$[\mathrm{kN}]$} & {$[\mathrm{mm}]$} & {$[\mathrm{mm}]$} & {$[\mathrm{MN} / \mathrm{mm}]$} & {$[-]$} \\
\hline (1) & (2) & (3) & (4) & (5) & (6) & (7) & (8) & (9) & (10) \\
\hline ST a & $47.6 / 47.6$ & 39.6 & 30.7 & 36800 & 726.8 & 6.10 & 0.64 & 0.995 & 1.08 \\
\hline ST b & $47.6 / 47.6$ & 39.6 & 28.9 & 36800 & 737.0 & 5.80 & 0.47 & 1.308 & 1.10 \\
\hline ST c & $47.6 / 50.0$ & 40.8 & 30.7 & 36800 & 770.8 & 6.60 & 0.52 & 1.204 & 1.15 \\
\hline TDA a & $49.0 / 50.0$ & 41.5 & 30.7 & 36800 & 735.6 & 7.76 & 0.52 & 1.188 & 1.09 \\
\hline TDA b & $48.0 / 49.3$ & 40.65 & 30.7 & 36800 & 764.7 & 7.27 & 0.45 & 1.363 & 1.14 \\
\hline TDA c & $47.6 / 49.3$ & 40.65 & 30.7 & 36800 & 762.2 & 8.22 & 0.49 & 1.219 & 1.13 \\
\hline LDA1 a & $49.0 / 47.6$ & 40.3 & 28.9 & 36800 & 799.4 & 13.0 & 0.60 & 1.276 & 1.19 \\
\hline LDA1 b & $48.0 / 49.3$ & 40.65 & 28.9 & 36800 & 784.7 & 10.7 & 0.52 & 1.400 & 1.17 \\
\hline LDA1 c & $48.0 / 50.0$ & 41.0 & 30.4 & 36800 & 686.1 & 9.0 & 0.68 & 1.142 & 1.02 \\
\hline LDA1 d & $39.3 / 42.0$ & 32.65 & 33.1 & 34200 & 722.5 & 8.16 & 0.74 & 1.077 & 1.15 \\
\hline LDA1 e & $39.3 / 42.0$ & 32.65 & 33.1 & 34200 & 643.2 & 6.86 & 0.75 & 1.121 & 1.02 \\
\hline$\overline{\text { LDA2 a }}$ & \begin{tabular}{|l|}
$47.6 / 47.6$ \\
\end{tabular} & 39.6 & 28.9 & 36800 & 744.5 & 8.25 & 0.570 & 1.045 & 1.11 \\
\hline LDA2 b & $47.6 / 49.3$ & 40.65 & 28.9 & 36800 & 757.6 & 6.98 & 0.520 & 1.202 & 1.13 \\
\hline LDA2 c & $47.6 / 50.0$ & 40.8 & 30.4 & 36800 & 758.3 & 5.94 & 0.490 & 1.302 & 1.13 \\
\hline G1 a & $39.3 / 42.0$ & 32.6 & 29.8 & 34200 & 769.2 & 13.9 & 0.56 & 1.137 & 1.23 \\
\hline G1 b & $39.3 / 43.0$ & 33.2 & 29.8 & 34200 & 740.2 & 12.5 & 0.57 & 1.137 & 1.17 \\
\hline G1 c & $39.3 / 42.0$ & 32.6 & 29.8 & 34200 & 750.9 & 11.2 & 0.60 & 1.059 & 1.20 \\
\hline G1 d & $39.3 / 43.0$ & 33.2 & 29.8 & 34200 & 728.0 & 9.78 & 0.63 & 1.013 & 1.15 \\
\hline GR1 a & $39.3 / 42.0$ & 32.6 & 34.2 & 34200 & 758.0 & 12.5 & 0.64 & 0.973 & 1.21 \\
\hline GR1 b & $39.3 / 43.0$ & 33.2 & 34.2 & 34200 & 759.6 & 13.2 & 0.65 & 0.927 & 1.20 \\
\hline GR1 c & $39.3 / 42.0$ & 32.6 & 34.2 & 34200 & 752.0 & 1 & 0.53 & 1.127 & 1.20 \\
\hline GR1 d & $39.3 / 43.0$ & 33.2 & 34.2 & 34200 & 789.9 & 12.8 & 0.55 & 1.100 & 1.25 \\
\hline
\end{tabular}

Characteristic value of shear resistance for a group of studs have been determined using Annex B of Eurocode 4 [1], for series of three specimens, and in accordance with Annex D of Eurocode 0 [10], for series of four specimens.

If the deviation of individual measured parameter in respect to the average value is not higher than $10 \%$, the characteristic value of shear resistance can be determined according to the B.2.5 of Annex $\mathrm{B}$. The characteristic shear resistance of the specimen is equal to the minimum shear resistance of all the tested specimens reduced for $10 \%$ :

$F_{\text {stat } 1, \mathrm{Rk}}=0.9 F_{\mathrm{u}, \min }$

The characteristic values $F_{\text {stat1,Rk }}$ are shown in column (5) of Table 3. In column (6) of Table 3, the characteristic shear resistance $F_{\text {stat2,Rk }}$ according to the Annex D of Eurocode 0 are presented. The characteristic values $F_{\text {stat2,Rk }}$ of shear resistance according to the Eurocode 0, Annex D is: 
$F_{\text {stat } 2 \text { Rk }}=m_{\mathrm{X}}\left(1-k_{\mathrm{n}} V_{\mathrm{X}}\right)$

where are:

$m_{\mathrm{X}}$ average value,

$k_{\mathrm{n}}$ according to table D1 in [10] (for 4 specimens $k_{\mathrm{n}}=2,63$ ),

$V_{\mathrm{X}}=s_{\mathrm{X}} / m_{\mathrm{X}}$ coefficient of variation ( $s_{\mathrm{X}}$ is estimated value of standard deviation).

The characteristic values for series of three specimens obtained by Annex D and Annex B are almost equal.

Table 3. Characteristic Shear Resistance of the Group of Headed Studs

\begin{tabular}{|c|c|c|c|c|c|c|}
\hline Specimens & $F_{\mathrm{av}}$ & $\delta_{\mathrm{av}}$ & $F_{\mathrm{u}, \text { min }} / F_{\mathrm{u}, \text { max }}$ & $F_{\text {stat } 1, \mathrm{Rk}}$ & $F_{\text {stat } 2, \mathrm{Rk}}$ & $F_{\mathrm{Rk} \text {,exp }}$ \\
\hline & {$[\mathrm{kN}]$} & {$[\mathrm{mm}]$} & {$[-]$} & {$[\mathrm{kN}]$} & {$[\mathrm{kN}]$} & {$[\mathrm{kN}]$} \\
\hline (1) & (2) & (3) & (4) & (5) & (6) & (7) \\
\hline $\begin{array}{l}\mathrm{ST} \\
f_{\mathrm{ck}}=40 \mathrm{MPa}\end{array}$ & 370.6 & 6.1 & 0.94 & 327.0 & & 336.5 \\
\hline $\begin{array}{l}\text { TDA } \\
f_{\text {ck }}=40 \mathrm{MPa}\end{array}$ & 376.4 & 7.6 & 0.96 & 331.0 & & 336.5 \\
\hline $\begin{array}{l}\text { LDA1 } \\
f_{\text {ck }}=40 \mathrm{MPa}\end{array}$ & 368.8 & 9.4 & 0.86 & 308.7 & & 336.5 \\
\hline $\begin{array}{l}\text { LDA1 } \\
f_{\text {ck }}=32 \mathrm{MPa}\end{array}$ & 339.6 & 7.8 & 0.89 & / & 288.5 & 313.5 \\
\hline $\begin{array}{l}\text { LDA2 } \\
f_{\text {ck }}=40 \mathrm{MPa} \\
\end{array}$ & 372.6 & 7.1 & 0.98 & 335.0 & & 336.5 \\
\hline $\begin{array}{l}\mathrm{G} 1 \\
f_{\mathrm{ck}}=32 \mathrm{MPa}\end{array}$ & 375,7 & 13.1 & 0.95 & 333.1 & 350.5 & 314.5 \\
\hline $\begin{array}{l}\text { GR1 } \\
f_{\text {ck }}=32 \mathrm{MPa}\end{array}$ & 384,0 & 12.9 & 0.95 & 338.45 & 360.1 & 314.5 \\
\hline \multicolumn{7}{|c|}{$\begin{array}{l}F_{\text {stat } 1, \mathrm{Rk}} \text { Annex B }- \text { Eurocode } 4 \\
F_{\text {stat2,Rk }} \quad \text { Annex D }- \text { Eurocode } 0 \\
F_{\text {av }} \text {-average shear resistance of tested specimens } \\
\delta_{\text {av }}-\text { longitudinal slip that correspond to the average max. load }\end{array}$} \\
\hline
\end{tabular}

Average force-slip diagrams of each tested group are shown in Figure 9. Two reference values $F_{\mathrm{Rk} 1}$ and $F_{\mathrm{Rk} 2}$ for the diagrams presented in Figure 9, represent a characteristic design value of shear resistance calculated according to Eurocode 4 with actual characteristics of the materials used in experiments $F_{\mathrm{Rk} \text {,exp }}$.

The diagrams in Figure 9 clearly illustrate that the shear resistance of all the tested specimens is higher than the values of characteristic shear resistance $\left(F_{\mathrm{Rk}, \text { exp }}\right)$ given by [1] assuming no reduction due to a smaller space between studs. 


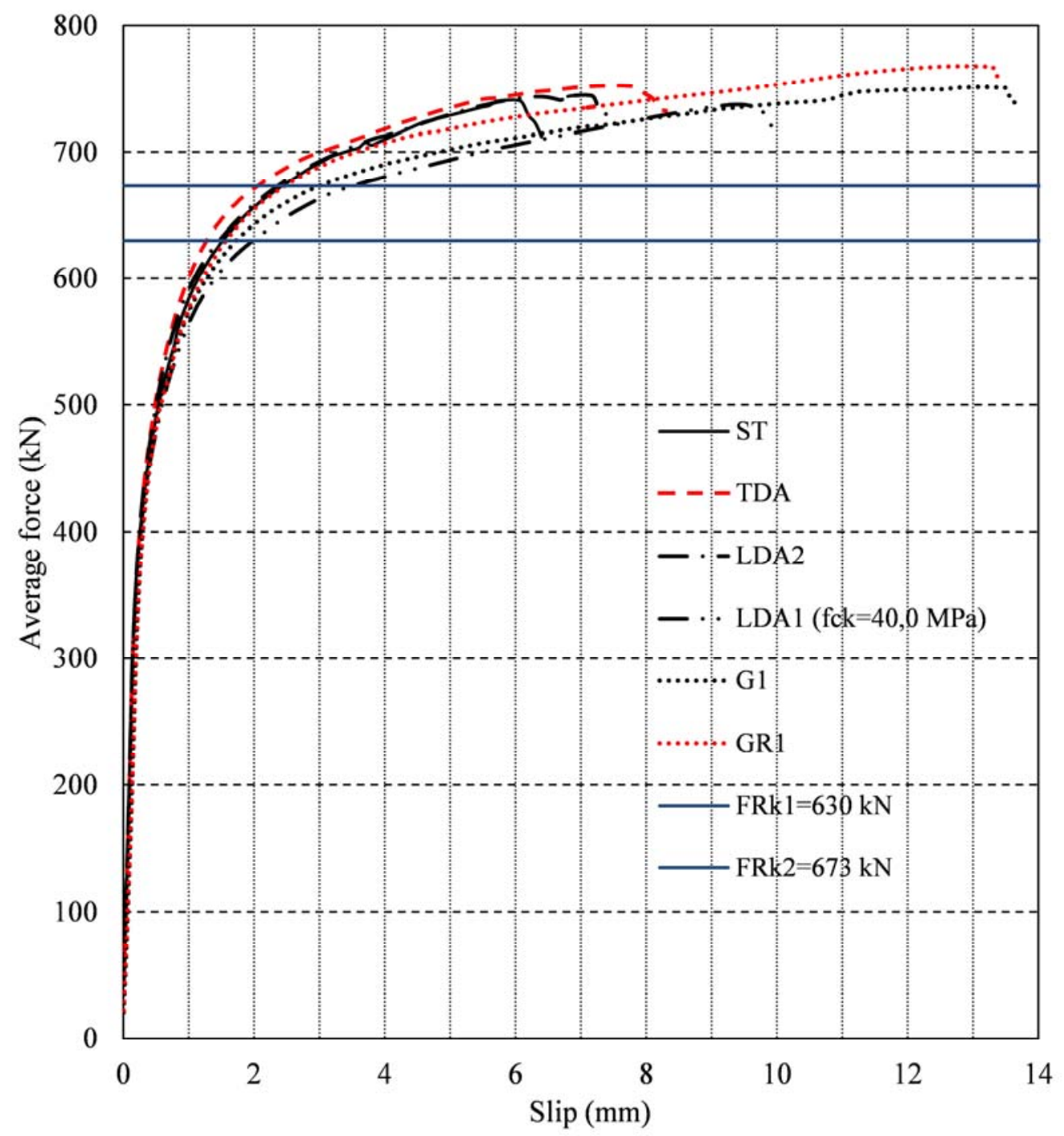

Figure 9. Load-slip Behavior for Test Specimens

\subsection{Characteristics of Failure Mechanisms}

The results of specimens ST, which comply with [1], create reference data for analysis of results and behavior of other specimen types. In case of specimens with group types ST, LDA1, LDA2 and TDA there was the shear failure of headed studs. The higher measured slip of the LDA1 type specimens, see Table 4, column (3), in respect to the ST specimens indicate that major plastic deformations (crushing) of concrete in the zone around the headed studs occurred.

In series G1 and GR1 the failure also occurred by shearing of the headed stud. However, in the case of G1 and GR1 series, considerably higher deformations at failure were measured, which was affected by application of lower strength of infill concrete $\left(f_{\mathrm{ck}}=32 \mathrm{MPa}\right)$ in respect to the infill concrete used for the first phase specimens. Higher deformations of G1 and GR1 specimens are also resulted by higher plastic deformations of concrete close to headed studs group, which gave rise to combined deformations of headed studs due to bending and tension.

The ST specimens failure, at the average value of ultimate force of $762 \mathrm{kN}$, occur to be shear of studs with the average ultimate deformation of $6.6 \mathrm{~mm}$. No cracks occurred in the reinforced concrete slab at failure. In the case of TDA type specimens, failure also occurs by studs shear, and the value of shear resistance is $754 \mathrm{kN}$ with the failure deformation of $7.75 \mathrm{~mm}$. Considering that 
the TDA specimens were constructed in full accordance with [1], in terms of arrangement of headed studs, such behavior of the specimen is expected. However, the TDA type specimen, showed considerable cracks in reinforced concrete slab around studs and in the slab area in front of the studs (see Figure 10a). The cracks appeared in concrete slab as early as with loads of $595 \mathrm{kN}$ to $620 \mathrm{kN}$. The onset of these cracks is caused by high tensile stresses, perpendicular to main compression stresses. The force flow (strut-and-tie model) and the scheme of the cracks in the concrete slab are presented in Figure 10a. It is clear that the concentration of the load, in the section of the slab at the location of the headed stud row, initiates the formation of two heavily compressed diagonals. In this way the infill part of concrete acts as rigid element to precast concrete slab. Higher strength of infill concrete slab compared to precast slab results in larger cracks of the precast slab. Confinement effects are neglected because the precast slab concrete has similar properties as the infill concrete. No separation between infill part of concrete and precast concrete slab was noticed.

Analyzing the presented mechanism of the load transfer, it is clear that by adequate layout of reinforcement in the slab, cracks could be reduced or even fully prevented.

Table 4. Comparison of Experimental Results

\begin{tabular}{|l|l|l|l|l|l|}
\hline Specimens & $F_{\text {av }} / F_{\text {ST,av }}$ & $\delta_{\text {av }} / \delta_{\text {ST,av }}$ & $\frac{F_{\text {stat1,Rk }}}{F_{\text {ST, stat } 1, \mathrm{Rk}}}$ & $\frac{F_{\text {stat } 1 \text { Rk }}}{F_{\text {Rk,exp }}}$ & $\frac{F_{\text {stat } 2 \text { Rk }}}{F_{\text {Rk,exp }}}$ \\
\hline$(1)$ & $(2)$ & $(3)$ & $(4)$ & $(5)$ & $(6)$ \\
\hline ST & 1.000 & 1.00 & 1.00 & 0.972 & $/$ \\
\hline TDA & 1.016 & 1.25 & 1.01 & 0.983 & $/$ \\
\hline $\begin{array}{l}\text { LDA1 } \\
f_{\text {ck }}=40 \mathrm{MPa}\end{array}$ & 0.995 & 1.56 & 0.944 & 0.917 & $/$ \\
\hline $\begin{array}{l}\text { LDA1 } \\
f_{\text {ck }}=32 \mathrm{MPa}\end{array}$ & 0.916 & 1.30 & $/$ & $/$ & 0.92 \\
\hline LDA2 & 1.005 & 1.18 & 1.024 & 0.995 & $/$ \\
\hline G1 & 1.012 & 2.14 & 1.018 & 1.057 & 1.113 \\
\hline GR1 & 1.036 & 2.11 & 1.034 & 1.074 & 1.143 \\
\hline
\end{tabular}

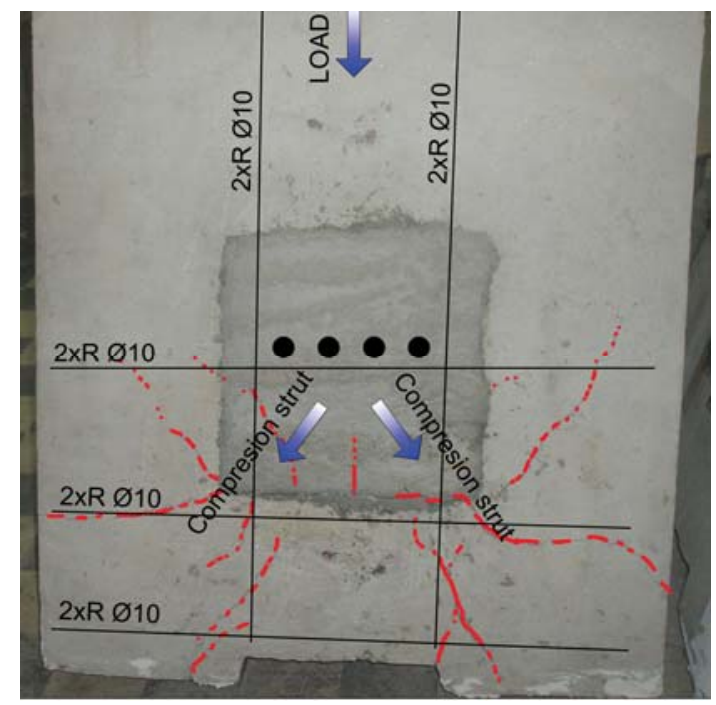

a) TDA

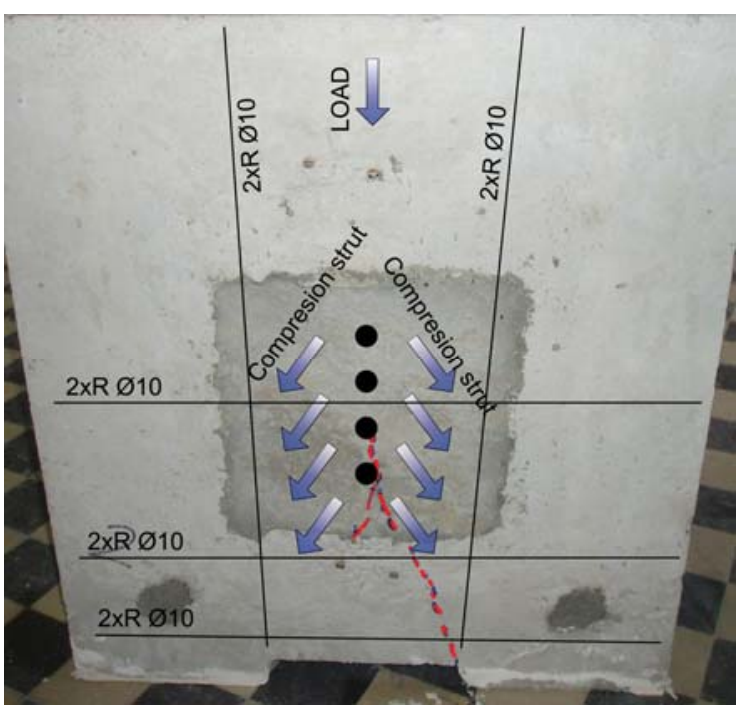

b) LDA1

Figure 10. Cracks in the Concrete and a Model of Internal Forces 
Obtained values of shear resistance of the G1 and GR1, LDA2 types specimens, with two headed studs in the direction of the load at a smaller distance than recommended $5 \mathrm{~d}$ are the same or higher than the obtained ultimate values of shear resistance of standard ST type specimens (see Table 4). Due to the small distance, the headed studs in the group have approximately the same deformation, which results in the uniform redistribution of forces between the headed studs. The common work of all the studs in the group and redistribution of load between the individual headed studs resulted in smaller differences between the measured failure load values between the specimens of the same type. Hegger et al. [5] used concretes with higher strengths and two studs in a row $\left(h_{\mathrm{sc}} / d=80 / 19\right.$ $\mathrm{mm}=4.21$ ) with the distance of $2 \mathrm{~d}$ in the direction of the force, and obtained only $5.4 \%$ lower shear resistance. The average value of the shear resistance of tested specimens of the G1, GR1 and LDA2 types are within the range of $\pm 3 \%$ in respect to the standard ST specimen. The statistic values of the shear resistance $\left(F_{\text {stat1,Rk }}, F_{\text {stat2,Rk }}\right)$ of the specimens of these groups of headed studs have higher values than the shear resistance of the standard specimen. It should be pointed out that G1, GR1 and two LDA1 specimens were monolitized with the concrete having strength of $f_{\mathrm{ck}}=32 \mathrm{MPa}$. Comparison results of tested specimens with headed studs in line of force with results in [5] indicate the importance of headed studs height to diameter ratio $\left(h_{\mathrm{sc}} / d\right)$.

The average value of failure force of LDA1 type specimens $\left(f_{\mathrm{ck}}=40 \mathrm{MPa}\right)$ of $757 \mathrm{kN}$ is $0.6 \%$ smaller than the average value obtained for standard specimens (ST). Failure forces of LDA1 specimens are $2-19 \%$ higher than the characteristic values. Shear resistance of individual LDA1 type specimens were characterized by slightly higher deviation from the average value for this type. The characteristic shear resistance of LDA1 is $8.0 \%$ smaller than the characteristic shear resistance of ST specimens.

It should be mentioned that at failure of LDA1 type specimens the cracks in the concrete slab did not emerge, or were very small, and they emerged only at the loads very close to the shear resistance of the specimen. In case of longitudinal orientation of headed studs, when the load is transferred a larger number of compressed diagonals in concrete is formed, as opposed to the transversal orientation of studs (TDA type) in which case two compressed diagonals are formed, see Figure 10. The flow of internal forces (strut-and-tie model) in the concrete slab presented in the Figure 10b clearly illustrate that in the case of LDA1 headed stud group, two horizontal rows are engaged for reception of tensile forces.

However, one must take into account both the way of application of load by the headed studs group onto the concrete slab, and the internal flow of forces, and provide adequate reinforcement in the concrete slab. Also, the appropriate reinforcement for transfer of longitudinal shear force in concrete must be present.

G1 and GR1 groups are identical in geometrical terms, but they were constructed with the different type of concrete slabs. Combined type of failure is characteristic for both types of specimens. Average values of ultimate failure load of $747 \mathrm{kN}$ for the G1 type specimens, i.e. $753 \mathrm{kN}$ for GR1 type specimens demonstrate that transversal reinforcement in the slab does not have considerable influence on the shear resistance of the headed stud group. The same conclusion was presented in Okada's paper [2]. The slip at the failure of G1 specimen was $11.8 \mathrm{~mm}$, while for GR1 specimen it was $12.8 \mathrm{~mm}$. From the presented results and load-slip characteristics of G1 and GR1 specimens, the conclusion can be drawn that the reinforcement of the slab does not affect the shear resistance and behavior of the group of headed studs. The role of reinforcement in the slab is primary important because of the flow of force inside the reinforced concrete slab. The reinforcement is important for strut-and-tie model in concrete slab in the zone with considerable concentrated load onto the concrete slab, at the location of the headed stud group. 
The strength of the infill concrete plays a dominant role. The higher shear resistance and stiffness of the shear connector is achieved using the high strength infill concrete. Therefore, it is cost-effective to use it.

\section{SHEAR RESISTANCE OF STUDS GROUP}

Shear resistance of headed studs in a group may be predicted as a sum of the shear resistance of individual headed studs. In this approach, it is important to take into account a position of the shear stud in a group. A similar interpretation of the shear resistance of two headed studs is provided by Hegger, Sedlacek et al. [5].

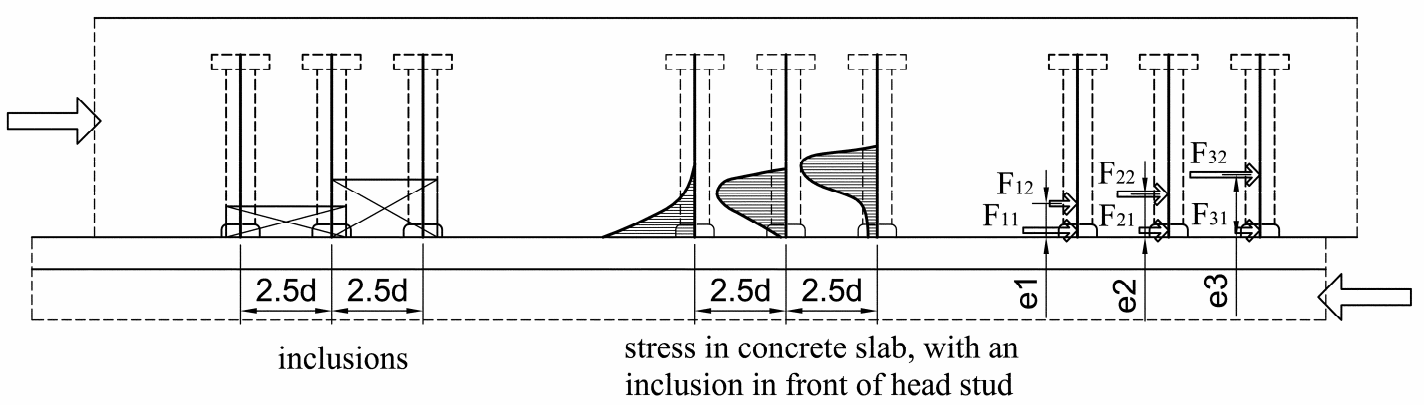

Figure 11. Load Distribution Model for the Group of Headed Studs

The first stud in the column can achieve the full shear resistance. The shear failure occurred in this stud. It can be considered that the shear resistance of concrete has been used in a layer which is approximately equal to the diameter of the headed stud, at the first stud. The second headed stud in the row behaves as a headed stud with an inclusion in front of it, as shown in Figure 11. It is similar to the case of a stud installed in the corrugated steel sheet. With the same analogy the shear resistance of the subsequent studs in the row can be analyzed. The second, third and other studs may have the same or slightly lower shear resistance which directly depends on the height of the shank of headed stud at which the concrete pressure ocures. These headed studs are characterized by the shear-bending failure mode. According to Figure 11 it can be define as follow: $F_{11}>F_{21}>F_{31}$, $F_{12}<F_{22}<F_{32}$ and $e_{1}<e_{2}<e_{3}$. The higher force $F_{2 \mathrm{i}}$ and eccentricity $e_{\mathrm{i}}$ results in higher bending moment in the shank. The higher values of bending moment results in a dominate bending-shear failure which is typical for the third and the fourth head stud in the row. Forces $F_{\mathrm{ij}}$ are influenced by stud diameter, clearance between studs and the bending stiffness of headed stud. The concrete strength is one of most dominated factors to shear resistance of headed studs group. Thickness of concrete layer that will be engaged for load transfer depends not only on geometry but also the concrete class. In a case of single headed studs, the concrete class determines the form of the stud failure, Lam et.al. [11] and Oehlers [6].

Okada et al. in [2] analyzed the influence of the stud distance to the group shear resistance in the similar way. They suggested the reduction factor for the group of studs which is in relation to concrete strength and longitudinal spacing factor $C_{1}=d_{1} / d$ ( $d_{1}$ - longitudinal distance between studs). 
According to [2] for specimens LDA1,G1 and GR1 following values could be calculated:

- concrete $\mathrm{C} 30 / 37$

$F_{\mathrm{Rk}}=\eta \cdot F_{\mathrm{Rk}, \exp }=\left(0.021 \cdot C_{1}+0.73\right) F_{\mathrm{Rk}, \exp }$

for $d_{1}=45 \mathrm{~mm} \rightarrow C_{1}=d_{1} / d=2.8125 \rightarrow \quad \eta=0.021 \cdot C_{1}+0.73=0.789$

for $d_{1}=50 \mathrm{~mm} \rightarrow C_{1}=d_{1} / d=3.125 \rightarrow \quad \eta=0.021 \cdot C_{1}+0.73=0.796$

- concrete $\mathrm{C} 40 / 50$

$F_{\mathrm{Rk}}=\eta \cdot F_{\mathrm{Rk}, \exp }=(0.016 \cdot \mathrm{C} 1+0.80) F_{\mathrm{Rk}, \exp }$

for $d_{1}=45 \mathrm{~mm} C_{1}=d_{1} / d=2.8125 \rightarrow$

$$
\begin{aligned}
& \eta=0.016 \cdot C_{1}+0.80=0.845 \\
& \eta=0.016 \cdot C_{1}+0.80=0.85
\end{aligned}
$$

Table 5 and Figure 12 present the test result and Okada's recommendation for the group shear resistance using the empirical reduction factor $\eta$. The best agreement is obtained for LDA1 specimens. Okada analyzed specimens with three studs in force direction. Therefore, specimens LDA1 with four studs have the good match with the estimated resistance. This may indicate that the diameter and the total number of studs are also parameters which are important for shear resistance of studs group. Shear resistance of tested specimen ST should not be reduced. There are significant deviations between results for G1 and GR1 series and reduced resistance according to [2]. This deviation indicates that the number of studs in the force direction and the total number of studs in the group are relevant factors for the shear resistance. It is necessary to take these variables into account for the reduction parameter $\eta$.

Table 5. Comparisons of the Specimens Shear Resistance with the Estimation based on [2]

\begin{tabular}{|l|l|l|l|l|l|}
\hline Specimens & $\begin{array}{l}F_{\text {Rk,exp }} \\
\text { acc. to EC4 }\end{array}$ & $F_{\text {stat1,Rk }}$ & $F_{\text {stat2,Rk }}$ & $\begin{array}{l}\text { Distance } \\
\text { between } \\
\text { studs }\end{array}$ & \multicolumn{1}{|c|}{$\begin{array}{c}\text { Acc. to } \\
\text { Okada [2] }\end{array}$} \\
\hline & {$[\mathrm{kN}]$} & {$[\mathrm{kN}]$} & {$[\mathrm{kN}]$} & {$[\mathrm{mm}]$} & {$[\mathrm{kN}]$} \\
\hline$(1)$ & $(2)$ & $(3)$ & $(4)$ & $(5)$ & $(6)$ \\
\hline $\begin{array}{l}\mathrm{ST} \\
f_{\mathrm{ck}}=40 \mathrm{MPa}\end{array}$ & 336.5 & 327.0 & & $\begin{array}{l}100 \mathrm{~mm} \\
6.25 d\end{array}$ & 302.5 \\
\hline $\begin{array}{l}\text { LDA1 } \\
f_{\mathrm{ck}}=40 \mathrm{MPa}\end{array}$ & 336.5 & 308.7 & & $\begin{array}{l}50 \mathrm{~mm} \\
3.125 d\end{array}$ & 286.0 \\
\hline $\begin{array}{l}\text { LDA1 } \\
f_{\mathrm{ck}}=32 \mathrm{MPa}\end{array}$ & 314.0 & & 288.5 & $\begin{array}{l}50 \mathrm{~mm} \\
3.125 d\end{array}$ & 250.0 \\
\hline $\begin{array}{l}\mathrm{G} 1 \\
f_{\mathrm{ck}}=32 \mathrm{MPa}\end{array}$ & 313.5 & 331.1 & 350.5 & $\begin{array}{l}45 \mathrm{~mm} \\
2.8 d\end{array}$ & 247.5 \\
\hline $\begin{array}{l}\text { GR1 } \\
f_{\mathrm{ck}}=32 \mathrm{MPa}\end{array}$ & 315.0 & 338.4 & 360.0 & $\begin{array}{l}45 \mathrm{~mm} \\
2.8 d\end{array}$ & 248.0 \\
\hline
\end{tabular}




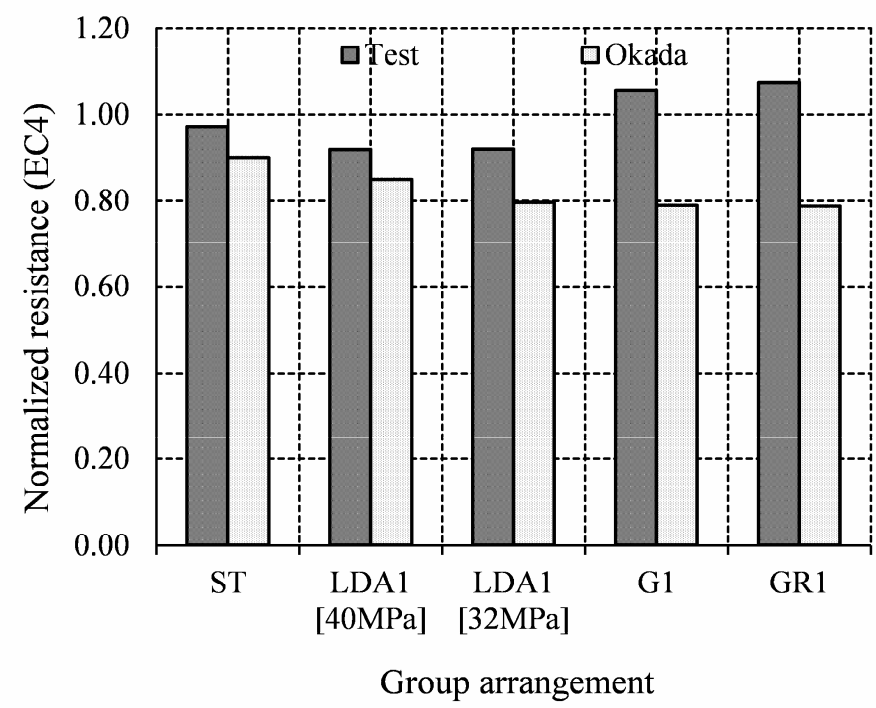

Figure 12. Test Results Comparison with EC4 and Okada

If higher concrete classes are used, the layer of concrete engaged for load transfer is lower, and the loading of the headed studs is concentrated closer to the root. This results in smaller bending of the headed studs. Use of higher concrete classes comprises that the layers of concrete engaged for load transfer on the second, third and other headed studs also lie closer to the root of the headed stud. In Figure 13 are displayed deformed headed studs after the failure of LDA1 specimen. One may observe from the Figure 13 that the fourth headed stud in the column has broken. It should be noted that the third headed stud endured considerably greater deformation than the first two studs. This justifies the assumption that the last stud is exposed to the highest bending moment due to larger lever arm of the resulting stresses in the concrete.

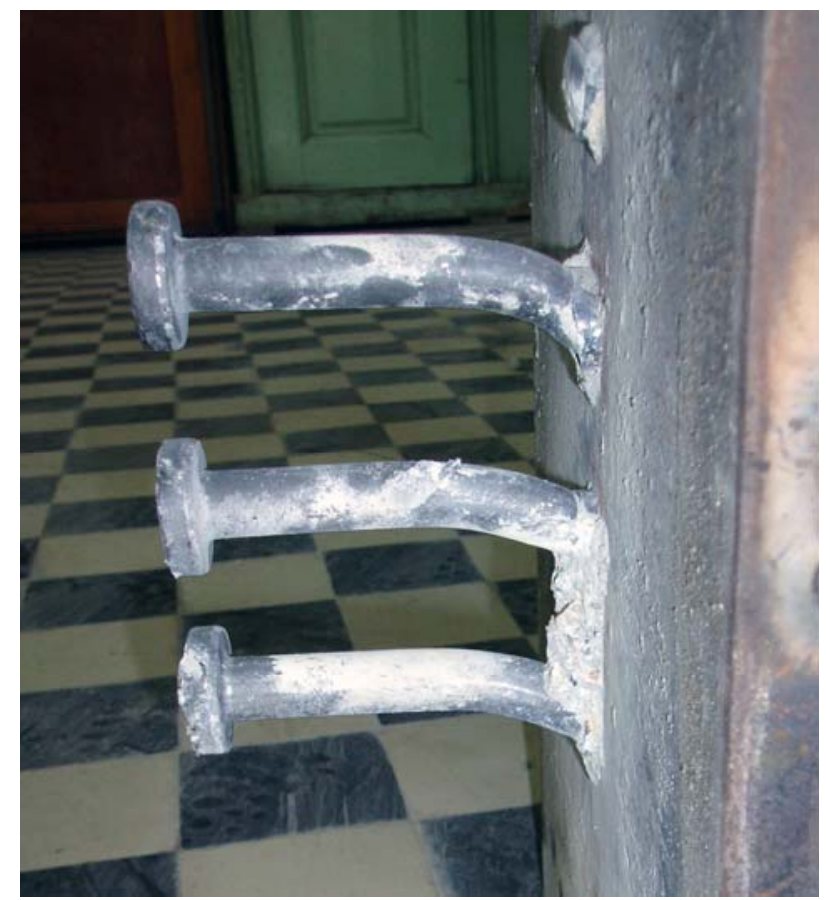

Figure 13. Deformed Shape of Headed Studs after Failure of LDA1 Specimen 


\section{DEFORMATIONS AND STIFFNESS}

Stiffness and deformability of the shear connectors is an important input for the analysis of composite beams. Beam deflections are affected by the slip in the shear connection interface. These effects are not covered in design codes for composite beams with the full shear connection and the standard arrangement of studs. Since grouped arrangement of headed stud is a non-standard arrangement, the slip in shear connection was analyzed. The slip of the shear connection in the group of studs is also compered to the standard arrangement for the serviceability load level (SLS). According to values in Table 2 column (8), the slip of the shear connection with four headed studs in the group arrangement is equal to the slip for the standard arrangement. Consequently, it may be expected that the deflection of a composite beam with grouped studs will be equal to the deflection of a beam with the standard studs arrangement for SLS.

Characteristics of the concrete, used for the monolitization, have a dominant influence on the stiffness of the shear connection. It is well known, that the higher the concrete class is the lower plastic deformation of the concrete is and thus the deformation of the headed studs. This would result in a higher stiffness of the shear connection. Transfer of the load from the headed studs into the concrete slab at initial values of the load occurs through the concrete layer near the root of the headed stud. Application of the low strength concrete comprises onset of plastic deformations and cracks in the layer of concrete near the root of the headed stud, even at low values of the force. It further results in bending of headed studs and engaging of a thicker concrete layer for load transfer. Early plastic deformations and cracks in the concrete slab in case of the low strength concrete comprise higher initial deformations of the shear connector and higher ultimate deformations at failure.

In Figure 14 the initial parts of load-slip curves are presented calculated for one headed stud.

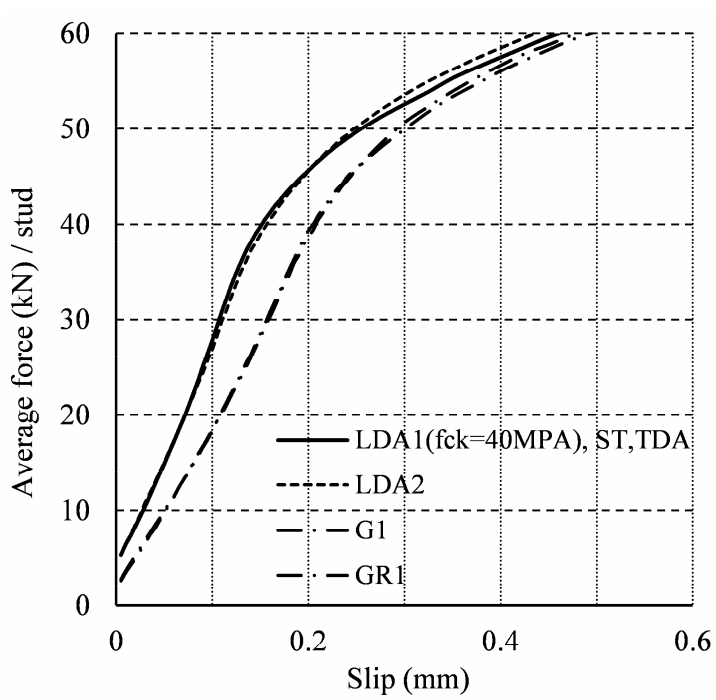

a) Initial load-slip curves

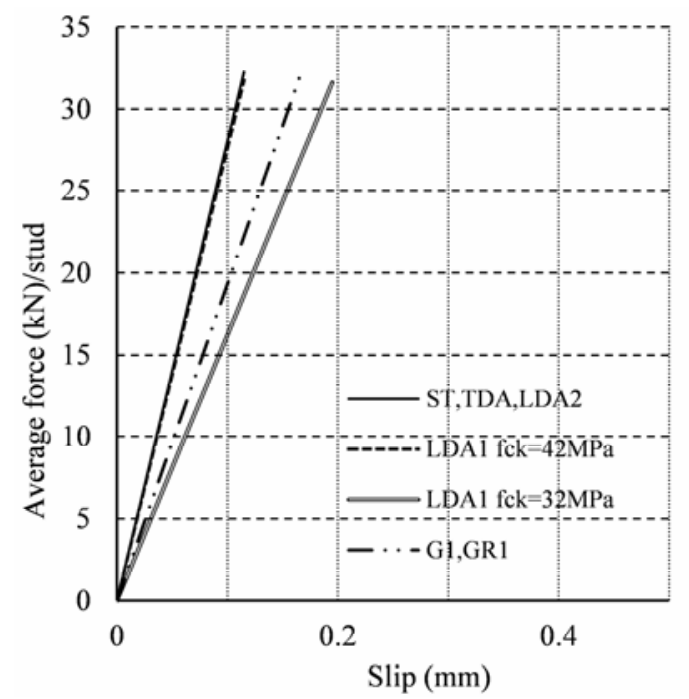

b) Initial stiffness

Figure 14. Initial Stiffness for Tested Groups

It can be observed in Figure $14 \mathrm{~b}$ that the tangential modules of ST, TDA, LDA1 and LDA2 type specimens are almost identical. The tangent modules coincide for specimens G1 and GR1. It can be concluded that the arrangement of headed studs in the group and the orientation of the group do not affect the initial stiffness of the group importantly, but it primarily depends on the strength of concrete used for monolitization. It was noted that the difference in slip of the various types of studs groups for the load level of $0,7 P_{\mathrm{Rk}}$ (see Table 2 and Figure 15) is within the range of $0.1 \mathrm{~mm}$. 
Same slip deformations of the G1 and GR1 group types demonstrate that transversal reinforcement has no important influence on the group.
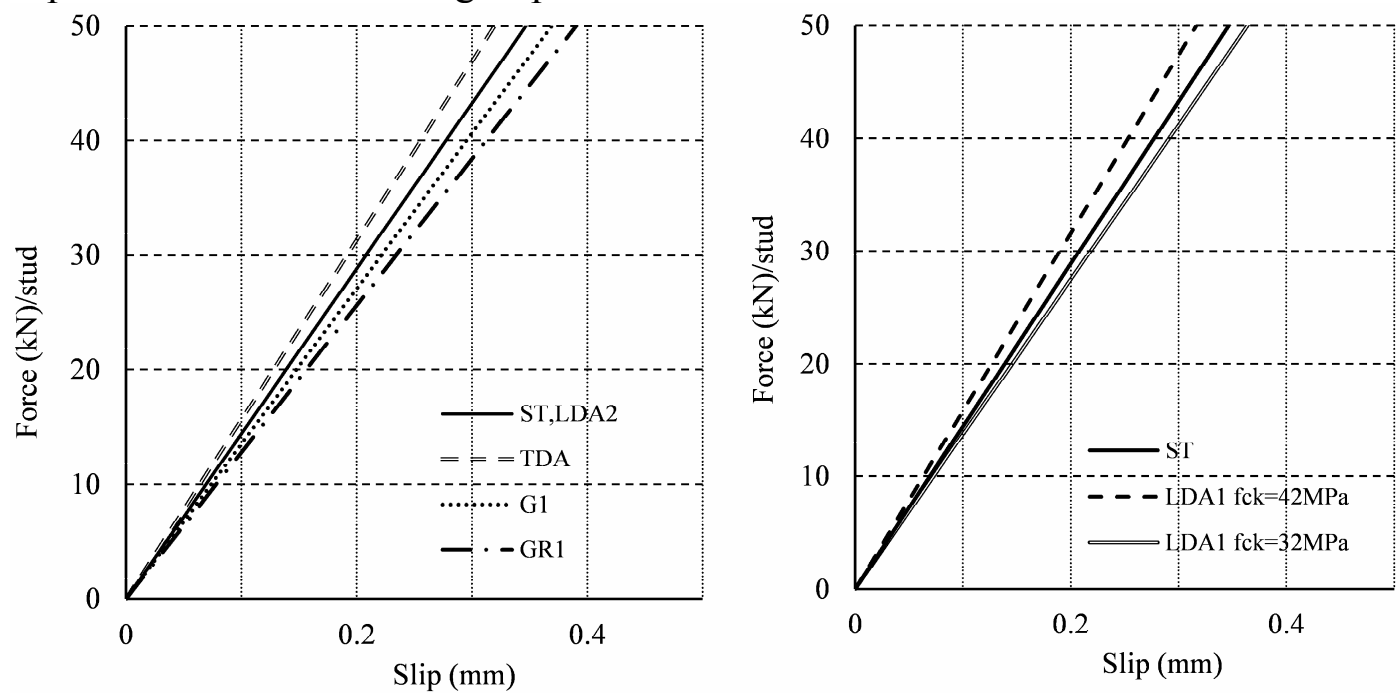

Figure 15. Stiffness $k_{\text {sc }}$ for Tested Groups of Headed Studs

Table 6 presents the values of separation between steel beam and concrete slab. Average specimen values of separation for the maximum values of shear force are presented. Presented values are uniform for all type of specimens. Grouped arrangement of headed studs has no influence on separation between steel beam and concrete slab.

Table 6. Separation between Steel Beam and Slab

\begin{tabular}{|l|l|l|l|l|l|l|l|}
\hline specimen & ST & TDA & LDA1 & LDA2 & G1 & GR1 \\
\hline & \multicolumn{7}{|l|}{ Average value - separation between the beam and the slab [mm] } \\
\hline a & 1.06 & 1.12 & 0.81 & 0.53 & 1.0 & 0.85 \\
\hline b & 1.25 & 0.67 & 1.12 & 0.47 & 0.87 & 0.66 \\
\hline c & 1.09 & 1.03 & 0.90 & 0.81 & 1.17 & - \\
\hline $\mathrm{d}$ & & & 1.03 & & 1.16 & 0.84 \\
\hline e & & & 1.2 & & & \\
\hline
\end{tabular}

Analyzing the damaged areas in concrete around headed studs (Figure 16) it may be observed that the zones of plastic deformations in concrete are different both in form and the volume. Even though the TDA specimens comply with [1], the arrangement of studs in the slab and the application of force onto the slab as well as the internal force flow (see Figure 10) result in a considerably larger zone of plastic deformations in the concrete slab. It was expected that the arrangement of headed studs in LDA1 specimen will undergo significant plastic deformations in the concrete slab, especially when it is considered that the space between the headed studs is reduced, but this was not experimentally proved. This indicates that the internal flow of forces in the concrete slab has a considerable effect on the resistance of grouped shear connectors. 


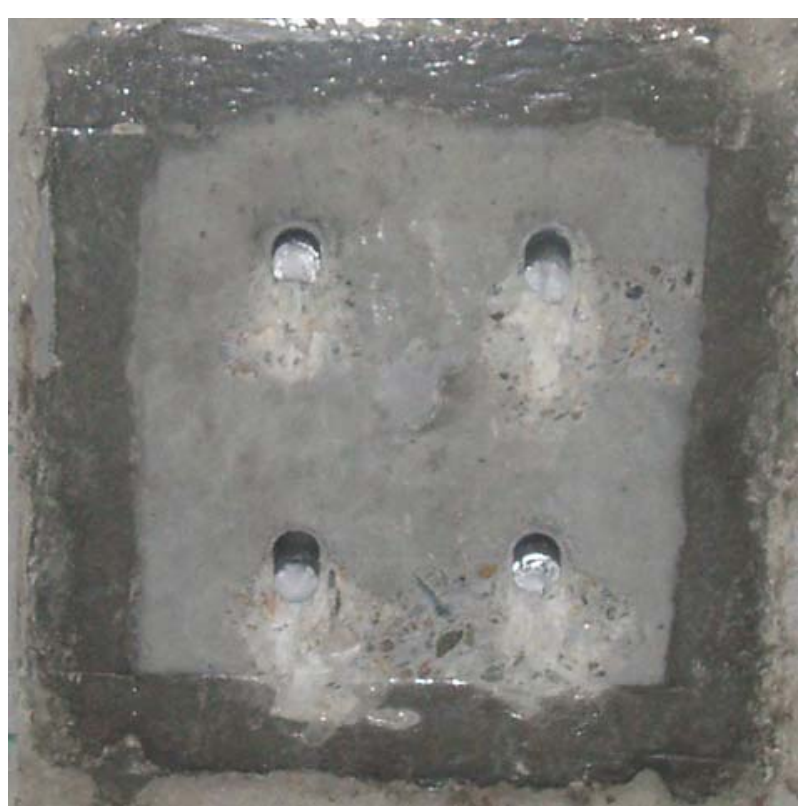

a) ST

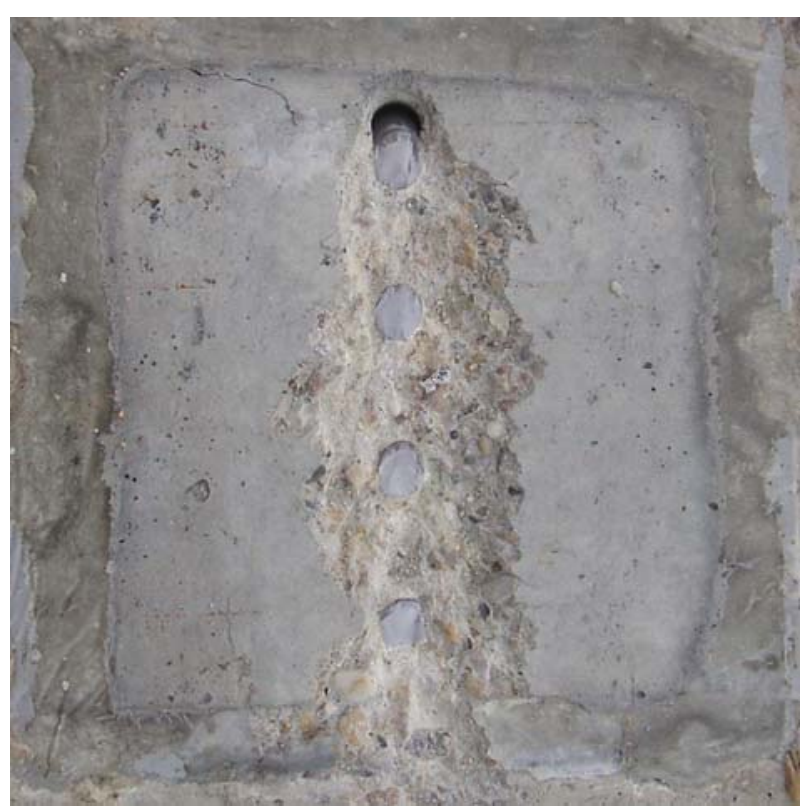

c) LDA1

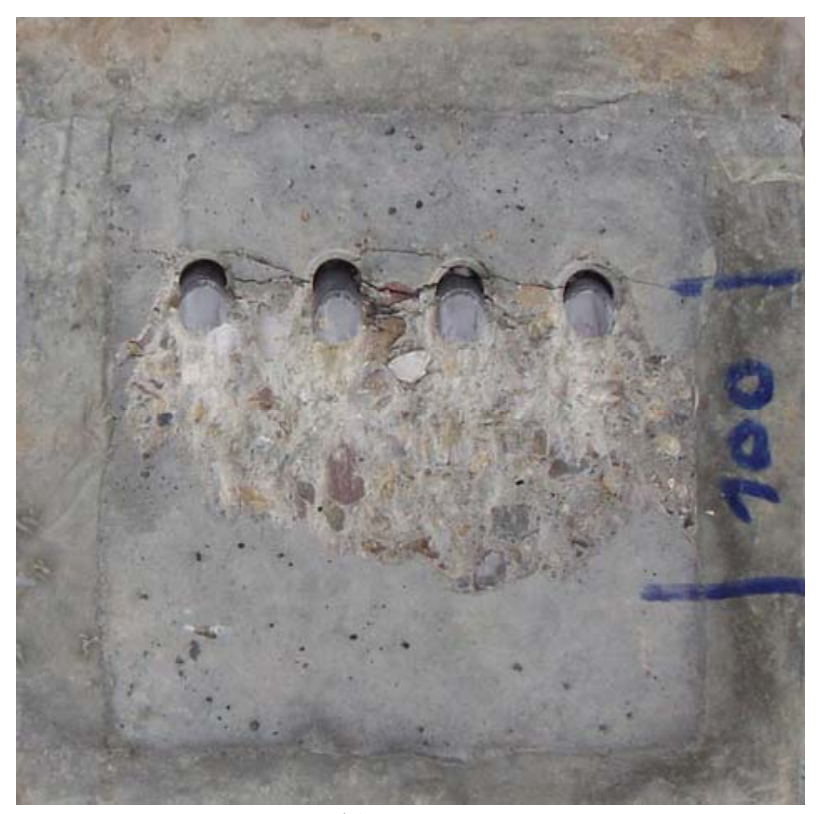

b) TDA

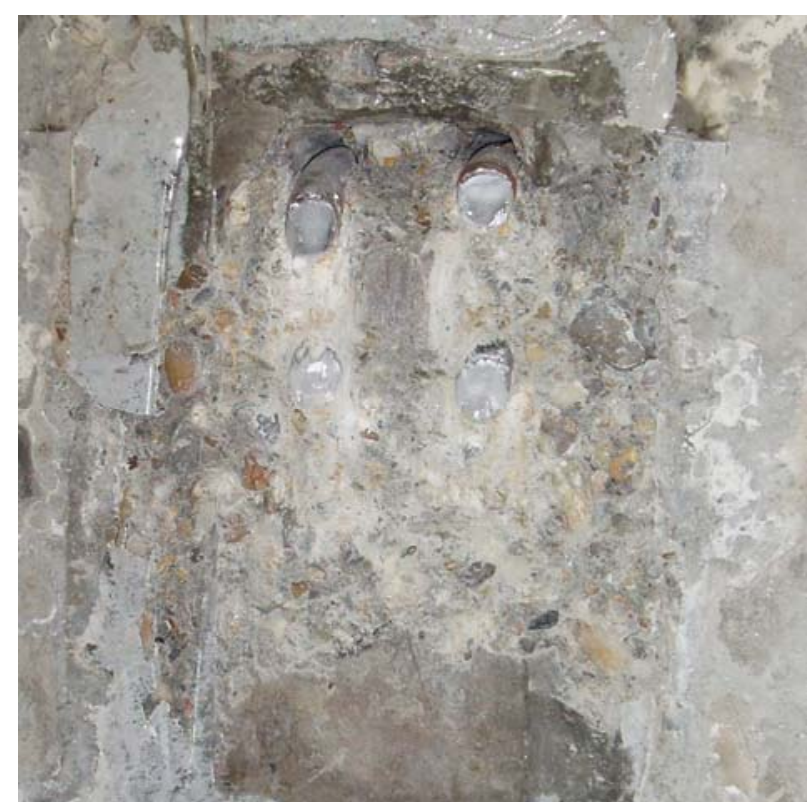

d) G1 and GR1

Figure 16. Crashing Zone (Failure Mode) in Concrete Slab

\section{CONCLUSIONS}

The experimental study demonstrated that headed studs groups can be efficiently used when welded in the group even if the distance between studs is smaller than the minimum required (5d) [1]. The findings of the study are given below:

- Shear resistance of a group of four headed shear studs $\varnothing 16 \mathrm{~mm}$, in a row in the longitudinal direction at the distance of $3 d$, is equal to $92 \%$ of the sum of the shear resistance of individual shear connectors in the solid concrete slab.

- Two headed studs in a longitudinal direction at the distance of $2.5 \mathrm{~d}$ with the ratio of the height and diameter of a stud bigger than $h_{\mathrm{sc}} / d \geq 6.25$ have the same shear resistance as two individual studs, when the concrete strength $f_{\mathrm{ck}} \geq 32 \mathrm{MPa}$ is used. 
- Recommendation on the reduction factor given in Okada et all [2] may be used as the safe prediction of the shear resistance of the specimen with four studs in the row, the LDA1 specimen., Acc. to [2] the reduction factor would be 0.93 and 0.87 for the characteristic resistance of the specimen with the concrete strength $f_{\mathrm{ck}}=40 \mathrm{MPa}$, and $f_{\mathrm{ck}}=32 \mathrm{MPa}$; respectively. Further studies are on-going to derive an accurate prediction for more than three headed shear studs in the group.

- The stiffness and deformability of the connection depends of the concrete strength. Stiffness of studs group in specimen with concrete strength $f_{\mathrm{ck}}=32 \mathrm{MPa}$ is $10 \%$ lower than the stiffness of the same group of studs in specimen with concrete strength $f_{\mathrm{ck}}=40 \mathrm{MPa}$.

- A group of headed studs (two or four in the row) with reduced distance, less than $5 d$, may be used instead of a larger diameter single headed stud. The group has ductile behavior at the longitudinal slip greater then $6,0 \mathrm{~mm}$;

\section{ACKNOWLEDGEMENT}

The writers would like to acknowledge the support provided by "MB steel" Ltd. and "GEMAX" Concrete production Ltd. The authors thank the members of the technical staff of the Laboratory for Materials and Structures of the Faculty of Civil Engineering at the University of Belgrade.

\section{NOTATION}

$\begin{array}{ll}d & \text { diameter of the shank of a stud connector } \\ h_{\mathrm{sc}} & \text { overall nominal height of a stud connector } \\ \text { ST } & \text { standard test } \\ \text { LDA } & \text { longitudinal distance arrangement } \\ \text { TDA } & \text { transversal distance arrangement } \\ \text { G } & \text { group arrangement without reinforcement near the group of headed studs } \\ \text { GR } & \text { group arrangement with reinforcement near the group of headed studs } \\ F_{\mathrm{u}} & \text { the shear resistance of tested specimens } \\ F_{\mathrm{u}, \text { min }} & \text { minimum shear resistance of tested specimens with a same group of headed studs } \\ F_{\mathrm{u}, \text { max }} & \text { maximum shear resistance of tested specimens with a same group of headed studs } \\ F_{\mathrm{av}} & \text { average shear resistance of tested specimens with a same group of headed studs } \\ \delta_{\text {max }} & \text { maximal longitudinal slip at failure load } \\ \delta_{\mathrm{av}} & \text { longitudinal slip that correspond to the average max. load } \\ k_{\mathrm{sc}} & \text { stiffness of shear connection and Stiffness of a shear connector } \\ F_{\mathrm{Rk}, \mathrm{exp}} & \text { characteristic shear resistance on the basis of experimental characteristics of the } \\ f_{\mathrm{c}, \mathrm{cube}} & \text { material } \\ f_{\mathrm{ck}} & \text { characteristic compressive cube strength of concrete at } 28 \text { days } \\ f_{\mathrm{u}} & \text { characteristic compressive cylinder strength of concrete at } 28 \text { days } \\ E_{\mathrm{cm}} & \text { the ultimate tensile strength } \\ P_{\mathrm{Rk}} & \text { secant modulus of elasticity of concrete } \\ \alpha & \text { characteristic value of the shear resistance of a single connector } \\ F_{\mathrm{stat} 1, \mathrm{Rk}} & \text { coefficient } \\ F_{\mathrm{stat} 2, \mathrm{Rk}} & \text { characteristic resistance according to EC4 Annex B } \\ m_{\mathrm{x}} & \text { characteristic resistance according to EC0 Annex D } \\ k_{\mathrm{n}} & \text { mean of the n sample results } \\ V_{\mathrm{x}} & \text { coefficient for the } 5 \% \text { characteristic value } \\ s_{\mathrm{x}} & \text { coefficient of variation } \\ \text { estimate value of the standard deviation }\end{array}$




$\begin{array}{ll}\eta & \text { the reduction factor [2] } \\ n & \text { number of same specimens } \\ C_{1} & \text { longitudinal spacing factor [2] } \\ d_{1} & \text { longitudinal distance between the studs [2] }\end{array}$

\section{REFERENCES}

[1] EN1994-1-1, Eurocode 4, "Design of Composite Steel and Concrete Structures. General Rules end Rules for Buildings", CEN (European Committee for Standardization), December 2004.

[2] Okada, J., Yoda, T. and Lebet, J.P., "The Study of the Grouped Arrangements of Stud Connectors on Shear Strength Behavior", Structural Eng./Earthquake Eng.,JSCE, Vol. 23, No. 1, pp. 75-89, April 2006.

[3] EN1994-2, Eurocode 4, "Design of Composite Steel and Concrete Structures. General Rules and Rules for Bridges", CEN (European Committee for Standardization), 2005.

[4] Shim, C.S., Lee, P.G., Kim, D.W. and Chung, C.H., "Effects of Group Arrangement on the Ultimate Strength of Stud Shear Connection", Proceedings of the 2008 Composite Construction in Steel and Concrete Conference VI, ASCE Conf. Proc. doi:10.1061/41142(396)8.

[5] Hegger, J., Sedlacek, G., Doinghaus, P. and Trumpf, H., "Studies on the Ductility of Shear Connectors when using High-strength Steel and High-strength Concrete", Conf. Proc. Ed. by Eligehausen, R." Connections between Steel and Concrete", Stuttgart, Germany, 10-12 September 2001, pp. 1025-1046.

[6] Oehlers, D.J., "Stud Shear Connectors for Composite Beams", PhD Thesis, The University of Warwick, 1980, /http://go.warwick.ac.uk/wrap/3977.

[7] Pallarés, L. and Hajjar, J.F., "Headed Steel Stud Anchors in Composite Structures. Part I Shear", Journal of Constructional Steel Research, 2010, Vol. 66, pp. 198-212.

[8] BS 5950-3.1:1990, "Structural Use of Steelwork in Building. Part 3 Design in Composite Construction", UK British Standard Institution, 1990.

[9] EN1992-1-1, Eurocode 2, "Design of Concrete Structures, General Rules and Rules for Buildings", CEN (European Committee for Standardization), 2004.

[10] EN1990, Eurocode 0, "Eurocode - Basis of Structural Design", CEN (European Committee for Standardization), 2002.

[11] Lam, D., Asce, M. and El-Lobody, E., "Behavior of Headed Stud Shear Connectors in Composite Beam", Journal of Structural Engineering, Vol. 131, No.1, ASCE, January 2005.

[12] Ollgaard, J.G., Slutter, R.G. and Fisher, J.W., "Shear Strength of Stud Connectors in Lightweight and Normal-weight Concrete", Engineering Journal, AISC 1971, Vol. 8, No. 2, pp. 55-64.

[13] Oehlers, D.J. and Bradford, M.A., "Elementary Behaviour of Composite Steel and Concrete Structural Members“, Butterworth-Heinemann, 1999.

[14] Spremic, M., Fric, N., Markovic, Z. and Budjevac, D., "Shear Capacity of Anchor Plate with Group of Headed Studs“, International Conference, GNP 2010, Zabljak, 15-19 February 2010, pp. 649-655. 


\section{APENDIX 1}

Test results of all tested specimens

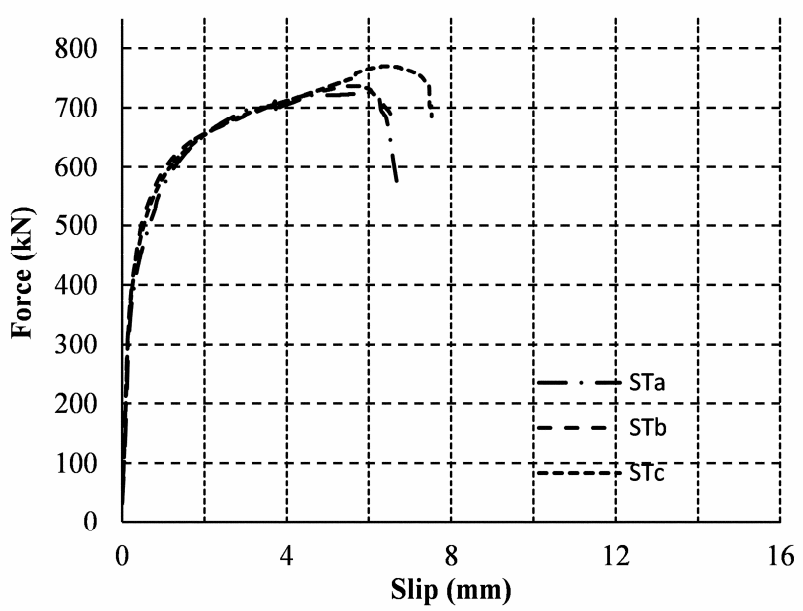

a) Specimens ST

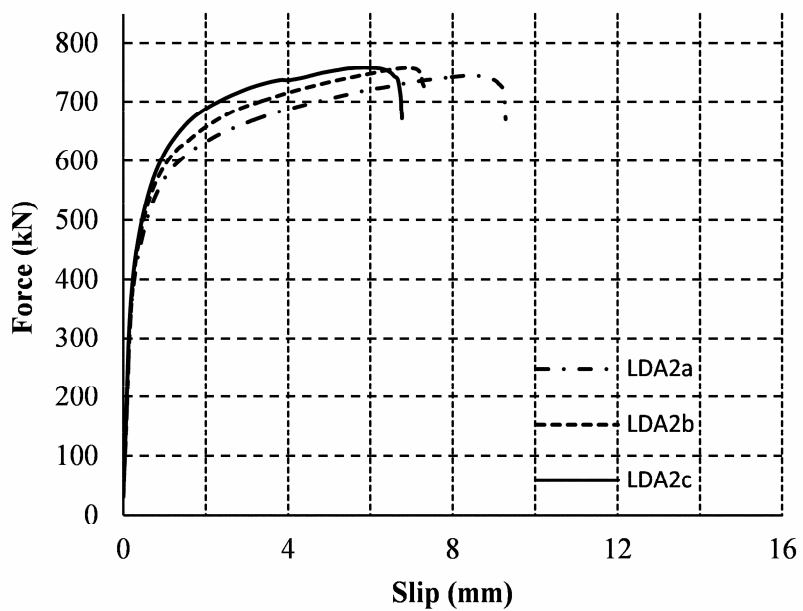

c) Specimens LDA2

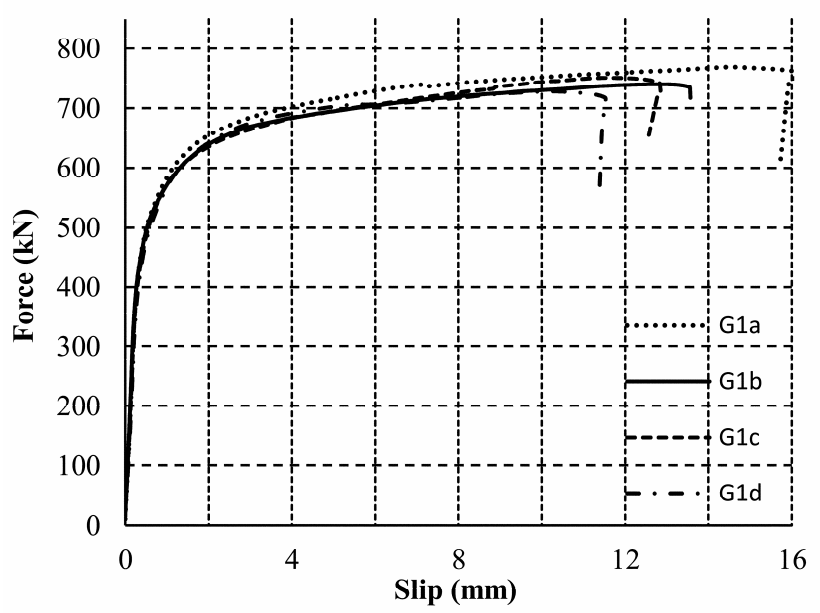

e) Specimens G1

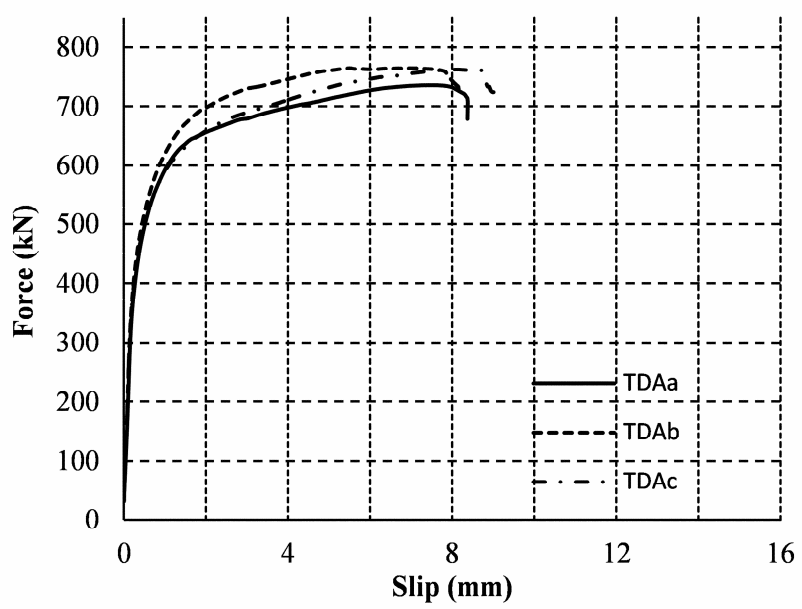

b) Specimens TDA

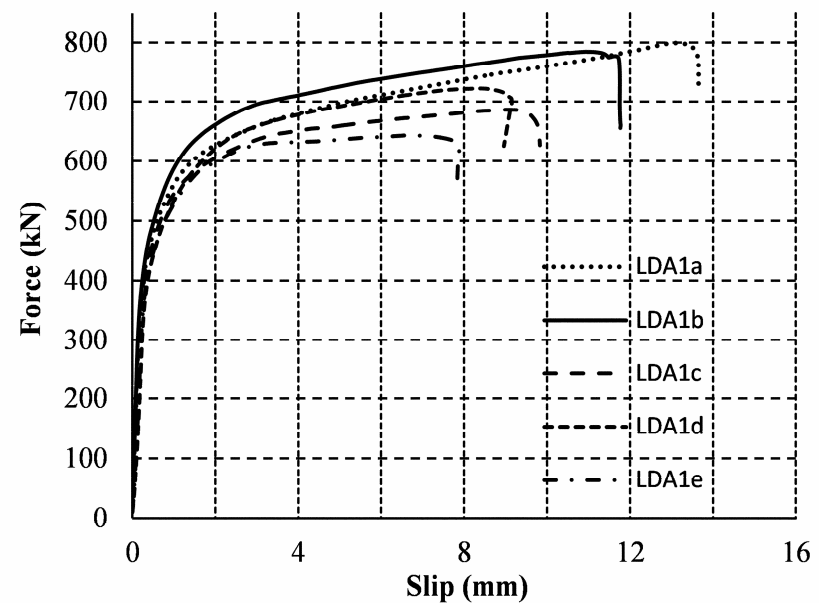

d) Specimens LDA1

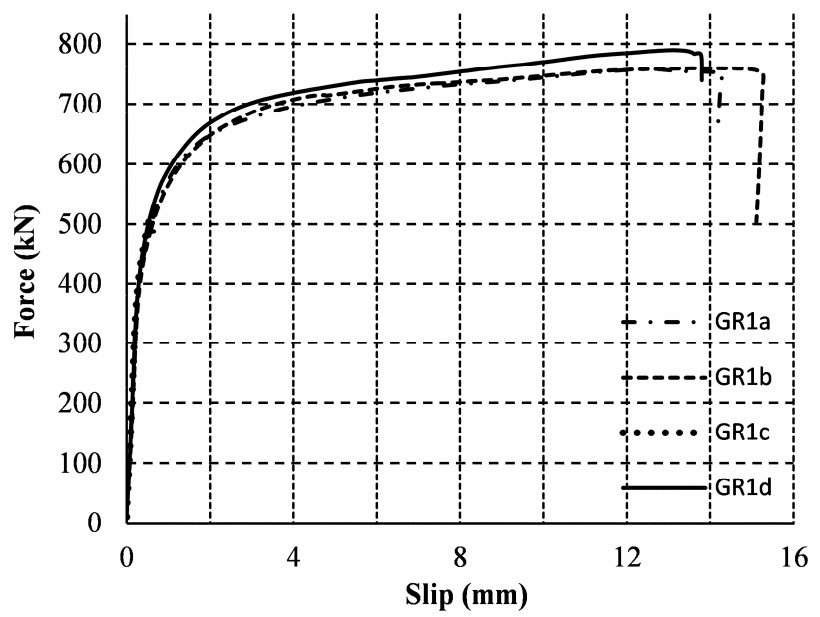

f) Specimens GR1 


\title{
PROGRESSIVE COLLAPSE ANALYSIS OF TRANSMISSION TOWER-LINE SYSTEM UNDER EARTHQUAKE
}

\author{
W.M. Wang ${ }^{1, *}$, H.N. $\mathrm{Li}^{2}$ and L. $\operatorname{Tian}^{3}$ \\ ${ }^{1}$ Faculty of Infrastructure Engineering, Dalian University of Technology, Dalian, PR China \\ ${ }^{2}$ Professor, Faculty of Infrastructure Engineering, Dalian University of Technology, Dalian, PR China \\ ${ }^{3}$ School of Civil and Hydraulic Engineering, Shandong University, Jinan, PR China \\ *(Corresponding author: E-mail: wangwenming87110@163.com)
}

Received: 11 July 2012; Revised: 30 October 2012; Accepted: 5 December 2012

\begin{abstract}
High-voltage electric transmission tower may collapse under the strong earthquake and studies on the collapse mechanism, routine and capacity of transmission tower-line system are important for the structural design of tower. In this paper, a progressive collapse analytical procedure for the system is proposed based on the finite element method (FEM). During this procedure, the mass of the elements is still retained rather than removal after elements lose the load-bearing capacity. The proposed procedure is coded using the user subroutine VUMAT and then implemented in the advanced finite element program ABAQUS. A three-dimensional finite element model for the system of three towers and four-span lines is created. By using the coded subroutine, the collapse analysis of the tower-line system under the strong earthquake is performed. Collapse processes along longitudinal and lateral direction are studied, respectively. Furthermore, the influences of ultimate strain and strain rate effect of materials on the collapse mode and capacity are studied. The results indicate that the collapse analysis of the tower-line system by using the proposed procedure can provide collapse mode and vulnerable points for use in seismic performance and retrofit evaluation of structure. It is found from the numerical modeling that the influences of ground motion and ultimate strain on the collapse modes are apparent. The collapse-resistant capacity of system increases remarkably with the increase of ultimate strain and influences of strain rate on collapse routine and capacity are tiny in analytical results.
\end{abstract}

Keywords: Tower-line system, collapse analysis, collapse routine, collapse-resistant capacity, vulnerable points, ultimate strain, strain rate

\section{INTRODUCTION}

Overhead high-voltage electric transmission lines play an important role in the operation of a reliable electrical power system, whose damage can cause great economic loss and bring inconvenience to human life ( $\mathrm{Li}$ and Bai [1]; Xie and $\mathrm{Li} \mathrm{[2]).} \mathrm{A} \mathrm{substantial} \mathrm{number} \mathrm{of} \mathrm{transmission}$ lines were damaged by catastrophic earthquakes around the world. The transmission tower tilt or collapse, conductor breakage, foundation subsidence and insulator destruction were the major types of failure. It is necessary to study not only the seismic response of transmission lines in the elastic and plastic phase, but also their collapse process. Progressive collapse analysis is a well-understood physical occurrence in which loss of local load-bearing capacity propagates through a system, precipitating complete collapse or a major portion of it. Vulnerable points, collapse mode and capacity of structure can be evaluated by it, which can be used for the design of new towers or for evaluating existing towers.

Over past years, many scholars have studied the nonlinear responses of single transmission tower or tower-line system ( $\mathrm{Li}$ et al. [3]; Albermani et al. [4]; Rao et al. [5]). Li et al. investigated the ultimate status of several transmission tower-line systems under earthquake using the simplified model in which lines were treated as concentrated mass (Li et al. [3]). That means the coupling effects between towers and lines cannot be considered. Alberman et al. presented a non-linear methodology considering both material and geometric non-linearity, and applied it to a new transmission tower (Albermani et al. [4]). The proposed methodology was proved to be accurate enough to predict structural failure by calibrating with the results from the full-scale tower test. Rao 
et al. presented different types of premature failures of transmission towers observed during full-scale testing and pointed out their mechanisms (Rao et al. [5]). However, there is no study related to the progressive collapse analysis of transmission tower-line system under earthquake.

Current civil engineering practice prefers to use the FEM for structural analysis. During the collapse process under earthquake, some elements lose load-bearing capacity, which is a problem for the FEM. Commonly, the method removing these elements is used, which is called the birth-death element method. With the method, some elements are removed during the simulation process, which is not agree with realistic situation. The method retaining the mass of these elements rather than removal is proposed.

The main objective of this investigation is to study the collapse process of a transmission tower-line system using the approach proposed in the paper. First, numerical methods for the progressive collapse used before and proposed are introduced. The proposed procedure is then used for a transmission tower-line system. Collapse processes along longitudinal and lateral direction under different earthquake excitations are studied and influences of ultimate strain and strain rate effect on the collapse mode and capacity are analyzed.

\section{BRIEF INTRODUCTION OF COLLAPSE SIMULATION METHODS}

Numerical simulation of progressive collapse is a challenging task, which includes the material and geometrical non-linearity, contact and collision between elements, losing load-bearing capacity of elements and so on. Nowadays, there are mainly four numerical analytical methods used for the collapse analysis: the discrete element method (DEM), combined finite-discrete element method, applied element method (AEM) and FEM.

The DEM was initially developed for the study of jointed rock systems in 1971 (Cundall and Strack [6]), in which individual material element was considered to be separate and was connected only along its boundaries by frictional contact. With an introduction of joint-spring that represented the continuity of material, Meguro and Hakuno (Meguro and Hakuno [7]) developed an extended DEM (EDEM), which might be used for complex or heterogeneous materials such as concrete. Due to its capacity to explicitly represent the motion of multiple and intersecting discontinuities, the method is particularly suitable for analysis of the structure consisting of granular materials. However, it has not been used for the collapse analysis of large and complex structures due to its low efficiency and modeling complexity.

The combined finite-discrete element method is a recently developed numerical method aimed at modeling fracturing and failing elements, which combines aspects of both finite elements and discrete elements (Munjiza et al. [8]). In the method, solid domains are discretized into finite elements in the usual way dictated by the FEM, and contact between interacting domains is defined in a similar way to the DEM. The method can concentrate the advantages of FEM and DEM and has been applied to a wide range of engineering problems. However, each particular application requires the development of specific algorithmic procedures (Munjiza et al. [9]).

The AEM, which can predict the behaviors of structure from zero loading to collapse in a reasonable CPU time, is an innovative method adopting the concept of discrete cracking (Meguro and Tagel-Din [10]; Meguro and Tagel-Din [11]). With the AEM, a structure is modeled as an assembly of relatively small rigid elements that are connected by pairs of normal and shear springs loacted at contact points. With the AEM, crack initiation and propagation in the material can be predicted, the rigid body motion and the collision process can also be modeled. 
The FEM, based on continuum mechanics, is the most widely used method in structure engineering. For the linear elastic problems, the method has been proved to be advantageous. Furthermore, the method is very effective for solving nonlinear problems by using reasonable constitutive relationship. The method can be used in the solution of large scale and complex industrial problems, while other methods are extremely difficult to be used.

\section{PROPOSED METHOD}

Nowadays, the FEM is the only numerical method that has been used for transmission tower, which is used here also. The method can be divided into the explicit finite element method (EFEM) and implicit finite element method (IFEM) according to whether a new value is related to other new values in each increment step. The IFEM is unconditional stable, but the computational cost in the tangent stiffness matrix increases dramatically as the material non-linearity increases. The EFEM is conditional stable, and can overcome the disadvantage of the IFEM mentioned above. The CPU cost is approximately proportional to the size of the model (Sun et al. [12]). Therefore, the EFEM is more suited for the collapse analysis of complex and large projects.

For the transmission tower-line system, the non-linear dynamic analysis should be used because of its importance and complexity. The motion equation of structure under the seismic excitation is as follows:

$M(t) \ddot{x}(t)+C(t) \dot{x}(t)+K(t) x(t)=-M(t) \ddot{x}_{g}(t)$

where $\ddot{x}(t), \dot{x}(t)$ and $x(t)$ are the relative acceleration, velocity and displacement vectors; $\ddot{x}_{g}(t)$ is the acceleration vector of ground motion; $M(t), K(t)$ and $C(t)$ are the mass, stiffness and damping matrices, respectively. Generally, $M(t)$ is an invariant, while $K(t)$ and $C(t)$ change during the earthquake.

During the collapse process under earthquake, some elements lose load-bearing capacity one after another. Commonly, the birth-death element method is used (Lu et al. [13]; Kwasniewski [14]; Marjanishvili and Aganew [15]), in which these elements no longer contribute to $M(t)$ and $K(t)$. However, it has been already noticed that these elements still attached to the structure especially for the transmission tower. In other words, these elements still contribute to $M(t)$. The analytical approach of removing these elements is unsuiable, especially if the mass of these elements is unneglectable compared to the mass of the whole structure. The method considering the mass of these elements is more reasonable, which is the proposed method.

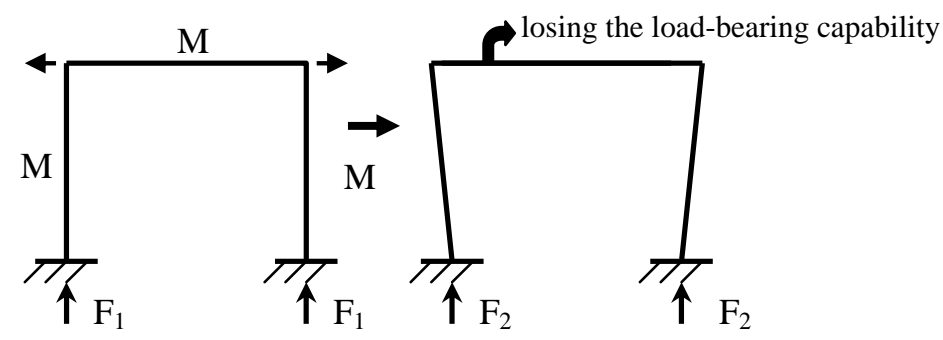

Figure 1. Description of the Model and the Loading Mode 
The rationality of the proposed method is illustrated with a case study. The description of the model and the loading mode are shown in Figure 1. The used model contains three components, with the same section and the same mass $\mathrm{M}$. The reaction force $\mathrm{F}_{1}$ is equal to $1.5 \mathrm{Mg}$ before loading. With the proposed method, the reaction force $F_{2}$ is equal to $1.5 \mathrm{Mg}$ after loading also. If the birth-death element method is used, the reaction force $F_{2}$ is equal to $1.0 \mathrm{Mg}$ after loading. In most cases, the beam still attaches to the columns after losing load-bearing capacity. Therefor, the proposed method is more rational than the birth-death element method.

\section{PROGRAM DEVELOPMENT FOR PROGRESSIVE COLLAPSE SIMULATION}

Elastic-perfectly plastic material model is used, which is shown in Figure 2. The constitutive relationship is coded using the user subroutine VUMAT (ABAQUS Inc. [16]), which can be implemented in the advanced finite element program ABAQUS. According to the proposed method, once the strain exceeds ultimate strain, the stiffness of the element is zero while the mass is still retained.

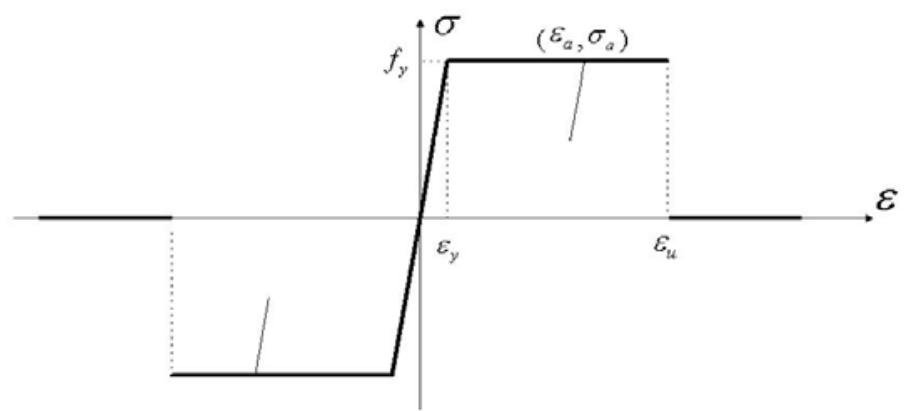

Figure 2. Stress-Strain Curve of Steel

For uniaxial loading, the stress-strain relationship of steel is as follows:

$\sigma=\left\{\begin{array}{cc}E_{s} \varepsilon & \varepsilon \leq \varepsilon_{y} \\ f_{y} & \varepsilon_{y} \leq \varepsilon \leq \varepsilon_{u} \\ 0 & \varepsilon>\varepsilon_{u}\end{array}\right.$

Where $\varepsilon$ and $\sigma$ are the strain and stress; $E_{s}$ is the elastic modulus; $\varepsilon_{y}$ and $f_{y}$ are the yield strain and yield stress; $\varepsilon_{u}$ is the ultimate strain.

For cyclic loading, the stress-strain relationship is as follows:

$\sigma=\sigma_{a}+E_{s}\left(\varepsilon-\varepsilon_{a}\right)$

Where $\sigma_{a}$ and $\varepsilon_{a}$ are the stress and strain of the starting point in the unloading curve.

\section{DESCRIPTION OF THE SELECTED STRUCTURE}

The selected tower for the collapse analysis is illustrated in Figure 3, which has a height of $60.5 \mathrm{~m}$ from the ground and a square base area of $10.16 \mathrm{~m} \times 10.16 \mathrm{~m}$ at ground level. The angle steel with equal section is used for all tower members. Main members of the tower are made of Q345, and secondary members Q235. The mechanical properties of Q345 and Q235 are shown in Table 1. 


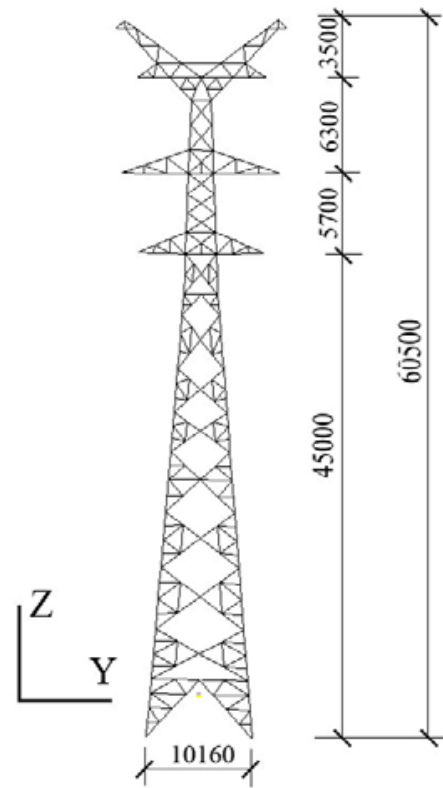

Figure 3. Transverse View of a Transmission Tower (mm)

Table 1. Mechanical Properties of Q345 and Q235

\begin{tabular}{ccccc}
\hline Material & $\begin{array}{c}\text { Yield stress } \\
(\mathrm{Pa})\end{array}$ & $\begin{array}{c}\text { Young's modulus } \\
(\mathrm{Pa})\end{array}$ & Poisson's ratio & $\begin{array}{c}\text { Density } \\
\left(\mathrm{Kg} / \mathrm{m}^{3}\right)\end{array}$ \\
\hline Q345 & $3.45 \mathrm{E}+08$ & $2.00 \mathrm{E}+11$ & 0.3 & 7800 \\
Q235 & $2.35 \mathrm{E}+08$ & $2.00 \mathrm{E}+11$ & 0.3 & 7800 \\
\hline
\end{tabular}

A transmission line system consists of many towers and lines, and the coupling effects of tower and line are prominent. However, it is unrealistic to use a model that includes all towers and lines. Here, the used model contains three towers and four-span lines, which was verified to be reasonable (Shen et al. [17]; Tian et al. [18]). The schematic view of the model is shown in Figure 4, in which the conductors and towers are connected with insulators and the materials for conductor and ground wire are steel-cored aluminium strand. The properties and performance indices of conductor, ground wire and insulator are depicted in Table 2.

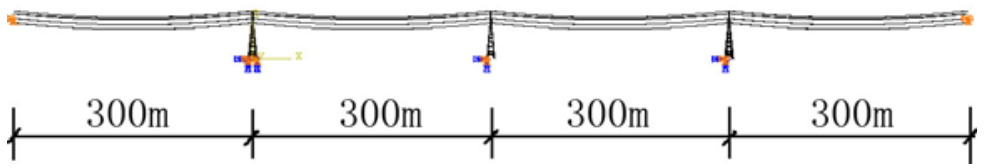

Figure 4. Three-Dimensional Finite Element Model of Tower-Line System

Table 2. Properties and Performance Indices of Conductor, Ground Wire and Insulator

\begin{tabular}{cccccc}
\hline Type & Area $\left(\mathrm{m}^{2}\right)$ & $\begin{array}{c}\text { Young's modulus } \\
(\mathrm{Pa})\end{array}$ & Poisson's ratio & $\begin{array}{c}\text { Density } \\
\left(\mathrm{Kg} / \mathrm{m}^{3}\right)\end{array}$ & $\begin{array}{c}\text { Yield force } \\
(\mathrm{N})\end{array}$ \\
\hline Conductor & $4.25 \mathrm{E}-04$ & $6.50 \mathrm{E}+10$ & 0.3 & 3172 & 98710 \\
Ground wire & $1.53 \mathrm{E}-04$ & $1.05 \mathrm{E}+11$ & 0.3 & 4631 & 74200 \\
Insulator & 0.02 & $7.65 \mathrm{E}+10$ & 0.2 & 7500 & 1000000 \\
\hline
\end{tabular}

The three dimensional beam elements type, B31, with three translational and three rotational degrees of freedom per node is employed to model the tower members, and the three dimensional truss elements type, T3D2, with three translational degrees of freedom per node is applied to model the lines and insulators in the ABAQUS software. Each tower contains 741 beam elements, each insulator contains one element, and the mesh selected for each conductor and ground wire consists of 100 truss elements. 


\section{PROGRESS COLLAPSE ANALYSIS OF TRANSMISSION TOWER-LINE SYSTEM}

\subsection{Earthquake Ground Motions Selected}

The method of dynamic time history analysis is used to assess the structural response. Here, three ground acceleration records are chosen for collapse analysis: (1) Kobe wave (1995); (2) Northbridge wave (1994); (3) El Centro wave (1940). To obtain the collapse process of the model, the peak ground accelerations are set equal to $20 \mathrm{~m} / \mathrm{s}^{2}, 40 \mathrm{~m} / \mathrm{s}^{2}$ and $25 \mathrm{~m} / \mathrm{s}^{2}$, respectively.

\subsection{Collapse Analysis Along Longitudinal Direction}

For nonlinear dynamic problems, the ABAQUS offers two integration methods including the implicit and explicit methods. The later is selected for analytical simulation based on the proposed approach. In this section, seismic records are input along longitudinal direction, and the ultimate strain of materials takes 0.02 . For transmission tower-line system, geometrical nonlinearity is prominent, which is considered in the analysis.

For the tower-line system, the middle tower is used for analyses of collapse process under Kobe, Northbridge and El Centro waves, and results are shown in Figure 5, Figure 6 and Figure 7, respectively. To show the collapse process more clearly, lines, insulators and the elements that lost the load-bearing capacity are removed from the figures.

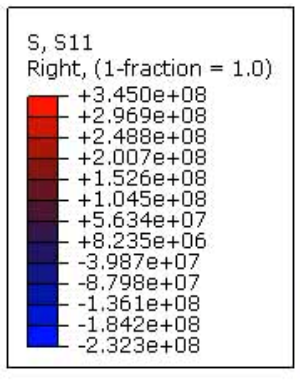

(a) $\mathrm{t}=6 \mathrm{~s}$

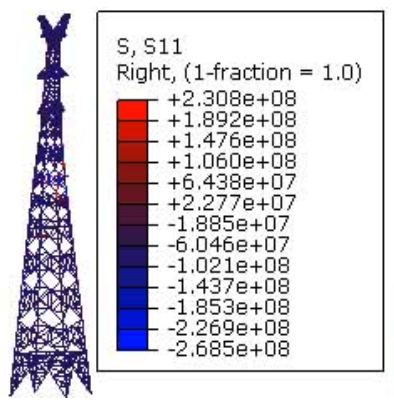

(b) $\mathrm{t}=7 \mathrm{~s}$

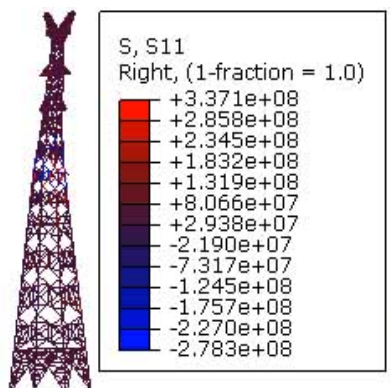

(c) $\mathrm{t}=9 \mathrm{~s}$

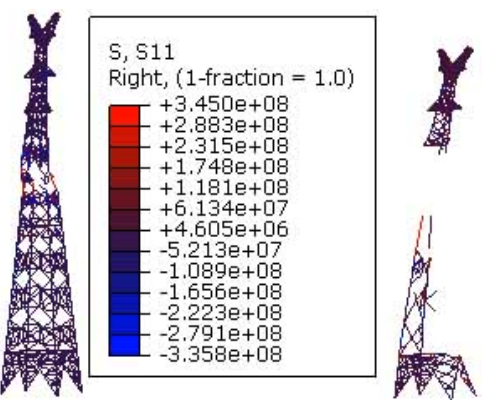

(d) $\mathrm{t}=10 \mathrm{~s}$

Figure 5. Collapse Process of the Middle Tower Along Longitudinal Direction Under Kobe Wave

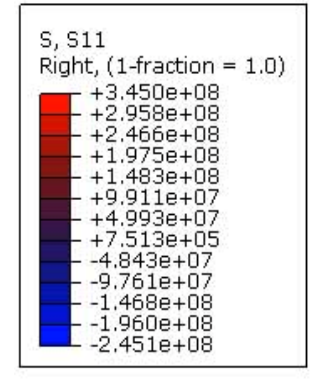

(a) $\mathrm{t}=4 \mathrm{~s}$

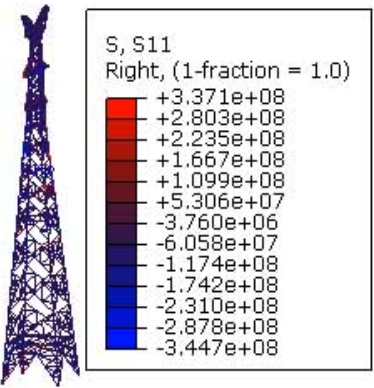

(b) $t=5 \mathrm{~s}$

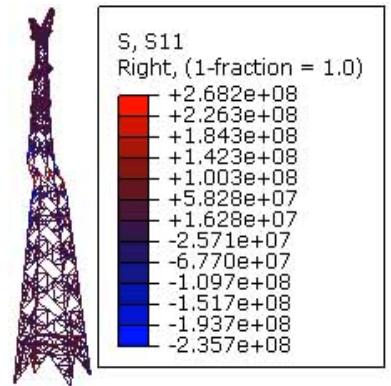

(c) $\mathrm{t}=5.2 \mathrm{~s}$

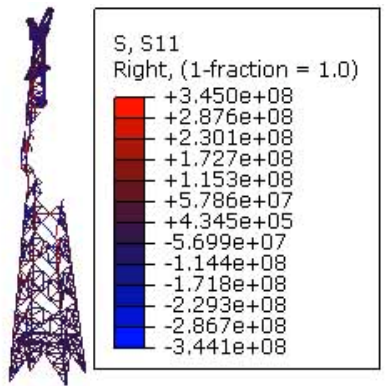

(d) $\mathrm{t}=5.5 \mathrm{~s}$

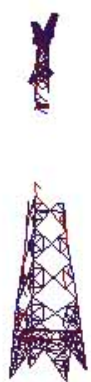

Figure 6. Collapse Process of the Middle Tower Along Longitudinal Direction Under Northbridge Wave 

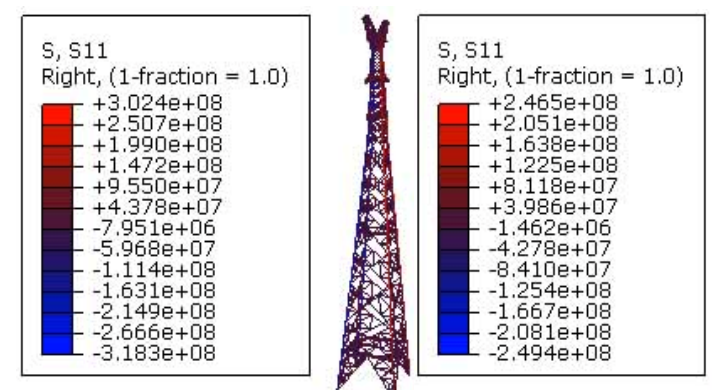

(a) $\mathrm{t}=9 \mathrm{~s}$

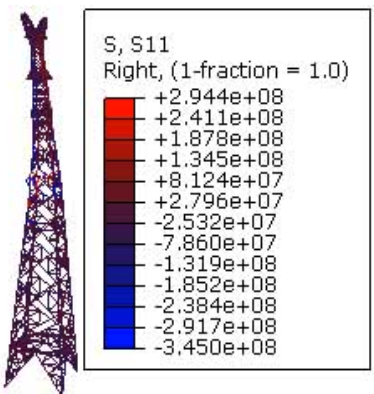

(c) $\mathrm{t}=9.8 \mathrm{~s}$

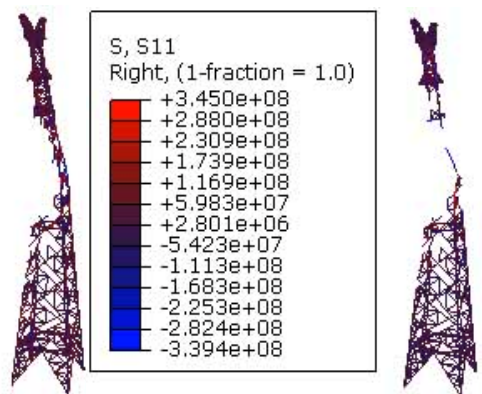

(d) $\mathrm{t}=10 \mathrm{~s}$

Figure 7. Collapse Process of the Middle Tower Along Longitudinal Direction Under El Centro Wave

Under the Kobe wave, an element of main leg at $Z=34.90 \mathrm{~m}$ yielded first at $4.58 \mathrm{~s}$. And then, at $5.06 \mathrm{~s}$, the element yielded first and a bracing component of diaphragm at $\mathrm{Z}=26.62 \mathrm{~m}$ lost the load-bearing capacity at the same time. From $5.06 \mathrm{~s}$ to $5.94 \mathrm{~s}$, most elements of diaphragm at $\mathrm{Z}=26.62 \mathrm{~m}$ lost the load-bearing capacity one by one. At $9.62 \mathrm{~s}$, the tower lost the vertical load transfer path.

Under Northbridge wave, at $3.62 \mathrm{~s}$, an element of main leg at $\mathrm{Z}=34.90 \mathrm{~m}$ yielded first. And then, at $3.77 \mathrm{~s}$, the element yielded first and a bracing component at $\mathrm{Z}=26.62 \mathrm{~m}$ lost load-bearing capacity at the same time. From $3.77 \mathrm{~s}$ to $5.11 \mathrm{~s}$, most elements of diaphragm at Z=26.62 m lost load-bearing capacity. A few elements of other locations lost load-bearing capacity in the process. From 5.11s, lots of elements lost load-bearing capacity. At $5.34 \mathrm{~s}$, the tower lost vertical load transfer path.

Under El Centro wave, at $2.25 \mathrm{~s}$, an element of main leg at $\mathrm{Z}=34.90 \mathrm{~m}$ yielded first. And then, at $9.12 \mathrm{~s}$, the element yielded first lost load-bearing capacity. From $9.12 \mathrm{~s}$ to $9.71 \mathrm{~s}$, a few elements lost load-bearing capacity. From 9.71s, lots of elements lost load-bearing capacity. At $9.96 \mathrm{~s}$, the tower lost vertical load transfer path. In the whole process, none elements of diaphragm at $\mathrm{Z}=26.62$ $\mathrm{m}$ lost load-bearing capacity.

From the analysis results, we can see, the main leg at $\mathrm{Z}=34.90 \mathrm{~m}$ is more prone to yield than other locations. What's more, the location is prone to lose load-bearing capacity. Under Kobe wave and Northbridge wave, the diaphragm at $\mathrm{Z}=26.62 \mathrm{~m}$ is prone to lose load-bearing capacity. It can be seen that the two locations are the potential vulnerable points of the tower. Therefore, the collapse-resistant capacity of the tower can be improved by strengthening or optimizing the two locations. Under El Centro wave, the diaphragm at $\mathrm{Z}=26.62 \mathrm{~m}$ is safe. It can be seen that the collapse routines of tower are different under different ground motion time histories. Therefore, three or more ground motion time histories should be used for collapse analysis of tower-line system.

\subsection{Collapse Analysis Along Lateral Direction}

In this section, the seismic records are inputted along lateral direction, and the ultimate strain of materials takes 0.02. Collapse process of the middle tower under Kobe, Northbridge and El Centro waves are shown in Figure 8, Figure 9 and Figure 10, respectively. 


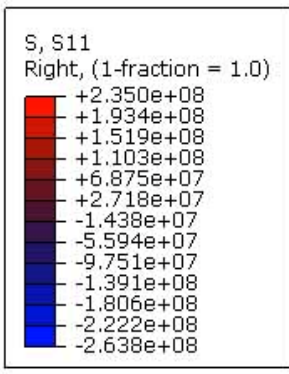

(a) $\mathrm{t}=7 \mathrm{~s}$

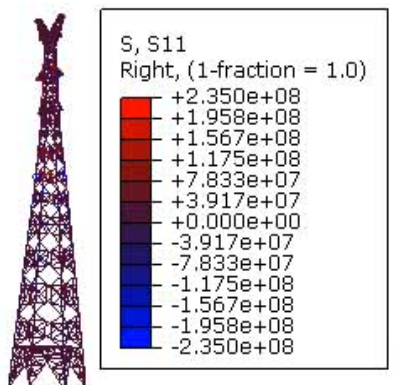

(b) $\mathrm{t}=7.2 \mathrm{~s}$

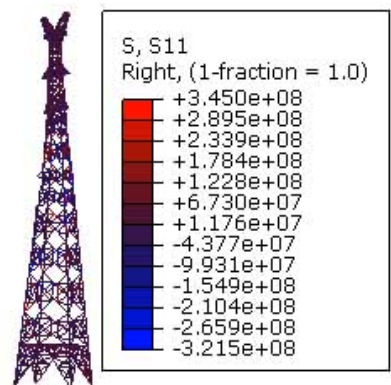

(c) $\mathrm{t}=8 \mathrm{~s}$

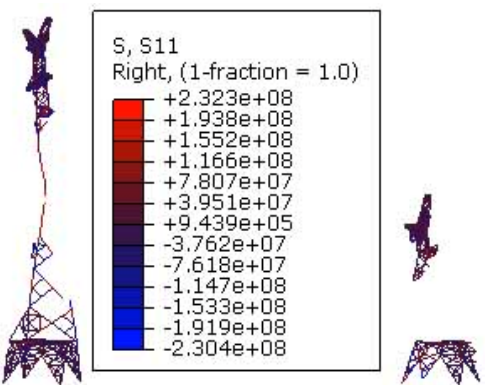

(d) $\mathrm{t}=10 \mathrm{~s}$

Figure 8. Collapse Process of the Middle Tower Along Lateral Direction Under Kobe Wave

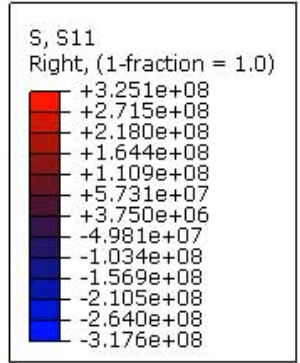

(a) $\mathrm{t}=4 \mathrm{~s}$

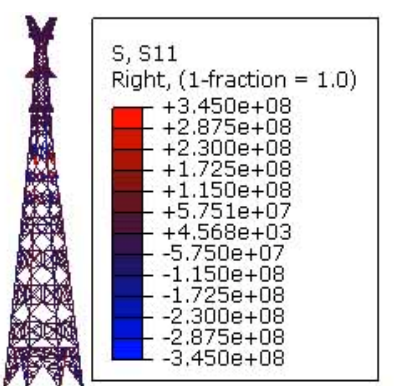

(b) $\mathrm{t}=4.5 \mathrm{~s}$

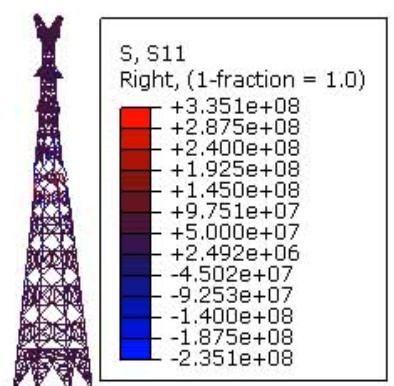

(c) $\mathrm{t}=5 \mathrm{~s}$

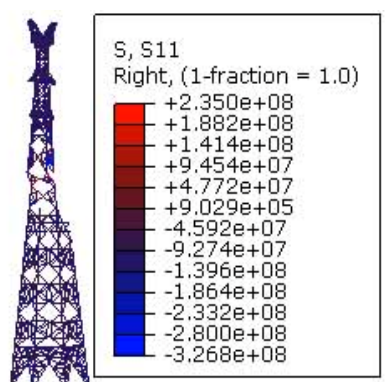

(d) $t=6 s$

Figure 9. Collapse Process of the Middle Tower Along Lateral Direction Under Northbridge Wave

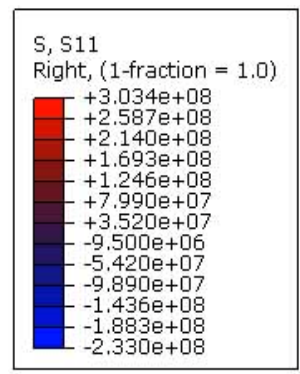

(a) $\mathrm{t}=5.5 \mathrm{~s}$

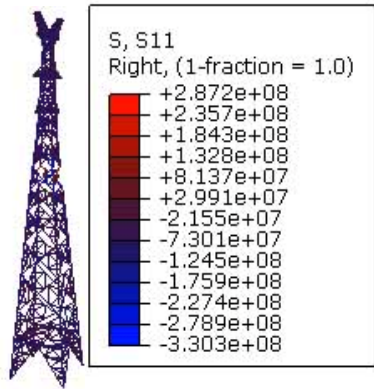

(b) $\mathrm{t}=6 \mathrm{~s}$

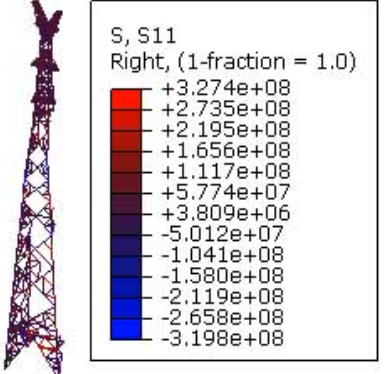

(c) $\mathrm{t}=6.5 \mathrm{~s}$

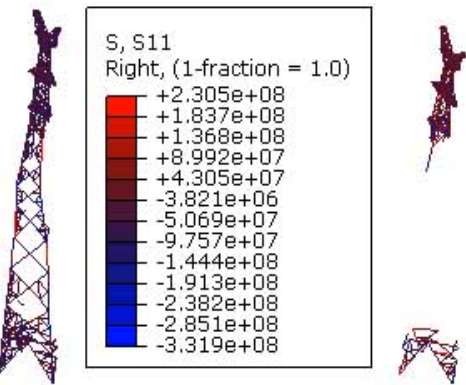

(d) $\mathrm{t}=7 \mathrm{~s}$

Figure 10. Collapse Process of the Middle Tower Along Lateral Direction Under El Centro Wave

Under Kobe wave, at $4.17 \mathrm{~s}$, an element of main leg at $\mathrm{Z}=34.90 \mathrm{~m}$ yielded first. And then, at $4.74 \mathrm{~s}$, the element yielded first lost load-bearing capacity. From $4.74 \mathrm{~s}$ to $7.17 \mathrm{~s}$, a few elements lost load-bearing capacity, and none elements of diaphragm at $\mathrm{Z}=26.62 \mathrm{~m}$ lost load-bearing capacity. From $7.17 \mathrm{~s}$, lots of elements lost load-bearing capacity. At $7.19 \mathrm{~s}$, most elements of diaphragm at $\mathrm{Z}=26.62 \mathrm{~m}$ lost load-bearing capacity. At $7.98 \mathrm{~s}$, the tower lost vertical load transfer path.

Under Northbridge wave, at $3.63 \mathrm{~s}$, an element of main leg at $\mathrm{Z}=34.90 \mathrm{~m}$ yielded first. And then, at $3.79 \mathrm{~s}$, the element yielded first lost load-bearing capacity. At $5.27 \mathrm{~s}$, the tower lost vertical load transfer path. In the whole process, none elements of diaphragm at $\mathrm{Z}=26.62 \mathrm{~m}$ lost load-bearing capacity.

Under El Centro wave, at $2.30 \mathrm{~s}$, an element of main leg at $\mathrm{Z}=34.90 \mathrm{~m}$ yielded first. At $3.67 \mathrm{~s}$, an element of diaphragm at $\mathrm{Z}=26.62 \mathrm{~m}$ lost load-bearing capacity. And then, at $3.68 \mathrm{~s}$, the element yielded first lost load-bearing capacity. From 5.71s, lots of elements lost load-bearing capacity. At $6.89 \mathrm{~s}$, the tower lost vertical load transfer path. It can be seen from Figure 10 and Figure 7 that the tower is easier to collapse along lateral direction for El Centro wave. 
The results above show that the element of main leg at $Z=34.90 \mathrm{~m}$ and the diaphragm at $\mathrm{Z}=26.62 \mathrm{~m}$ are the potential vulnerable points of the tower. Under different ground motion time histories, the collapse routines of the tower along lateral direction are different.

\subsection{The Effect of Ultimate Strain on Collapse Routine and Collapse-resistant Capacity}

The ductility of material has a great influence on the performance of structure. The main objective of this section is to study the influences of ultimate strain of material on collapse routine and capacity of the tower-line system. The ultimate strain used above takes 0.02, and used in this section is 0.1 . Kobe wave is used only and inputted along lateral direction. The collapse process is shown in Figure 11.

At $\mathrm{t}=4.17 \mathrm{~s}$, an element of main leg at $\mathrm{Z}=34.90 \mathrm{~m}$ yielded first, which is the same as the result when ultimate strain takes 0.02 . At $\mathrm{t}=5.05 \mathrm{~s}$, an element of diaphragm at $\mathrm{Z}=26.62 \mathrm{~m}$ lost load-bearing capacity. At $\mathrm{t}=6.68 \mathrm{~s}$, all elements of diaphragm at $\mathrm{Z}=26.62 \mathrm{~m}$ lost load-bearing capacity. Comparing it with the result when ultimate strain takes 0.02 , the influence of ultimate strain to collapse routine is obvious. In the whole process, none element of the main leg lost load-bearing capacity. It is obvious that the collapse-resistant capacity of the structure increases remarkably with the increase of ultimate strain.

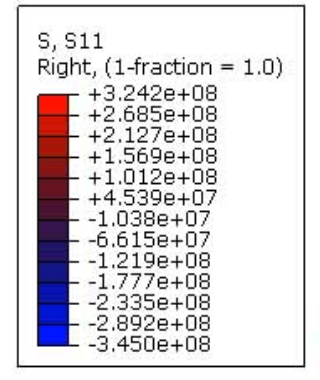

(a) $\mathrm{t}=7 \mathrm{~s}$

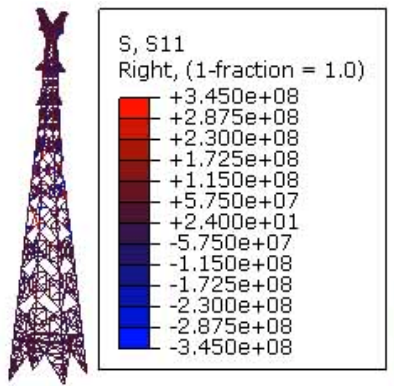

(b) $\mathrm{t}=7.2 \mathrm{~s}$

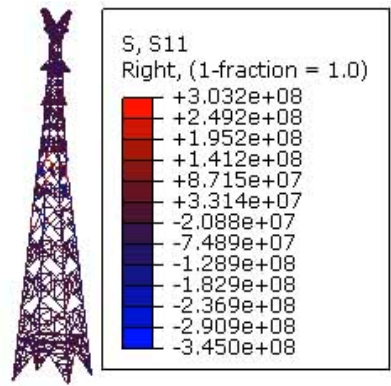

(c) $\mathrm{t}=8 \mathrm{~s}$

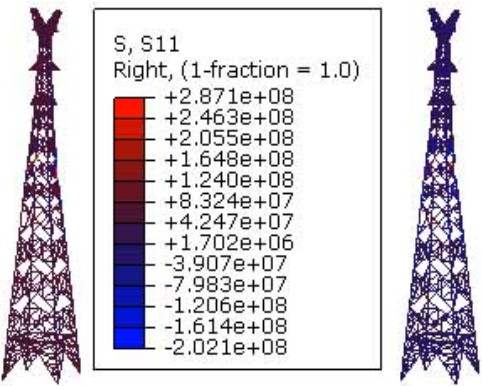

(d) $t=10 \mathrm{~s}$

Figure 11. Collapse Process of the Middle Tower Along Lateral Direction Under Kobe Wave (ultimate strain is 0.1)

\subsection{Effect of Strain Rate on Collapse Mode and Collapse-resistant Capacity}

Most materials used in civil engineering are sensitive to strain rate. Over the past decade, many researchers studied dynamic properties of the HPB235, HRB335 and HRB400 (Lin et al. [19]; Li and $\mathrm{Li} \mathrm{[20]).} \mathrm{The} \mathrm{results} \mathrm{showed} \mathrm{that} \mathrm{different} \mathrm{types} \mathrm{of} \mathrm{steel} \mathrm{have} \mathrm{different} \mathrm{sensitivities} \mathrm{to} \mathrm{the} \mathrm{strain}$ rate; the yield strength and tensile strength increase with the increase of strain rate; generally, the lower the yield strength is, the more obvious of the sensitivity is; the Young's modulus is almost invariable with the increase of strain rate. For dynamic phenomena, using dynamic constitutive relation is more rational than using static constitutive relation, and the mechanism lies in that the stiffness matrix is relative to strain rate. Bhowmick et al. investigated the effect of loading rate on the dynamic behavior of steel plate shear wall by the non-linear dynamic analysis using the ABAQUS software, which revealed that the ductility of structure reduced and the average flexural demand at the base of the wall increased with higher strain rates (Bhowmick et al. [21]). In this paper, we studied the effect of strain rate on the collapse mode and collapse-resistant capacity of transmission tower-line system under earthquake. 
Under earthquake, the strain rate of steel is hard to exceed 1/s. The dynamic constitutive relationship model incorporated in the finite element analysis is as follows ( $\mathrm{Li}$ and $\mathrm{Li} \mathrm{[20]):}$

$$
\begin{aligned}
& f_{y d}=\left(1+c_{f} \lg \frac{\dot{\varepsilon}}{\dot{\varepsilon}_{0}}\right) f_{y s} \\
& c_{f}=0.1709-3.289 \times 10^{-4} f_{y s}
\end{aligned}
$$

where $\dot{\varepsilon}$ is the current strain rate; $\dot{\varepsilon}_{0}$ is the quasi-static strain rate, $\dot{\varepsilon}_{0}=2.5 \times 10^{-4} / \mathrm{s} ; f_{y s}$ is the yield strength at quasi-static strain rate; $f_{y d}$ is the dynamic yield strength at the current strain rate.

In this section, the ultimate strain used is 0.02 . The Kobe wave is used only and input along lateral direction. Figure 12 shows the collapse process of middle tower considering strain rate effect.

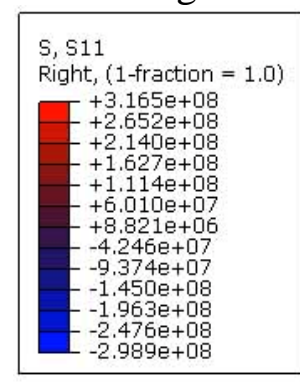

(a) $\mathrm{t}=7 \mathrm{~s}$

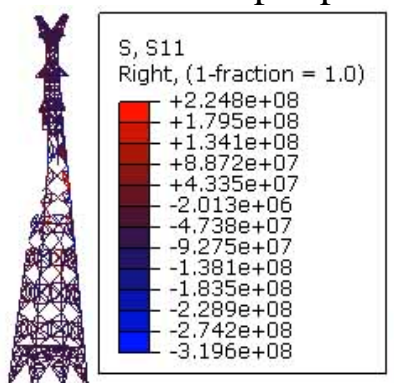

(b) $\mathrm{t}=7.2 \mathrm{~s}$

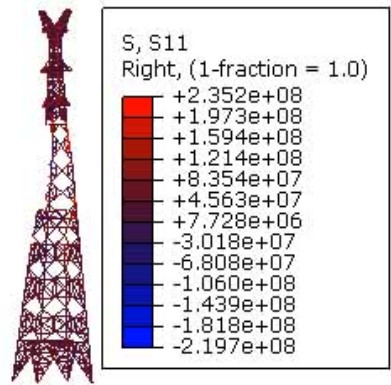

(c) $\mathrm{t}=8 \mathrm{~s}$

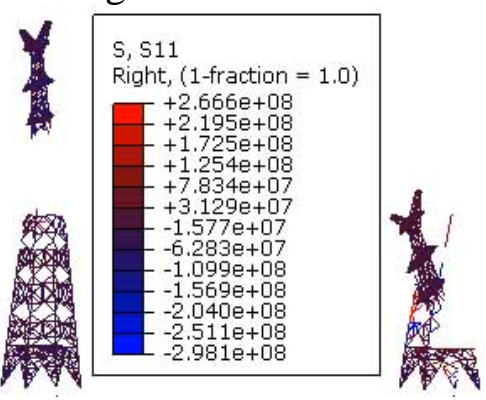

(d) $\mathrm{t}=10 \mathrm{~s}$

Figure 12. Collapse Process of the Middle Tower Along Lateral Direction Under Kobe Wave（with strain rate effect）

At $4.19 \mathrm{~s}$, an element of main leg at $\mathrm{Z}=34.90 \mathrm{~m}$ yielded first. It can be seen that the time was delayed slightly while the location was unchanged after considering strain rate effect. At $4.74 \mathrm{~s}$, the element yielded first lost load-bearing capacity, which is unchanged after considering strain rate effect. At $4.82 \mathrm{~s}$, some elements of diaphragm at $\mathrm{Z}=26.62 \mathrm{~m}$ lost load-bearing capacity, which is different with the result without considering strain rate effect. At $7.86 \mathrm{~s}$, the tower lost vertical load transfer path, which is earlier than the result without considering strain rate effect. It can be seen from Figure 12(d) and Figure 8(d) that there were more elements that still had load-bearing capacity at the end of the analysis.

Based on the above analysis, it is obvious that the influences of strain rate effect on collapse routine and collapse-resistant capacity of transmission tower-line system are tiny.

\section{CONCLUSIONS}

In this paper, a progressive collapse analysis procedure based on the FEM is proposed, by which the failure process of transmission tower-line system caused by the earthquake can be simulated to understand the collapse mechanism. During this procedure, the mass of the elements is still retained rather than removal after elements lose the load-bearing capacity. By applying the proposed approach, the progressive collapse analysis of a tower-line system is conducted. From the numerical results obtained, the following conclusions are drawn: 
(1) Using the proposed procedure, vulnerable points and collapse modes of tower-line system can be determined. Thereby, the proposed procedure is effective, which can be used for the design of a new tower or for checking the capacity of an existing tower.

(2) Under different seismic records, collapse modes and vulnerable points of transmission tower are different. To obtain more potential collapse modes and vulnerable points, three or more seismic records should be used for the collapse analysis of tower-line system.

(3) Influences of ultimate strain on the collapse mode and collapse-resistant capacity are obvious. With different ultimate strains, the collapse modes are different; the collapse-resistant capacity of structure increases remarkably with the increase of ultimate strain.

(4) The comparisons between the results considering the strain rate effect and the results without strain rate effect show that the strain rate effect on the collapse mode and capacity of transmission tower-line system are tiny.

\section{ACKNOWLEDGEMENT}

This research work was jointly supported by the National Natural Science Foundation of China (Grant No. 90815026, 50638010 and 51208285) and Key International Collaboration Project (Grant No. 51261120375), National Key basic Research and Development Program (973 Program) (Grant No. 2011CB013605) and the Science Fund for Creative Research Groups of the National Natural Science Foundation of China (Grant No. 51121005).

\section{REFERENCES}

[1] Li, H.N. and Bai, H.F., "State-of-the-art Review on Studies of Disaster resistance of High-voltage Transmission Tower-line Systems”, China Civil Engineering Journal, 2007, Vol. 40, No. 2, pp. 39-46.

[2] Xie, Q. and Li, J., "Current Situation of Natural Disaster in Electric Power System and Counter Measures”, Journal of Natural Disasters, 2006, Vol. 15, No. 4, pp. 126-131.

[3] Li, H.N., Hu, D. Zh. and Huang, L. Zh., "Plastic Limit Analysis of the Transmission Tower System Subjected to Earthquake Action”, Proceedings of the CSEE, 2006, Vol. 26, No. 24, pp. 192-199.

[4] Albermani, F., Kitipornchai, S. and Chan, R.W.K., "Failure Analysis of Transmission Towers”, Engineering Failure Analysis, 2009, Vol. 16, No. 6, pp. 1922-1928.

[5] Rao, N.P., Knight, G.M.S., Lakshmanan, N. and Iyer, N.R., "Investigation of Transmission Line Tower Failures”, Engineering Failure Analysis, 2010, Vol. 17, No. 5, pp. 1127-1141.

[6] Cundall, P.A. and Strack, O.D.L., “A Distinct Numerical Model for Granular Assemblies”, Geotechnique, 1979, Vol. 29, No. 1, pp. 47-65.

[7] Meguro, K. and Hakuno, M., "Fracture Analysis of Concrete Structures by the Modified Distinct Element Method”, Structural Engineering / Earthquake Engineering, 1989, Vol. 6, No. 2, pp. 283-294.

[8] Munjiza, A., Owen, D.R.J. and Bicanic, N., "A Combined Finite-Discrete Element Method in Transient Dynamics of Fracturing Solids”, Engineering Computions, 1995, Vol. 12, No. 2, pp. 145-174.

[9] Munjiza, A., Bangash, T. and John, N.W.M., "The Combined Finite-Discrete Element Method for Structural Failure and Collapse”, Engineering Fracture Mechanics, 2004, Vol. 71, No. 4-6, pp. 469-483. 
[10] Meguro, K. and Tagel-Din, H., “Applied Element Method for Structural Analysis: Theory and Application for Linear Materials”, Struct Engrg./Earthquake Engrg., 2000, Vol. 17, No. 1, pp. 21s-35s.

[11] Meguro, K. and Tagel-Din, H., “Applied Element Simulation of RC Structures Under Cylic Loading”, Journal of Structural Engineering, 2001, Vol. 127, No. 11, pp. 1295-1305.

[12] Sun, J.S., Lee, K.H. and Lee H.P., "Comparison of Implicit and Explicit Finite Element Methods for Dynamic Problems”, Journal of Material Processing Technology, 2000, Vol. 105, No. 1-2, pp. 110-118.

[13] Lu, X. Zh., Lin, X.Ch., Ye, L.P., Li, Y. and Tang D.Y., "Numerical Models for Earthquake Induced Progressive Collapse of High-rise Buildings”, Engineering Mechanics, 2010, Vol. 27, No. 11, pp. 64-70.

[14] Kwasniewski, L., "Nonlinear Dynamic Simulations of Progressive Collapse for a Multistory Building”, Engineering Structures, 2010, Vol. 32, No. 5, pp. 1223-1235.

[15] Marjanishvili, S. and Aganew, E., "Comparison of Various Procedures for Progressive Collapse Analysis”, Journal of Performance of Constructed Facilities, 2006, Vol. 20, No. 4, pp. 365-374.

[16] ABAQUS Inc., “ABAQUS Analysis User’s Manual”, ABAQUS Inc., 2010.

[17] Shen, G.H., Sun B.N., He, Y.X., Ye, Y. and Lou, W.J., "Seismic Response of Long-Span Transmission Tower-Line System”, Engineering Mechanics, 2008, Vol. 25, No. 11, pp. 212-217.

[18] Tian, L., Li, H.N. and Liu, G.H., "Seismic Response of Power Transmission Tower-Line System Subjected to Varying Ground Motions”, Mathematical Problems in Engineering, 2010, Article ID 587317.

[19] Lin, F., Gu, X.L., Kuang, X.X. and Yin, X.J., "Constitutive Models for Reinforcing Steel Bars Under High Strain Rates”, Journal of Building Materials, 2008, Vol. 11, No. 1, pp. 14-20.

[20] Li, M. and Li, H.N., “Dynamic Test and Constitutive Model for Reinforcing Steel”, China Civil Engineering Journal, 2010, Vol. 43, No. 4, pp. 70-75.

[21] Bhowmick, A.K., Driver, R.G. and Grondin, G.Y., "Seismic Analysis of Steel Plate Shear Walls Considering Strain Rate and P-Delta Effects”, Journal of Constructional Steel Research, 2009, Vol. 65, No. 5, pp. 1149-1159. 


\section{KEYNOTE SPEAKERS}

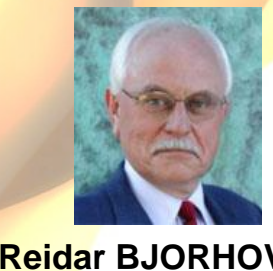

The Bjorhovde

Group, USA

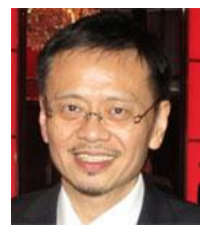

Siu-Lai CHAN

The Hong Kong

Polytechnic University,

Hong Kong

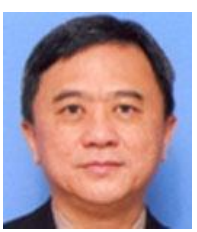

Sing Ping CHIEW Nanyang Technological University, Singapore

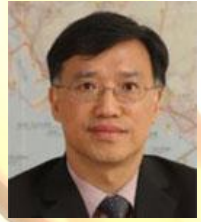

Kwok-Fai CHUNG

The Hong Kong

Polytechnic University, Hong Kong

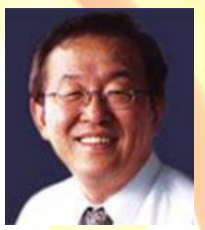

Jong Ho KIM Korean Society of Steel Construction, South Korea

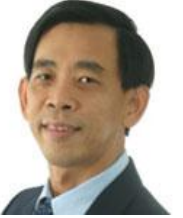

Chan Ghee KOH National University of Singapore, Singapore

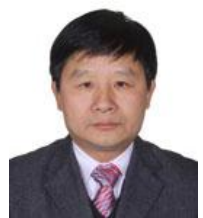

Guo-Qiang LI Tongji University, China

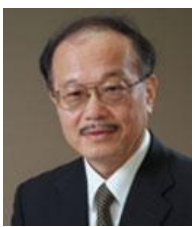

Masayoshi NAKASHIMA Kyoto University, Japan

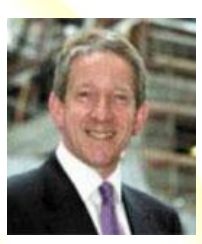

David NETHERCOT Imperial College London, UK

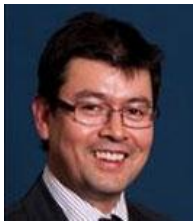

Brian UY

The University of New South Wales, Australia

\section{KEY DATES}

Final Abstract Submission

1 April 2013

Author's Notification

1 May 2013

Paper Submission

1 July 2013

Paper Acceptance

1 August 2013

End of Early-Bird Registration

15 July 2013

Conference

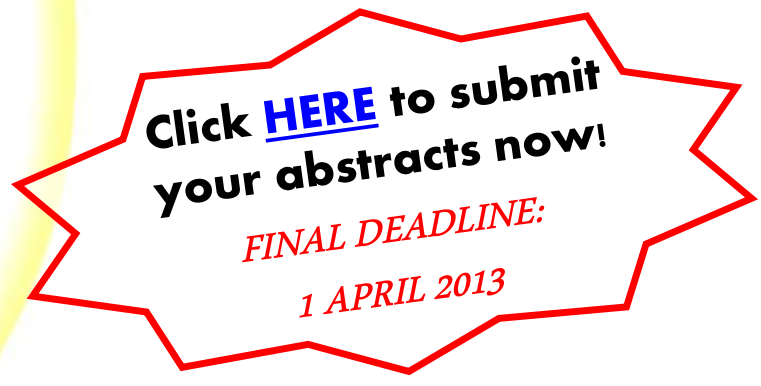

CONTACT US

Secretariat, PSSC 2013

1 Liang Seah Street, \#02-11 Liang Seah Place, Singapore 189022

(65) 63362583

(65) 63370338

pssc2013@cma.sg 


\section{PACIFIC STRUCTURAL STEEL CONFERENCE 2013 8 to 11 October 2013 Resorts World Sentosa, Singapore}

Advancements and Achievements in Structural Steel

ABOUT PSSC 2013

The Pacific Structural Steel Conference is a major initiative bringing together expertise in structural steel research, education and construction from all around the Pacific Rim and beyond to promote cooperation among the structural steel associations and communication on development in the field of steel structures in Pacific countries. It was originated in 1986 when the New Zealand Heavy Engineering Research Association organized the inaugural conference.

Since then the PSSC has been scheduled to be held every three years, the importance of which as a forum for technological discussion and inter-change was especially recognized and nurtured by the booming Asian-Pacific economies. The 2nd PSSC was held in Gold Coast, Australia in 1989; the 3rd one in Tokyo, Japan in 1992; the 4th PSSC in Singapore in 1995 while the next one was held in Korea in 1998. After the conference 2001 in China and 2004 in America , the PSSC returned to its land of origin in 2007. The PSSC has been held in Beijing in October 2010. Excitingly, the PSSC will be held in Singapore in Year 2013 with the administrator of Singapore Structural Steel Society. We are looking forward to seeing you and sharing ideas with all the friends.

\section{CALL FOR ABSTRACTS}

Prospective authors are invited to submit original abstracts that focus on the Advancements and Achievements in Structural Steel for the $10^{\text {th }}$ Pacific Structural Steel Conference (PSSC 2013). The conference topics are on (but not limited to): structural steel research and design; buckling \& stability analyses, innovative structural systems and elements, vibration, dynamics and seismic design, fabrication, corrosion protection materials and systems, erection of steel structures and construction safety.

Abstract should be approximately 150 words covering objectives of paper and indicating the main findings and conclusions. All abstracts are to be submitted online at www.pssc2013.org and will be subject to review on the basis of applicability to the conference theme and topics, a broad appeal to conference participants and readability.

\section{AUTHORS POLICY}

All published materials and spoken presentations will be in English. Authors are required to register for the conference to secure the publication of papers. PSSC 2013 is unable to reimburse authors for expenses incurred either for the presentation preparation, travel and hospitality or registration.

\section{INTERNATIONAL SCIENTIFIC COMMITTEE}

F Bijlaard, Netherlands

R Bjorhovde, USA

MA Bradford, Australia

D Camotim, Portugal

SL Chan, Hong Kong

ZH Chen, China

KF Chung, Hong Kong

GC Clifton, New Zealand

$P$ Collin, Sweden

LS da Silva, Portugal

$\mathrm{H}$ de Clercq, South Africa
UE Dorka, Germany
D Dubina, Romania
Leroy Gardner, UK
Y Goto, Japan
JF Hajjar, USA
LH Han, China
BA Izzuddin, UK
JP Jaspart, Belgium
SA Jayachandran, India
V Kodur, USA
D Lam, UK

RT Leon, USA
GQ Li, China
M Mahendran, Australia
M Nakashima, Japan
DA Nethercot, UK
JA Packer, Canada
K Rasmussen, Australia
WX Ren, China
DK Sang, South Korea
NE Shanmugam, Malaysia
GP Shu, China

T Sugiyama, Japan

LW Tong, China

T Usami, Japan

B Uy, Australia

Y Wang, UK

RY Xiao, UK

Y Xiao, USA

$B$ Young, Hong Kong

$\mathrm{R}$ Zandonini, Italy

XL Zhao, Australia

A Zingoni, South Africa
CONTACT US

Secretariat, PSSC 2013

1 Liang Seah Street, \#02-11 Liang Seah Place, Singapore 189022
JOINTLY ORGANISED BY

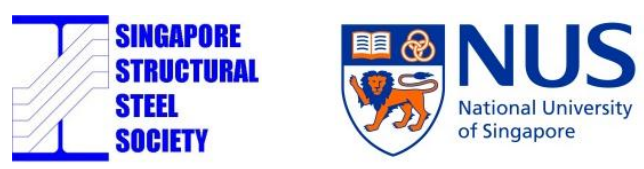

(65) 63370338

pssc2013@cma.sg
(65) 63362583

www.pssc2013.org 